\title{
Corticosteroid and nutrition induced muscle wasting in a rat model
}

Citation for published version (APA):

Koerts de Lang, E. (1999). Corticosteroid and nutrition induced muscle wasting in a rat model. [Doctoral Thesis, Maastricht University]. Maastricht University. https://doi.org/10.26481/dis.19991209ek

Document status and date:

Published: 01/01/1999

DOI:

10.26481/dis.19991209ek

Document Version:

Publisher's PDF, also known as Version of record

\section{Please check the document version of this publication:}

- A submitted manuscript is the version of the article upon submission and before peer-review. There can be important differences between the submitted version and the official published version of record.

People interested in the research are advised to contact the author for the final version of the publication, or visit the DOI to the publisher's website.

- The final author version and the galley proof are versions of the publication after peer review.

- The final published version features the final layout of the paper including the volume, issue and page numbers.

Link to publication

\footnotetext{
General rights rights.

- You may freely distribute the URL identifying the publication in the public portal. please follow below link for the End User Agreement:

www.umlib.nl/taverne-license

Take down policy

If you believe that this document breaches copyright please contact us at:

repository@maastrichtuniversity.nl

providing details and we will investigate your claim.
}

Copyright and moral rights for the publications made accessible in the public portal are retained by the authors and/or other copyright owners and it is a condition of accessing publications that users recognise and abide by the legal requirements associated with these

- Users may download and print one copy of any publication from the public portal for the purpose of private study or research.

- You may not further distribute the material or use it for any profit-making activity or commercial gain

If the publication is distributed under the terms of Article $25 \mathrm{fa}$ of the Dutch Copyright Act, indicated by the "Taverne" license above, 
Het verschijnen van dit proefschrift werd mede mogelijk gemaakt met financiële steun van de Stichting Pulmonologie, het Nederlands Astma Fonds en Nutricia Nederland B.V. 
Corticosteroid and nutrition induced muscle wasting in a rat model. 
The study presented in this thesis was performed at the Nutrition and Toxicology Research Institute Maastricht (NUTRIM) which participates in the Graduate School VLAG (Food Technology, Agrobiotechnology,

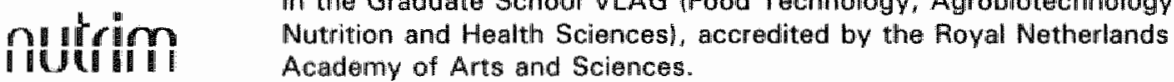

(C) Esther Koerts-de Lang

Druk: Datawyse | Universitaire Pers Maastricht

ISBN: $905278.261 x$ 


\title{
Corticosteroid and nutrition induced muscle wasting in a rat model.
}

\author{
PROEFSCHRIFT \\ ter verkrijgïng van de graad van doctor \\ aan de Universiteit Maastricht, \\ op gezag van de Rector Magnificus, \\ Prof. Dr. A.C. Nieuwenhuijzen Kruseman, \\ volgens het besluit van het College van Decanen, \\ in het openbaar te verdedigen \\ op donderdag 9 december 1999 om 12.00 uur
}

door

Esther Koerts-de Lang

geboren op 8 juni 1966 te Eindhoven.

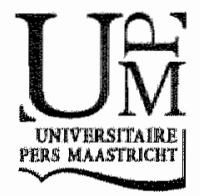




\section{Promotor}

Prof dr EFM Wouters

\section{Co-promotor}

Dr ir AMWJ Schols

\section{Beoordellngscommissie}

Prof dir ir WHM Saris (voorzitter)

Dr R Dekhuijzen (Katholieke Universiteit Nijmegen)

Prof dr JP van Hooff

Prof dr H Kuipers

Prof dr C Pison (CHU de Grenoble) 
Voor mijn vader

Bert

Casper 


\section{Contents}

Abbreviations

Chapter 1

General introduction

Chapter 2

Contractile properties and histochemical characteristics of the rat diaphragm after prolonged triamcinolone treatment and nutritional deprivation

Chapter 3

Different effects of corticosteroid-induced muscle wasting compared with undernutrition on rat diaphragm energy metabollism

\section{Chapter 4}

The effects of corticosteroids and undernutrition on work capacity of skeletal muscle in an in situ rat model

Chapter 5

Enzyme activity of rat tibialis anterior muscle differs between treatment with triamcinolone and prednisolone and nutritional deprivation

Chapter 6

Effects of muscle wasting induced by corticosteroids versus undernutrition on glutamine metabolism of the rat hindquarter

Chapter 7

$\alpha$ and $\beta$ glucocorticoid receptor mRNA expression in skeletal muscle

Chapter 8

Summary and general discussion

Samenvatting

Nawoord

Curriculum vitae

List of publications 


\section{Abbreviations}

ADP

AMP

ATP

ATPase

BCAA

BW

$\mathrm{CHF}$

CK

COPD

$\mathrm{Cr}$

CrP

CS

CSA

DW

EDL

FF

F/F

$\mathrm{Fm}, \mathrm{a}$

Fv,a

Fv, m

GA

GLIN

GLU

GP

$\mathrm{GR}$

GS

GS

HAD

$\mathrm{LDH}$

Lo

MHC

MRNA

ND

P

PF

PFK

PHE

$\mathrm{Po}$

$\mathrm{PR}$

$\mathrm{Pt}$

PW

$1 / 2 R T$

SEM

TAN

$\mathrm{TCr}$

TPT

TRR

UDP adenosine diphosphate

adenosine monophosphate

adenosine triphosphate

adenosine triphosphatase

branched chain amino acids

body weight

chronic heart fallure

creatine kinase

chronic obstructive pulmonary disease

creatine

creatine phosphate

citrate synthase

cross-sectional area

dry weight

extensor digitorum longus muscle

free fed

force-frequency

plasma membrane rate from the arterial to the free amino acid muscle pool

plasma membrane rate from the arterial to the vanous pool

plasma membrane rate from the free amino acid muscle to the venous pool

glutaminase

glutamine

glutamate

glycogen phosphatase

glucocorticoid receptor

glutamine synthetase

glycogen synthase

3-hydroxyacyl coenzyme A dehydrogenase

lactate dehydrogenase

oplimal length

myosin heavy chain

messenger ribonucleic acid

nutritional deprivation

p-value

pair fed

phosphofructokinase

phenylalanine

peak tetanic tension

prednisolane

peak twitch tension

pair weight

half relaxation time

standard error of the mean

total adenine nucleotides

total creatine pool

time to peak tension

triamcinolone

uridine diphosphate 



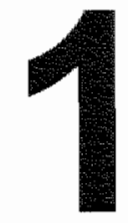

General introduction 


\subsection{Skeletal muscle dysfunction in chronic diseases}

Mary patients with chronic wasting diseases such as chronic obstructive pulmonary disease (COPD), chronic heart failure (CHF) and renal failure are severely limited in daily functioning. Although progression of these disorders can be slowed down with medication, reversion can only be (partially) achieved through surgical interventions and transplantation. It now becomes more and more clear that besides primary organ fallure, secondary factors contribute to the limitation in daily functioning. One of the major limiting factors in these conditions is exercise intolerance. Several recent reports have however revealed a poor relationship between measures of organ dysfunction and exercise capacity in cardiorespiratory diseases $(1,2)$. The fact that exercise intolerance in both disorders as well as in renal failure remains after surgical interventions or transplantation $(3,4)$, illustrates even more that secondary factors are involved in exercise limitation.

There is accumulating evidence that the skeletal muscles in these patient groups do not function normally and that this contributes to exercise intolerance (5). This is important because skeletal muscle dysfunction may well be a remediable source of exercise intolerance. Besides, muscle dysfunction is not limited to the peripheral skeletal muscles, but also affects the diaphragm and other respiratory muscles $(6,7)$. More specifically for respiratory muscle function a relationship with dyspnea was demonstrated (8) and furthermore it is well known that respiratory muscle fatigue predisposes to acute respiratory failure.

Recently it was shown that peripheral muscle wasting is an important predictor of peripheral muscle dysfunction $(9,10)$. However, as illustrated by the lower correlation between respiratory and peripheral muscle function in patients compared to healthy controls (11), intrinsic abnormalities in muscle might be involved. Analysis of muscle biopsies has indeed revealed alterations in key muscle enzymes involved in aerobic and anaerobic pathways as well as in muscle CSA and fibre type composition in COPD, CHF and renal failure (3, 12-14). Furthermore some studies have also reported myopathic features $(15,16)$. In order to extrapolate these observations to treatment strategies we need to know more about the underlying causes.

Nutritional depletion is recognised as an important factor in the treatment of these conditions since besides the functional consequences of imuscle wasting, weight loss has been identified as an independent determinant of mortality (17). The reversibility of weight loss. however is depending on the underlying mechanism: a decreased balance between energy intake and energy metabolism only, or involvement of altered anabolic and catabolic mediators. The former can be reversed by adequate nutritional support but the latter is yet more difficult to manage ( 18$)$. Absence of an anabolic response to nutritional support or exercise has among others been associated to the use of systemic corticosteroid treatment as maintenance therapy or during acute exacerbations. Side effects of corticosteroids in chronic diseases in particular on imuscle function has therefore received much attention in clinical studles (19-21). Furthermore one recent study also provides evidence for a contribution of systemic corticosteroids to increased mortality in chronic respiratory disease independent of weight loss (22).

\subsection{Muscle function}

Muscle activation is initiated by motorneurons, which form together with the muscle fibre the motor unit. Total muscle force depends on the number of motor units that are activated and on the force of separate motor units. Motor units can be classified on base of their mechanical and fatigue properties $(23,24)$, as shown in Table 1 . In general, a motor unit type comprises muscle fibres of a single type, as classified by histochemical staining for myofibrillar ATPase $(25,26)$. Histochemical enzyme staining showed that the different 
muscle fibres depended on different metabolic pathways (27). In recent studies it was shown that the different fibre types have different myos in heavy chain (MHC) isoforms.

Table 1. Motor unit and muscle fibre classification

\begin{tabular}{|c|c|c|c|c|}
\hline $\begin{array}{l}\text { Motor unit type } \\
\text { Muscle fibre type } \\
\text { Metabolic } \\
\text { enzymes } \\
\text { MHC }\end{array}$ & $\begin{array}{l}\text { slow-twitch, } \\
\text { fatigue resistant } \\
1 \\
\text { oxidatiwe } \\
M H C_{\text {siow }}\end{array}$ & $\begin{array}{l}\text { fast-twitch. } \\
\text { fatigue resistant } \\
\text { lla } \\
\text { oxidative, } \\
\text { glycolytic } \\
\mathrm{MHCC}_{2 \mathrm{~A}}\end{array}$ & $\begin{array}{l}\text { fast-wilch, } \\
\text { fatigue intermediate } \\
11 x \\
? \\
\text { glycolylic } \\
\mathrm{MHC}_{2 x}\end{array}$ & $\begin{array}{l}\text { fastwtwitch, } \\
\text { fatigable } \\
\text { lib } \\
\text { glycolytic } \\
\text { MHHC }\end{array}$ \\
\hline
\end{tabular}

Generally, the oxidative fibres are characterised by higher mitochondrial volume densities than fibres which are primarilly glycolytic (28). The higher oxidative capacity may at least partially account for the greater fatigue resistance of these fibres $(29,30)$. However, on the other hand, the higher mitochondrial volume density would presumably be at the expense of a corresponding lower myofibrillar volume density, lower MHC content, and thus fewer crossbridges in parallel for a given fibre cross-sectional area (31). This may explain the low tensions of oxidative fibres and the high tensions of glycolytic fibres.

Skeletal muscie mass comprises of about 60 to $80 \%$ of body cell mass and is therefore an important reserve system for the whole body protein pool. In catabolic conditions, it serves to supply amino acids for protein synthesis and energy metabolism elsewhere (32). Muscle protein is built of amino acids, which are derived from an active metabolic pool, originating from endogenous protein degradation and from dietary protein sources. Muscle wasting can occur by a depressed protein synthesis, an increased protein degradation or both. During muscle catabolism, degradation of muscle contractile protein is likely mediated via the ubiquitin-proteasome pathway (33). In this pathway the peptide ubiquitin is activated, which then covalently binds to protein substrates and this complex is finally degraded by an ATPdependent protease (34). Lysosomes are however not involved in the degradation of myofibrillar proteins (35), and also $\mathrm{Ca}^{2+}$-dependent proteinases were thought to play no major role in general intracellular protein turnover (36). However in recent experiments, both ubiquitin-proteasome proteolysis and calcium-dependent protein degradation were stimulated after corticosteroid administration (37).

ATP is the most important fuel for the cell, providing energy for cross-bridge cycling and active transport. At the onset of contractile activity, muscle fibres initially draw on a small pool of existing high-energy phosphates (39). Nevertheless, ATP levels do not change significantly because creatine phosphate (CrP) provides the substrate for rapid resynthesis catalysed by creatine kinase in the cytosol. The concentration of $\mathrm{CrP}$ in the cell is about four to six times higher than that of ATP. Therefore, CrP is considered as the highenergy phosphate reservoir. After only a few seconds of strenuous contractions, this energy source is depleted. The rates of glycogenolysis and glycolysis accelerate to provide a more sustainable energy source. As shown in Figure 1, during glycolysis, glucose is metabolised to pyruvate. Pynuvate can enter the mitochondria where it is converted into acetyl-CoA, which in turn enters the tricarboxylic acid cycle (TCA-Cycle). Strong reducing agents such as $\mathrm{NADH}$ and $\mathrm{FADH}_{2}$ formed during glycolysis and in the TCA-cycle, transfer their electrons via electron carriers to $\mathrm{O}_{2}$ to form $\mathrm{H}_{2} \mathrm{O}$. During this so called respiratory chain reaction, protons are transported over the inner mitochondrial membrane into the intermembranous space where ATP is synthesised. Thus, via the proton gradient, this oxidative phosphorylation is coupled to the respiratory chain.

As shown in Figure 1, ATP can also be derived from oxidation of dietary protein and fat sources. Compared to anaerobic glycolysis, aerobic metabolism requires longer time to be activated. Neverthelless, it has two important advantages to working muscle fibres. It produces more energy: 38 ATP per mole of glucose versus 2 ATP from anaerobic glycolysis and it enables the cell to utilise lipid as a fuel via $\beta$-oxidation. These properties are critical for 
muscle endurance and therefore mitochondrial content is a major determinant of muscle performance during prolonged exercise. In addition, other important determinants for muscle fatigue are the accumulation of inorganic phosphate, which is produced by ATP hydrolysis, and reactive oxygen species, produced by severe exercise, causing oxidative stress (40).

Figure 1. Nutriemt oxidation and ATP production. Adapted from Pison (38).

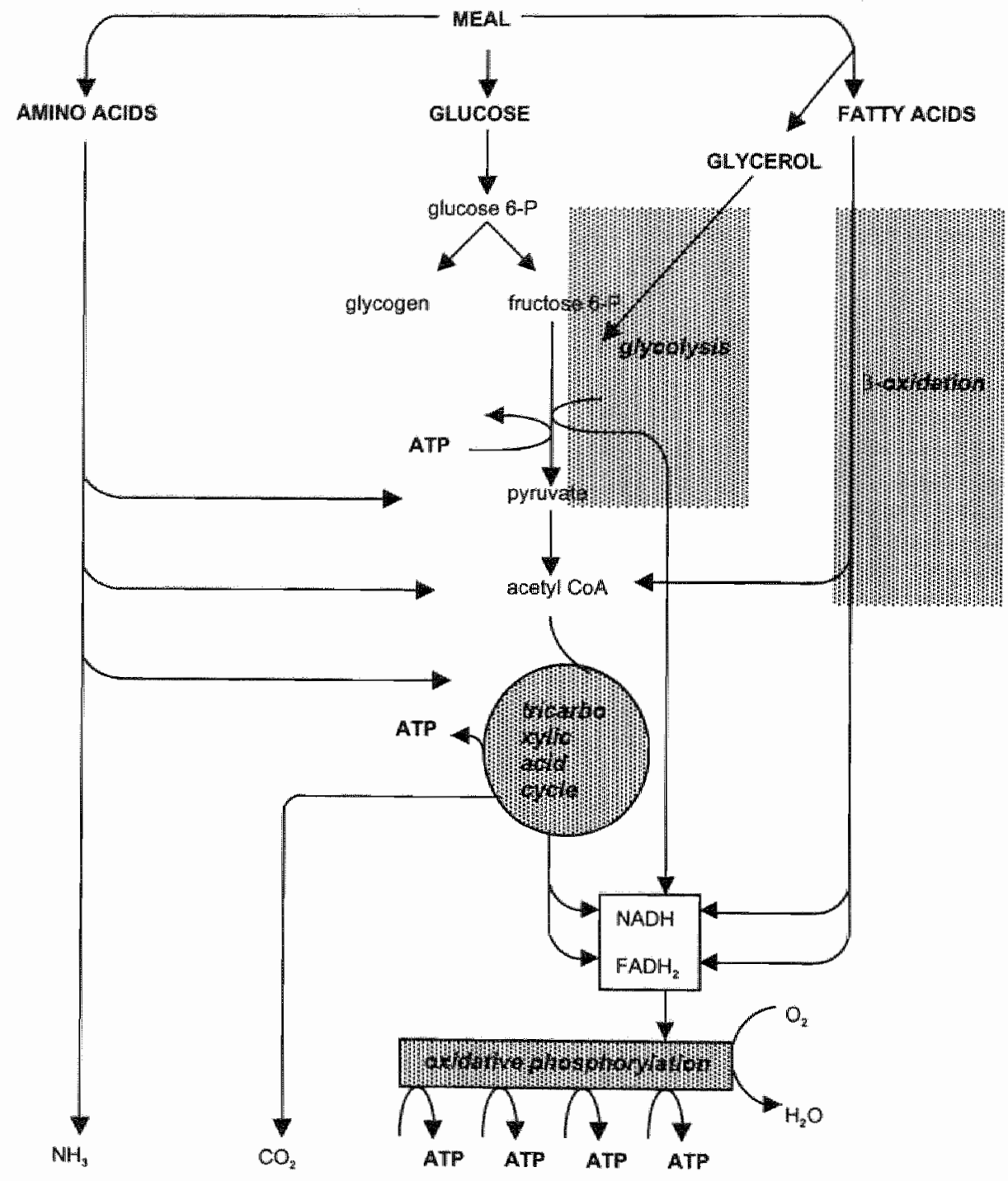

\subsection{Undernutrition}

Depletion of muscle mass as a consequence of undernutrition may affect muscle morphology, contractility and metabolism. Relatively few studies have investigated the effects of undernutrition on the combination of these factors. In contrast, many studies have investigated the effects of starvation or restriction of a specific dietary component. In this paragraph, the available experimental animal studies that investigated the effects of varying 
degrees and durations of undernutrition (i.e. semistarvation) on muscle morphology. metabolism and contractility are reviewed.

\subsubsection{Effects of undernutrition on muscle mass, mophology and contractility}

Muscle contractility can be assessed in wivo via nerve stimulation or in vitro with the use of a glass tissue chamber, in which the muscle nerve or the muscle itself can be stimulated directly with electrodes. Half-relaxation time ( $/ 2 R T)$ is obtained from baseline single twitch (Pt) and is defined as the time for tension to decay from maximum to half-maximum twitch tension. Force-frequency relationship can be examined by measuring the maxinum tension occurring at increasing stimulation frequencies. Muscle fatigue can be measured during prolonged stimulation and is characterised by a fall in tension. At a high frequency, tetanic tension (Po) can be assessed.

Table 2 summarises several studies on the effects of undernutrition on muscle mass, morphology and contractility. During undernutrition, muscle mass declined in a comparable extent as body weight. Muscle wasting of mixed muscles (like the diaphragm and the gastrocnemius) caused a generalised atrophic pattern after severe undernutrition whereas moderate undernutrition caused only type $\|$ fibre atrophy.

In general, muscle wasting caused a decreased muscle fatigability of the diaphragm muscle, but fatigability remarkably was found to be increased in the gastrocnemius and the soleus: (mainly type I fibres) muscles. This could be caused by specific muscle characteristics, since the diaphragm is continuously active and the gastrocnemius and the soleus are relatively inactive after undernutrition. The differences in muscle fatigability between the diaphragm and the peripheral skeletal muscles is likely caused by different fatigue protocols, since diaphragm fatigue resistance occurred only at low stimulation frequencies $(41,42)$ and fatigue of the peripheral skeletal muscles was only found at high stimulation frequencies (4345). In most studies, peak twitch and peak thetanic tensions were unchanged when expressed per amount of muscle mass. In the diaphragm and soleus muscles, half relaxation time was unchanged or increased, while in the gastrocnemius muscle, half relaxation time was found to be decreased. In general, force-frequency relationships were unchanged, but when expressed as percentage of tetanic force, it was found to be shifted to the left. This could be due to loss of force produced at high stimulation frequencies, while at low stimulation frequencies the force was maintained (43).

In summary, undernutrition induces muscle wasting, involving all fibre types "but predominantly type II fibres. It is not fully clear what the consequences are for the contractility of different muscles, since exercise protocols are not comparable. However, fatigue resistance is likely to be increased, since the relative cross-sectional area of oxidative fibres is increased. In addition, the results of in vitro and in vivo stimulation protocols have to be compared with caution, since whole body metabolism is affected after undernutrition, which in turn affects muscle performance in wivo, while in vitro muscle contractility is independent on whole body metabolism at time of contraction. 


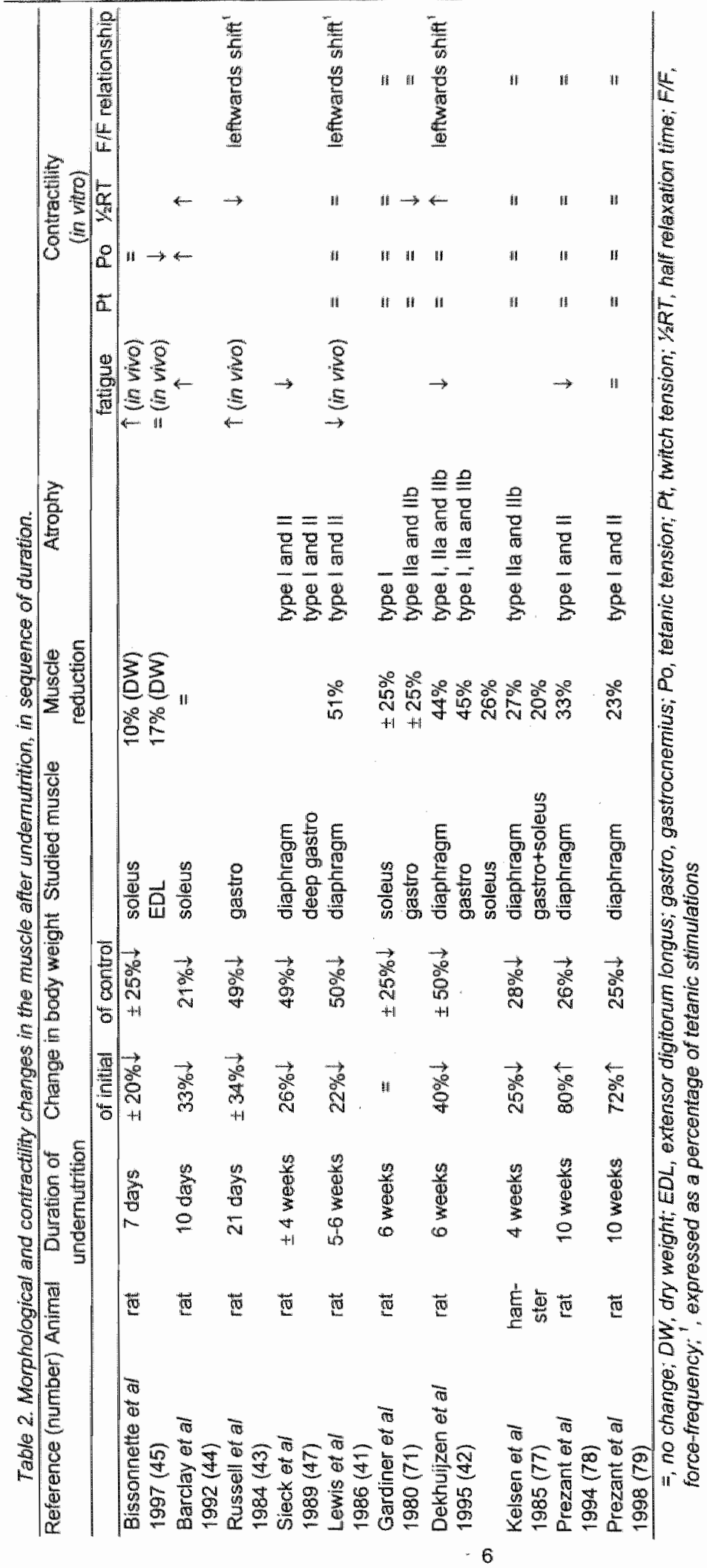




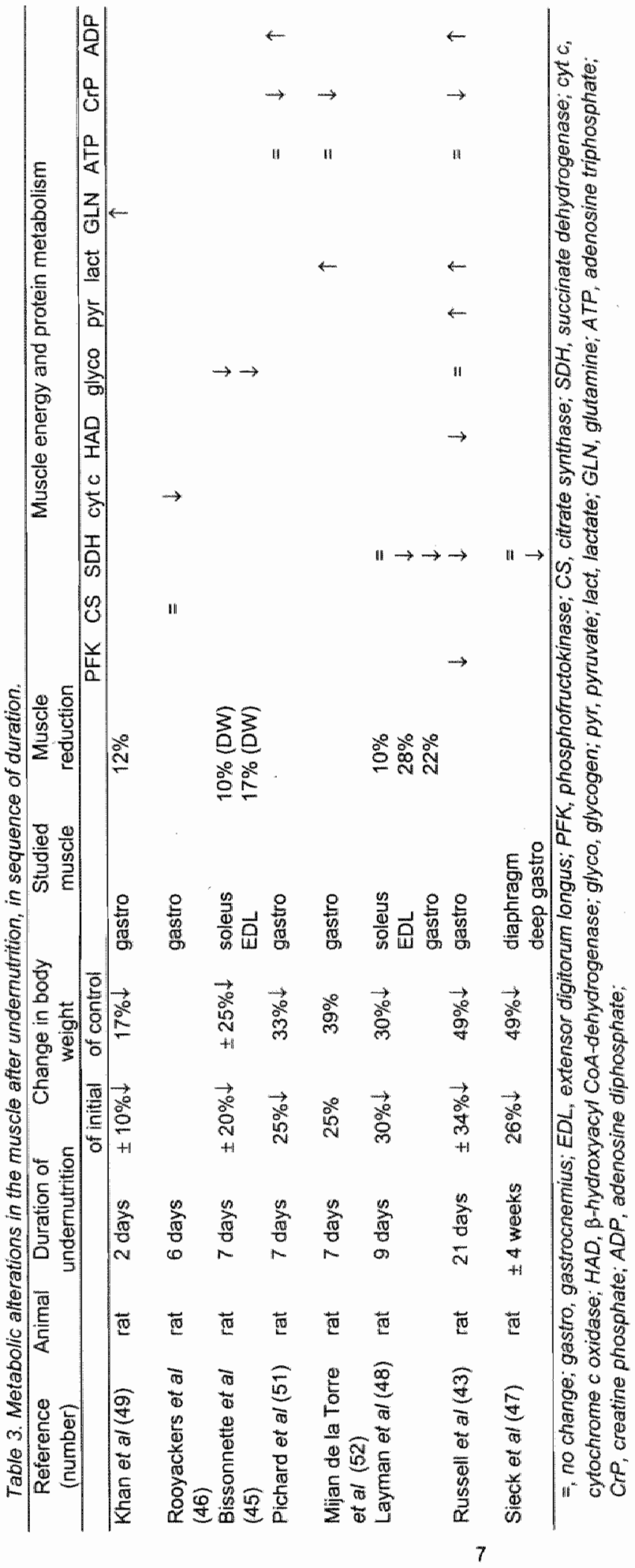




\subsubsection{Effects of undernutrition an muscle metabolism}

Remarkably, only a few studies have investigated muscle metabolism after nutritional deprivation (Table 3). A decreased phosphofructokinase (PFK) activity was reported in the gastrocnemius after 3 weeks of hypocaloric feeding (43), implying a decreased glycolytic activity. The activity of the TCA-cycle, as assessed by citrate synthase (CS) activity "was not changed after 6 days of undernutrition in the gastrocnemius muscle (46), but after 9 days or more, succinyl dehydrogenase (SDH) activity was reduced in this muscle $(43,47,48)$. SDH activities of the soleus and the diaphragm on the other hand were unchanged $(47,48)$. Sieck and colleagues suggested that the continuous activity of the diaphragm may preserve SDH activity, but this theory cannot be applied to the soleus muscle. It is possible that muscle enzyme activities are maintained in the soleus muscle, because of the relatively low level of muscle wasting. The activity of cytochrome c oxidase, involved in the respiratory chain, was reduced after 6 days of undernutrition (46). The acivity of $\beta$-hydroxyacyl-CoAdehydrogenase (HAD), the rate limiting enzyme in the intramitochondrial $\beta$-oxidation of fatty acids, was reduced after 3 weeks of undernutrition (43). Seven days of undernutrition resulting in muscle wasting of both the soleus and EDL resulted in decreased intramuscular glycogen concentrations (45). This reduced glycogen concentration was not found in the gastrocnemius muscle after 3 weeks of undernutrition, but instead an increased pyruvate and lactate concentration was observed (43). Furthermore, protein synthesis was also found to be decreased after undernutrition $(49,50)$. A decrease of $12 \%$ in gastrocnemius muscle mass was already related to an increase in intramuscular glutamine concentration, independently of reductions in muscle protein synthesis (49). Pichard and colleagues (1988) have studied the effects of hypocaloric feeding on rat muscle energetics by nuclear magnetic resonance in wivo. During 7 days of undernutrition, rats lost $25 \%$ of their body weight and intramuscular creatine phosphate (CrP) was reduced as well as the CrP/PI and CrP/ATP ratios in the gastrocnemius (51). ATP levels were maintained but ADP concentration was increased. The authors suggested that ATP production was disturbed by aerobic and anaerobic mechanisms. This concept of an impaired rephosphorylation of ADP in malnourished muscle was supported by other studies $(43,52)$.

In summary, it is difficult to compare various undernutrition studies, since the degree and/or duration of nutritional deprivation is different, as well as the studied muscles. One has to be cautious to compare different muscles because of differences in fibre types, activity patterns and metabolism. In general, undernutrition can suppress glycolytic, as well as glycogenolytic and oxidative metabolism in the muscle. This causes a disturbed ATP production, but ATP levels are maintained at the expense of CrP. 


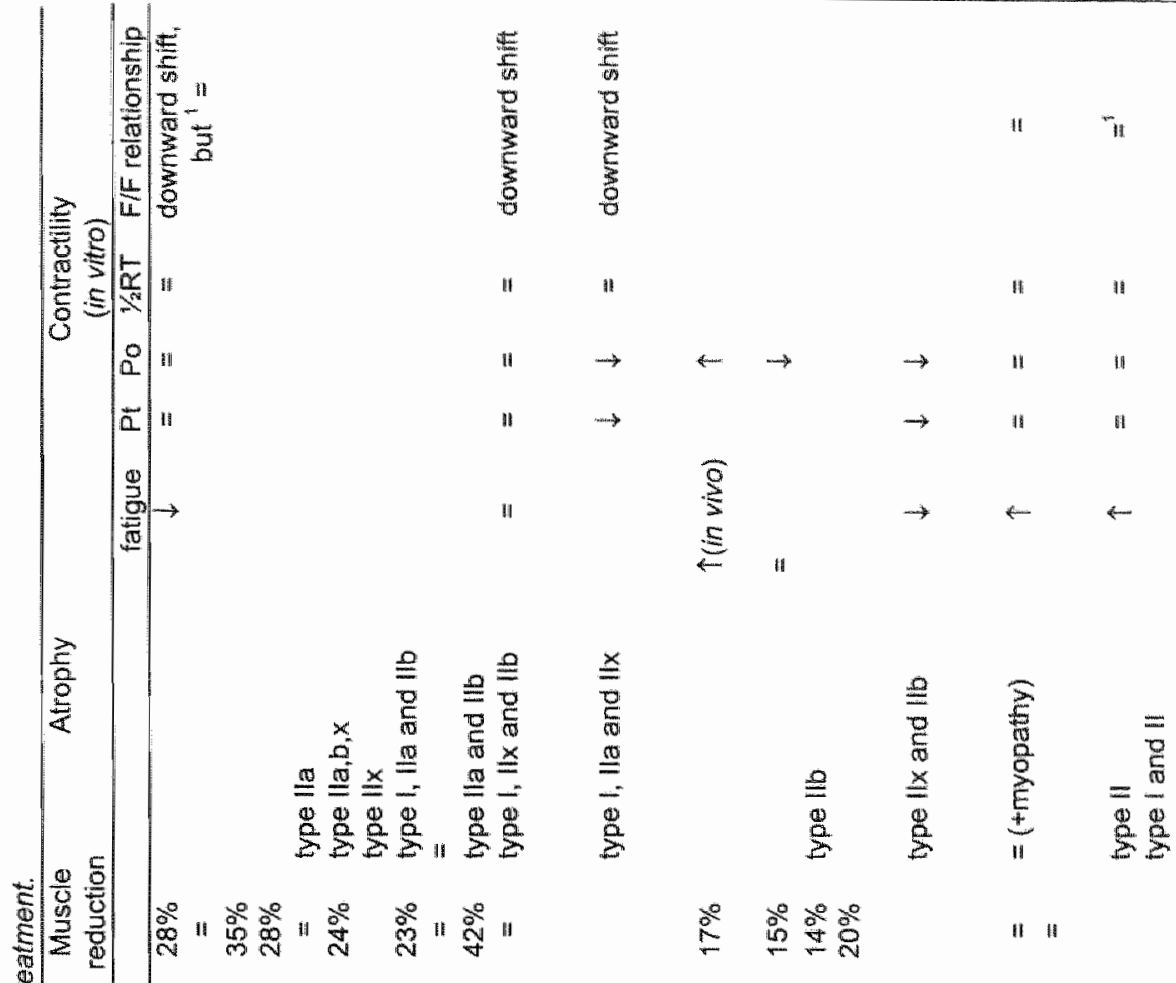

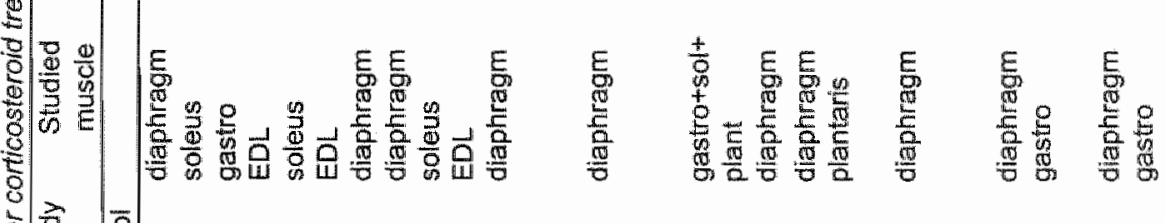

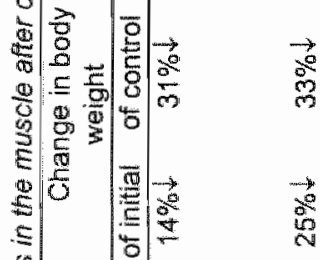

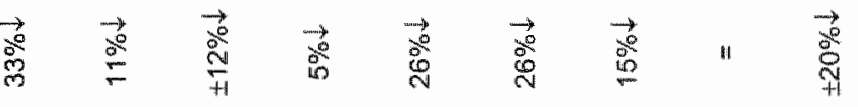

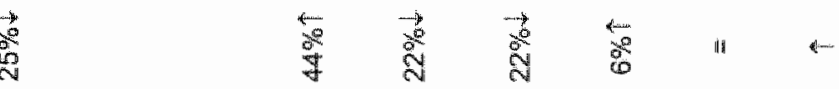

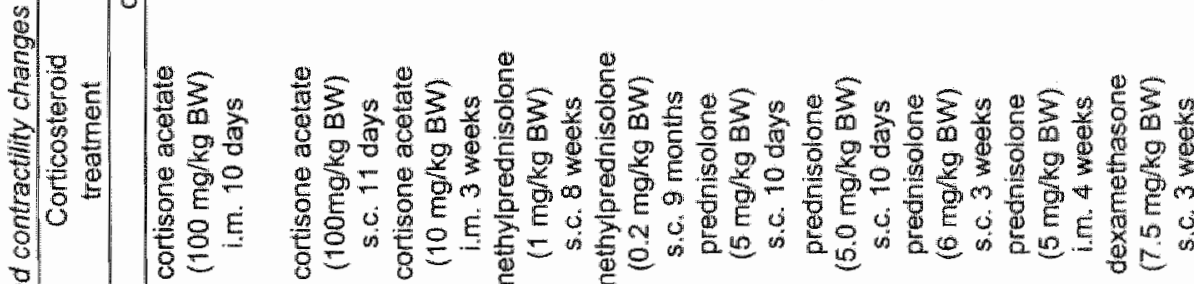

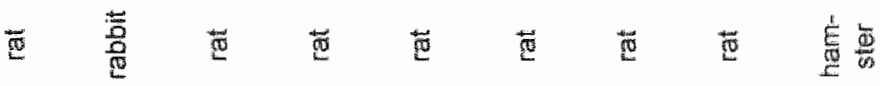

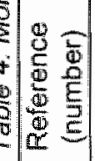

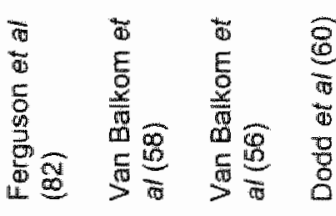

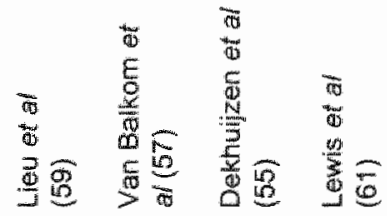




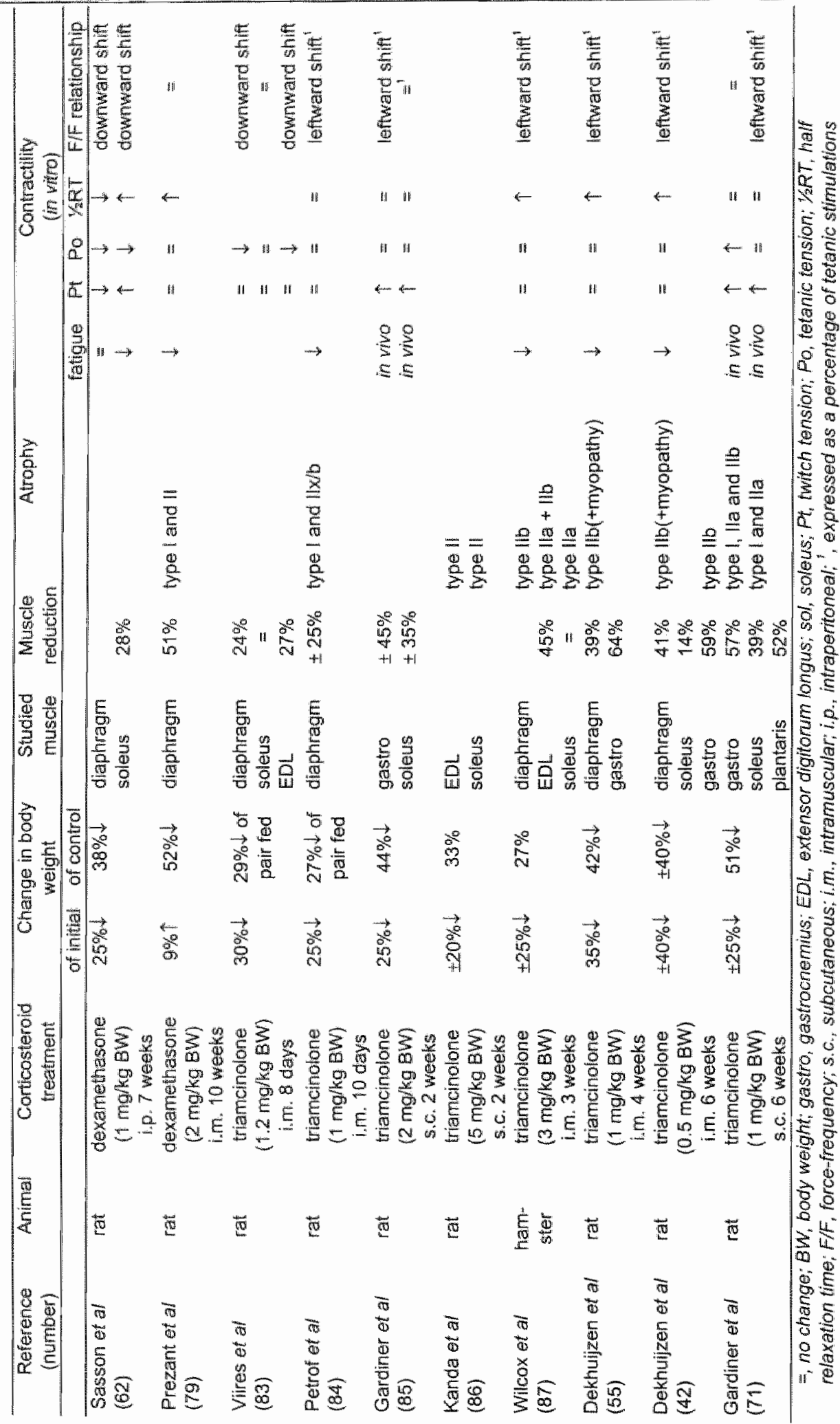




\subsection{Corticosteroids}

Cortisol is the major glucocorticoid secreted by the adrenal cortex and it protects the body during stressful sifuations. Gucocorticoids inhibit several aspects of the inflammatory process by modulating gene transcription in inflammatory cells present at the site of inflammation.

Exogenously administered corticosteroids have been used since 1940 in the treatment of several inflammatory diseases. From that moment on, a search for more ideal antiinflammatory therapeutics has begun, which should be more potent than cortisone with less mineralocorticoid side effects. Synthetic glucocorticoid derivates were developed instead of isolating cortisone from the adrenal glands. By introducing a fluoride group in the molecule, as in the fluorinated corticosteroids dexamethasone and triamcinotone, all biological activities (glucocorticoid and mineralocorticoid) of the corticosteroids were enhanced ( 53 , 54). The anti-inflammatory effect of triamcinolone is 5 times that of cortisol and the antiinflammatory effect of the non-fluorinated corticosteroid prednisolone is 4 times that of cortisol.

\subsubsection{Effects of corticosteroids on muscle mass, morphology, and contractility}

Besides its anti-inflammatory effectiveness, corticosteroids may induce several adverse side effects. Table 4 shows the effects of several corticosteroids on muscle wasting and morphology. Large doses of cortisone acetaie induced wasting of both respiratory and peripheral skeletal muscle, except for the soleus. Body wasting did not occur after intramuscular administration of prednisolone (55), but prolonged subcutaneous administration of low to normal doses of (methyl)prednisolone showed a decrease in body weight $(56-58)$ and muscle wasting $(59,60)$. It is likely that the route of prednisolone administration is of importance in inducing muscle wasting. Administration of the fluorinated corticosteroids dexamethasone and triamcinolone always caused muscle wasting, but the soleus muscle was less susceptible to it. In general, type II fibres were most prone to corticosteroild-induced muscle fibre atrophy, in particular the type $\| x / b$ fibres. In some studies, also some degree of type I muscle fibre atrophy was found.

Concerning muscle contractility, corticosteroid treated diaphragm muscles seem less susceptible to fatigue. However, a few studies demonstrated an increased fatigability of the muscle after prednisolone (55) or dexamethasone treatment (61). The type fof fatigue protocol cannot explain this discrepancy. Surprisingly, the fatigability of the soleus muscle (whether or not in combination with the gastrocnemius muscle) was increased after corticosteroid treatment $(60,62)$. Twitch and tetanic terisions were affected in various ways after corticosteroid treatment. Half relaxation time was unchanged or increased, except for the diaphragm in a study of Sasson and coworkers (1991), in which it was decreased. The force-frequency relationship was mostly shifted dowmward after corticosterold treatment, but when tensions were expressed as a percentage of letanic stimulations, the force-frequency relationship was shifted to the left after corticosteroid treatment.

In summary, corticosteroid treatment causes primarily muscle fibre type $\| \mathrm{x} / \mathrm{b}$ atrophy, with or without type lla and type | atrophy. Muscle contractility is mainly assessed in the diaphragm muscle under in vitro conditions. The diaphragm muscle is less fatigued after corticosteraid treatment. However in witro studies of the soleus muscle showed that this muscle was more fatigable. Interestingly, this discrepancy is also noticed after undernutrition. As above mentioned, the results of in witro and in vivo stimulation protocols have to be compared with caution, since whole body metabolism is affected after undernutrition, which in turn affects muscle performance in vivo, while in vitro muscle contractility is independent on whole body metabolism at time of contraction. 


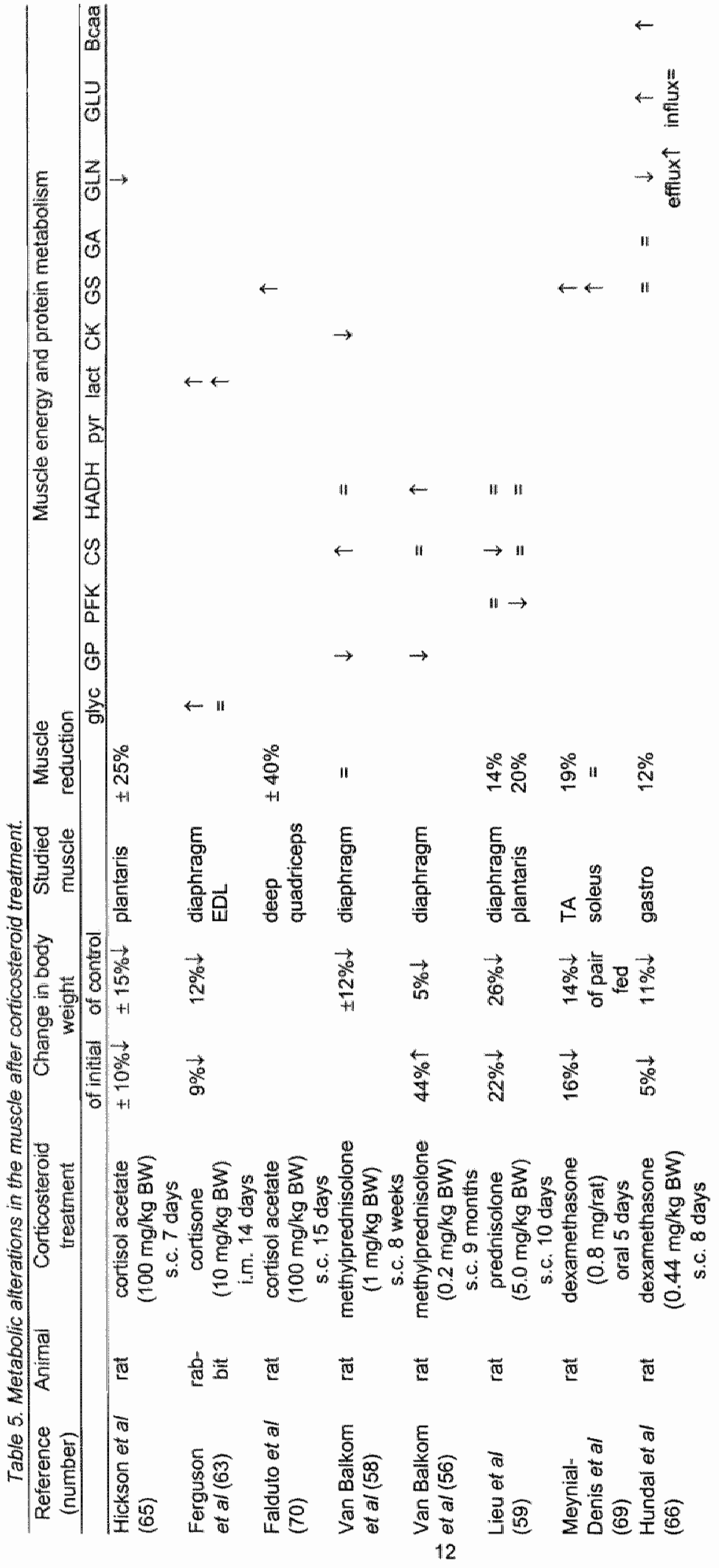




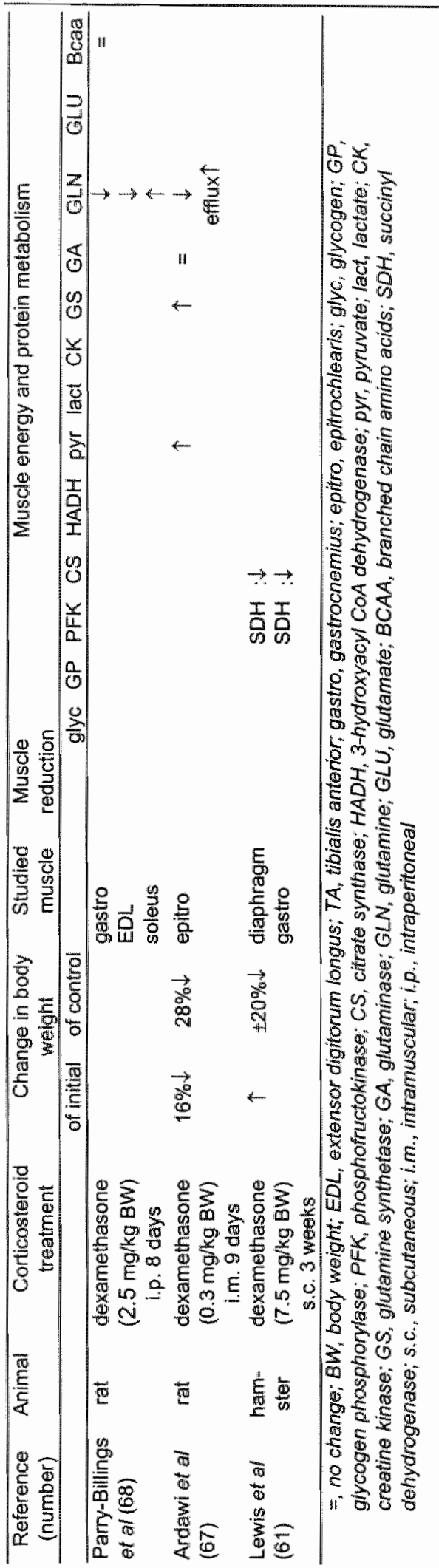




\subsubsection{Effects of corticosteroids on muscle metabolism}

As shown in Table 5, after cortisone treatment muscle glycogen was increased in the diaphragm but not in the EDL muscle (63). A possible explanation could be the observed decreased glycogen phosphorylase activity $(56,58)$. Lieu and colieagues (1993) suggested that a reduction in glycolytic capacity would likely increase the muscle's dependence on fat oxidation, resulting in a higher glycogen content. Indeed, both a decreased PFK and an (not significantly) increased HADH activity were found in the plantaris, but not in the diaphragm muscle. The oxidative capacity, as indicated by CS activity, was affected in several ways by (methyl)prednisolone treatment in the diaphragm, while it was unchanged in the plantaris muscle. Both the increased pyruvate and lactate levels in the diaphragm and peripheral skeletal muscles however, may indicate an increased glycolytic activity of the muscles. Furthermore, creatine kinase (CK) activity is decreased in the diaphragm after corticosteroid treatment, which implies a reduction in fast energy supply.

Protein metabolism, as reflected by amino acid metabolism, is also affected by corticosteroids. Gutumine, an important conditionally essential amino acid, has frequently been studied, because its an important nitrogen and ammonia carrier in interorgan metabolism (64). Glutamine efflux is reported to be increased (65-67). In most cases, this is accompanied by a decreased intramuscular glutamine concentration (65-68). Glutamine can be produced de novo from glutamate by glutamine synthetase (GS). GS activity and mRNA expression is often found to be increased after corticosteroid treatment $(66,67,69,70)$. An unchanged activity of glutaminase, which catalyses glutamate formation from glutamine, after corticosteroid treatment was shown $(66,67)$. Intramuscular glutamate concentration was found to be decreased after dexamethasone treatment in the epitrochlearis muscle (67) but increased in the gastrocnemius muscle, while glutamate influx was unchanged (66).

Dexamethasone treatment resulted also in most cases in an increased branched chain amino acid concentration in the peripheral skeletal muscle $(66,67)$.

In summary, glycogen stores can be increased after corticosteroid treatment, depending on the muscle. It is still unclear whether glycolytic and/or axidative metabolism are decreased, unchanged or increased. However, it is consistently found that glutamine efflux is increased after corticosteroid treatment. It is difficult to compare these studies because of the different corticosteroid treatments and only a few parameters are investigated simultaneously in one muscle, which is different from the muscle in another study. To obtain a better insight in muscle metabolism after corticosteroid treatment, one has to study several aspects together in one muscle after administration of a given corticosteroid.

\subsection{Outline of this thesis}

Considering the important role of both corticosteroids and undernutrition on muscle dysfunctioning in chronically ill patients, the purpose of the studies described in this thesis was to discriminate between the effects of corticosteroids and undernutrition on muscle functioning. as determined by muscle mass, morphology and metabolism. It is not possible to investigate the individual effects of corticosteroids or of undernutrition on muscle function in patients, due to ethical reasons and intervening disease related factors. Therefore, an experimental rat model was chosen. The fluorinated corticosteroid triamcinolone was used because it is known to induce muscle wasting, caused by both undernutrition as well as by hypermetabolism (71). The triamcinolone-treated group could be compared with two nutritional-control groups. Firstly a pair fed group was introduced, to adjust for the effects of triamcinolone treatment on daily food intake. This pair fed group had a comparable dailly food intake as the triamcinolone-treated group. Secondly the body weight of the rats was decreased to a greater extent than could be explained by the diminished food intake alone. To induce a comparable body weight as the triamcinolonetreated group, daily food intake was restricted severely. Finally a free fed control group was used. which had ain ad libitum food intake and was a reference for normal untreated rats. 
Food intake and body weight were registered daily and an acute and chronic response of triamcinolone treatment was shown. In our first study, we compared diaphragm muscle morphology and function after chronic triamcinolone treatment with (nutritional) control groups (chapter 2). This was performed in an isometric in vitro set-up. This means that a bundle of the diaphragm was placed in a glass tissue chamber and stimulated with an isometric force transducer. Since it was shown that the corticosteroid dose was too high (more than $50 \%$ mortality) and 2 weeks treatment was probably long enough to induce chronic muscle wasting (body weight was almost stable as shown in Figure 2B), we decided to adapt the model to a lower triamcinolone dose and a shorter treatment period. Additional to the effects on in vitro muscle function, diaphragm muscle metabolism was studied (chapter 3), especially the energy-rich phosphates, since alterations in energy metabolism may also reflect differences in muscle function.

In an in vitro experiment, muscle function is mainly dependent on substrates present in the muscle, which is muscle fibre dependent, and on diffusion for substrate metabolism and oxygen supply. In situ muscle function however, is also dependent on blood flow, which plays an important role in performing muscle function by supplying substrates and remove waste products. A peripheral skeletal muscle was studied. This is a relevant muscle since both peripheral skeletal muscle and respiratory muscle weakness is observed in chronically ill patients. In this in situ set-up, triamcinolone treatment was on the one hand compared with undernutrition and on the other hand with treatment of prednisolone in an equipotent antiinflammatory dose (chapter 4). This non-fluorinated corticosteroild is more frequently used in clinical practice and did not induce muscle wasting after intramuscular administration. Subsequently, in the same groups, muscle enzyme activities and glycogen of the peripheral skeletal muscle was determined (chapter 5), since they can give more insight in the underlying pathophysiology.

Protein metabolism is obviously disturbed after corticosteroid treatment (72-74) and has been related to an increased glutamine rellease from the muscle (66-68) "To investigate whether muscle wasting occurs during a chronic process or is mainly a reflection of acutely effects, muscle glutamine metabolism was studied after acute and chronic triamcinolone treatment (chapter 6). With the use of venous-arterial concentrations and stable isotope techniques muscle glutamine metabolism was studied. Glutamine is a conditionally essential amino acid and plays an important role during metabolic stressful conditions, such as after triamcinolone treatment. In all these described studies, triamcinolone and prednisolone were injected intramuscularly, which means that these corticosteroids diffuse in the circulation and may easily exert systemic effects in the whole body. Corticosteroids are often given locally instead of systemically, for instance in the form of inhalation corticosteroids given to patients with respiratory failure. A central role in the action of corticosteroids is played by the glucocorticoid receptors (GR). The presence of two functionally distinct receptors $\alpha$ and $\beta$ GR mRNAs have been described in several human tissues $(75,76)$. In rats, no information is available about the existence of the $\beta$ GR form in skeletal muscles and the ragulation of the $\alpha$ and $\beta$ form by corticosteroids. To investigate whether systemic effects could be found after corticosteroid inhalation, the expression of the $\alpha$ and $\beta$ GR forms were investigated in a peripheral skeletal muscle (chapter 7). Finally, the major findings of these studies are summarised and discussed in chapter 8 . 


\section{References}

1. McParland $C$, Resch EF, Krishnan $B$, Wang $Y$, Cujec $B$, Gallagher CG. Inspiratory muscle weakness in chronic heart falure: role of nutrition and electrolyte status and systemic myopathy. Am J Respir Crit Care Med 1995;151:1101-7.

2. Baarends EM, Schols. AM, Mostert $R_{i}$ Wouters EF. Peak exercise response in relation to tissue depletion in patients with chronic obstructive pulmonary disease. Eur Respir $J$ 1997:10:2807-13.

3. Stratton $J R_{n}$ Kernp GJ, Daly RC, Yacoub M, Rajagopalan B. Effects of cardiac transplantation on bioenergetic abnormalities of skeletal muscle in congestive heart failure. Circulation 1994;89:162:4-31.

4. Willams TJ, Snell GI. Early and long-term functional outcomes in unilateral, bilateral, and livingrelated transplant reciplents. Clin Chest Med 1997;18:245-57.

5. Skeletal muscle dysfunction in Chronic Obstructive Pulmonary Disease. Am J Respir Crit Care Med 1999:159:\$1-S40

B. Stassilins $G$, Lysens $R$, Decramer M. Peripheral and respiratory muscles in chronic heart failure. Eur Respir J 1996:9:2161-7.

7. Supinski $G$, Nethery D, Stofan D, DiMarco A. Companison of the effects of endotoxin on limb, respiratory, and cardiac muscles. J Appl Physiol 1996;81:1370-8.

8. O. Donnell D, Lam M, Webb KA. Measurement of symptoms, lung hyperinflation, and endurance during exercise in chronic obstructive pulmonary disease. Am J Respir Crit Care Med $1998 ; 158: 1557-65$

9. Bernard $S$, LeBlanc $P$. Whittom $F$, et al. Peripheral muscle weakness in patients with chronic obstructive pulmonary disease. Am J Respir Crit Gare Med 1998;158:629-34.

10. Engelen MPKJ, Schols AMWJ, Baken WC, Wesseling GJ, Wouters EFM. Nutritional depletion in relation to respiratory and peripheral skeletal muscle function in out-patients with COPD. Eur Respir J 1994;7:1793-1797.

11. Lands LC, Heigenhauser GJ, Jones NL. Respiratory and peripheral muscle function in cystic fibrosis. Am Rev Respir Dis 1993;147:865-9.

12. Maltais $F$, Simard $A$, Simard $C$, Jabin J, Desgagnes $P$, LeBlanc $P$. Oxildative capacity of the skeletal muscle and lactic acid kinetics during exercise in nomal subjects and in patients with COPD. Am J Respir Crit Care Med 1996;153:288-293.

13. Flaccadori $E_{1}$ Del $C S$, Vitale $P$, Coffrini $E$, Ronda $N$, Guariglia A. Skeletal muscle energetics, acid-base equilibrium and lactate metabolism in patients with severe hypercapnia and hypoxemia. Chest 1987;92:883-887.

14. Conjard A, Ferrier $B$, Martin $M$, Caillette $A$, Carrier $H$, Baverel $G$. Effects of chronic renal failure on enzymes of energy metabolism in individual human muscle fibers. J Am Soc Nephrol 1995:6:68-74.

15. Drexler $H_{1}$ Riede $U_{n}$ Munzel $T$, Konig $H_{2}$ Funke $E$, Just $H$. Alterations of skeletal muscle in chronic heart failure. Circulation 1992;85:1751-9.

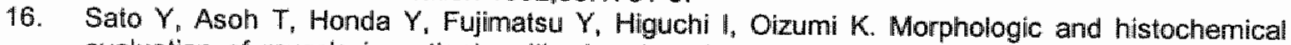
evaluation of muscle in palients with chronic pulmonary emphysema manifesting generalized emaciation, Eur Neurol 1997; 37:116-21.

17. Schals AM, Slangen J, Volovics L, Wouters EF. Weight loss is a reversible factor in the prognosis of chronic obstructive pulmonary disease. Am J Respir Crit Care Med 1998;157:17917 .

18. Creutzberg $E$, Schals A, Weling-Scheepers $C_{n}$ Buurman $W$, Wouters $E$. Characteristics of depleted COPD patients not responding to nutritional support. Am J Respir Crit Care Med 1996:153:A465.

19. Horber FF, Zurcher RM, Herren $H$, Crivell MA, Robotti $G$, Frey FJ. Altered body fat distribution in patients with glucocorticoid treatment and in patients on long-term dialysis. Am J Clin Nutr $1986 ; 43: 758-769$.

20. Danneskiold Samsoe B. Grimby G. Muscle marphology and enzymes in proximal and distal muscle groups of lower limb from patients with corticosteroid treated theumatoid arthritis: the relationship to maximal isokinetic muscle strength. Clin Sci 1986;71:685-691.

21. Decramer $M_{n}$ Lacquel $L M_{n}$ Fagard $R_{n}$ Rogiers $P$. Corticasteroids contribute to muscle weakness in chronic aifflow obstruction. Am J Respir Crit Care Med 1994:150:11-16.

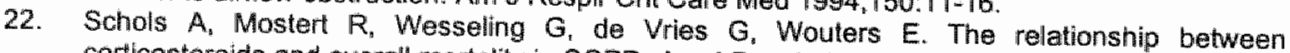
corticosteroids and overall mortality in COPD. Am J Respir Crit Care Med 1998;157:A802.

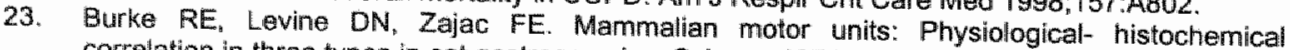
correlation in three types in cat gastrocnemius. Science 1971:174:709-712.

24. Burke RE, Levine DN, Tsairis $P$, Zajac FEd. Physiological types and histochemical profiles in motor units of the cat gastrocnemius. J Physiol Lond 1973;234:723-48. 
25. Brooke MH, Kaiser KK. Three "myosin adenosine triphosphatase" systems: the nature of their pH labilty and sulfhydryl dependence. $₫$ Histochem Cytochem 1970;18:670-2.

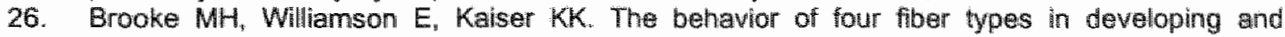
reinnervated muscle. Arch Neurol $4971,25: 360-6$.

27. Peter JB, Bamard RJ,Edgerton VR, Gillespie CA, Stempel KE. Metabolic profiles of three floer types of skeletal muscle in guinea pigs and rabbits. Biochemistry $1972,11: 2627-2633$.

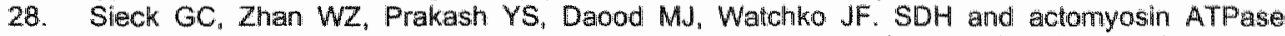
activities of different fiber types in rat diaphragm muscle. I Appl Physiol 1995;79:1629-39.

29. Watchko JF, Sieck GC. Respiratory muscle fatigue resistance relates to myosin phenotype and SDH activity during development. I Appl Physiol 1993;75:1341-7.

30. Enad $J_{\mathrm{G}}$ Foumier $M$, Sieck $\mathrm{GC}$. Oxidative capacity and capillary density of diaphragm motor Units. I Appl Physiol 1989;67:620-7.

31. Nomal muscle function. Am d Respir Crit Care Med 1999:159:52-59.

32. Schligtig $R_{\sharp}$ Ayres S. Protein metabolism: adaptations for stavalion and stress. In: Schligtig RaA, SM, ed. Nutritional support of the critically ill. Chicago: Year Book Medical Publishers, Inc., 1988:27-47

33. Mitch WE Goldberg AL. Mechanisms of muscle wasting. The role of the ubiquitin-proteasome pathway. N Engl J Med 1996;335:1897-905.

34. Ciechanover $\mathrm{A}$. The ubiquitin-proteasome proteolytic pathway. Cell 1994:79:13-21.

35. Lowell BB, Ruderman NB, Goodman MN. Evidence that lysosomes are not involved in the degradation of myofibrillar proteins in rat skeletal muscle. Biochem J 1986;234:237-40.

36. Johnson P. Calpains (intracellular calcium-activated cysteine proteinases): structure-activity relationships and involvement in normal and abnormal cellular metabolism. Int J Blochem $1990 ; 22: 811-22$

37. Wang L, Lwo GJ, Wang JW, Hasselgren PO. Dexamethasone stimulates proteasome- and calcium-dependent proteolysis in cultured L6 myotubes. Shock 1998; 10:298-306.

38. Pison. Role du fole dans l'adaptation a l'hypoxie. thesis .

39. Spriet LL, Soderlund $K_{n}$ Bergstrom $M_{n}$ Hultman $E$. Anaerobic energy release in skeletal muscle during electrical stimulation im men. J Appl Physiol 1987;62:6:1-5.

40. Andrade $\mathrm{FH}_{3}$. Reid MB, Allen DG, Westerblad H. Effect of hydrogen peroxide and dithiothreitol on contractile function of single skeletal muscle fibres from the mouse. I Physloll Lond $1998 ; 509.565-75$.

41. Lewis MI "Sieck GC Foumier M. Belman M.. Effect of nutritional deprivation on diaphragm contractility and muscle fiber size. J Appl Physiol 1986;60:596-603.

42. Dekhuijzen PNR, Gayan Ramirez $G$, Bisschop $A$, Bock de $V$, Dom $R$, Decramer M. Corticosteroid treatment and nutritional deprivation cause a different pattern of atrophy in rat diaphragm. J App| Physiol 1995;78:629-637.

43. Russell DM, Atwood HL, Whittaker JS, et al. The effect of fasting and hypocaloric diets on the functional and metabolic characteristics of rat gastrocnemius muscle. Clin Sci 1984;67:185-194.

44. Barclay C.l. Loiselle DS. Dependence of muscle fatigue on stimulation protocol: Effect of hypocaloric diet. J Appl Physiol 1992;72:2278-2284.

45. Bissonnette DJ, Madiapallimatam $\mathrm{A}_{\text {s }}$ Jeejeebhoy $\mathrm{KN}$. Effect of hypoenergetic feeding and highcarbotydrate refeeding on muscle tetanic tension, relaxation rate, and fatigue in show- and fasttwitich muscles in rats. Am J Clin Nutr 1997;66:293-303.

46. Rooyackers OE, Senden JMG, Soeters PB, Saris WHM, Wagenmakers AlM. Prolonged activation of the branched-chain alpha-keto acid dehydrogenase complex in muscle of zymosan ureated rats. Eur J Clin Invest 1995:25:548-552.

47. Sieck GC, Lewis MI, Blanco CE. Effects of undernutrition on diaphragm fiber size. SDH activity, and fatigue resistance. $J$ Appl Physiol 1989;66(5),2196-2205.

48. Layman D, Merdian-Bender $M$, Hegarty $P$, Swan $P$. Changes in aerobic and anaerobic metabolism in rat cardiac and skelelal muscles after total or partial dietary restrotions. J Nutr $1981 ; 111: 994-1000$.

49. Khan $K$, Wusteman $M$, Wood $S$, Elia $M$. The effect of severe dietary restriction on intramuscular glutamine concentrations and protein synthetic rate. Clin Wutr 1991;10:120-124.

50. Tawa NE, Goldberg AL. Suppression of muscle protein turnover and amino acid degradation by dietary protein deficiency. Am J Physiol 1992,263:E317-E325.

51. Pichard C. Vaughan $\mathrm{C}$, Struk R, Armstrong RL, Jeejeebhoy $\mathrm{KN}$. Effect of dielary manipulations (fasting, hypocaloric feeding, and subsequent refeeding) on rat muscle energetics as assessed by inuclear magnetic resonance spectroscopy. I Clin invest 1988;82:895-901. 
52. Milan dTA, Madapallimatiam A, Cross A, Amstrong RL, Jeejeebhoy KN. Effect of fasting. hypocaloric teeding, and refeeding on the energetics of stimulated rat muscie as assessed by nuclear magnetic resonance spectroscopy. I Chin invest 1993;92.114-12\%

53. Thalen A, Brattsand R, Anders son PH. Development of glucocorticosteroids with enhanced ratio between topical and systemic effects. Acta Dem Venereol 1989;69 (suppl 151):11-19.

54. Brattsand $R$. Thalem $A$, Roumpke $K$, Kallstrom $L$, Gruwstad E. Infuence of 16 alpha, 17 alphaacetal substitution and steroid nucleus fuorination on the topical to systemic activity ratio of glucocortieoids. J Steroid Blochem 1982,16:779-786.

55. Dekhulizen PNR, Gayan Ramirez $G$, Bock de V, Dom R, Decramer M. Triamcinolone and predinisolone affect contractle properties and histopathology of rat diaphragm differently. $\ \mathrm{Clin}$ Invest $1993 ; 92: 1534-1542$.

56. Batkom VRHH, Dekhulzen PNR, Folgering HTM, at al. Anabolic steroids in part reverse glucocorticoid-induced alterations in rat diaphagm. J Appl Physiol 1998:84:1492-1497.

57. Balkom VRHH, Zhan W, Prakash $Y$, Dektuizen $P$. Sileck $G$. Corticosteroid effects on isotonic contractle properties of rat diaphragm muscle. I Appl Physiol 1997;83:1062-1067.

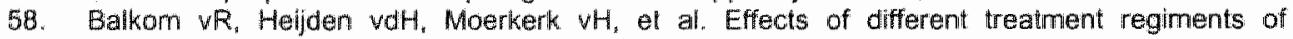
methylprednisolone on rat diaphragm contractility, immunohistochemistry and biochemistry. Eur Respir J 1996;9:1217-1223.

59. Lieu FK, Powers SK, Herb RA, et al. Exercise and glucocorticoidinduced diaphragmatic myopathy. A Appl Physiol 1993:75:763-771.

60. Dodd SL, Powers SK, Vrabias IS, Eason JM. Interaction of glucocorticoids and activity patterns affect muscle function. Muscle Nerve 1995;18:190-195.

61. Iewis MI, Monn SA. Sieck GC. Effect of corticosteroids on diaphragm fatigue, SDH activity, and muscle fiber size. J Appl Physiol 1992;72:1):293-301.

62. Sasson L. Tarasluk A, Heimer D, Bark H. Effect of dexemethasone on diaphragmatic and soleus muscle morphology and fatigability. Respir Physiol 1991;85:15-28.

63. Ferguson GT. Effects of cortisone and testosterone on diaphragmatic function and biochemistry in the rabbit.. I Appl Physiol $1995 ; 78: 1459-1468$.

64. Max SR, Mill $J$, Mearow $K_{\text {. }}$ et al. Dexamethasone regulates glutamine synthetase expression in rat skeletal muscies. Am a Physiol 1988:255:E397-E403.

65. Hickson RC, Czenwinski SH, Wegryn LE. Glutamine prevents downregulation of myosin heavy chain symthesis and muscle atrophy from glucocorticoids. Am J Physiol 1995;268:E730-734.

66. Hundal HS, Babil P, Taylor PM, Watt PW, Rennie MJ. Effects of corticosteroid on the transport and metabolism of glutamine in rat skeletal musche. Biochim Biophys Acta 1991:1092:376-383.

67. Ardawi MSM, Jamal YS. Glutamine metabolism in skeletal muscle of glucocorticoid-treated rats. Clin Sell 1990;79:139-147.

68. Parry Bilings M, Leighton B, Dimitriadis GD, Bond J, Newsholme EA. Effects of physiological and pathological levels of glucocorticolds on skeletal muscle glutamine metabolism in the rat. Biochem Pharmacol 1990;40:1145-1148.

69. Meynial Denis D, Mignon M, Miri A, et al. Gitamine synthetase induction by glucocorticoids is preserved in skeletal muscle of aged rats. Am J Physiol 1996;271:E1061-6.

70. Falluto MT, Young AP. Hickson RC. Exercise intertupts ongoing glucocorlicoid-induced muscie atrophy and glitumine symthetas induction. Am J Physiol 1992;263:E1157-E1163.

71. Gardiner PF Montanaro G. Simpson DR . Edgerton VR. Effects of glucoconticoid treatment and food restriction on rat hindlimb muscles. An J Physiol 1980,238:E124-E130.

72. Hall Angeras $M_{n}$ Angeras $U$, Zamir $O$, Hasselgren $P O$, Fischer $E$. Interaction between corticosterone and tumor necrosis factor stimulated protein breakdown in rat skeletal muscle, similar to sepsis. Surgery 1990;108:460m-456.

73. Smith OL, Wong CY "Gelfand RA. Influence of ghtucocorticoids on skeletal musell proteolysis in normal and diabetic-adrenalectomized ewiscerated rats. Metabolism 1990,39:641-6.

74. Auclair D, Garrel DR, Chaouki Zerouala A, Ferland LH. Activation of the ubiquitin pathway in rat skeletal muscie by catabolic doses of glucocorticoids. An J Physiol 1997"272:C1007-16.

75. Bamberge $\mathrm{CM}$. Bamberger $\mathrm{AM}$, de Castro M, Chrousos GP. Glucocorticoid receptar beta, a potential endogenous inhibitor of glucocorticoid action in humans. J Clin invest 1995;95:2435-41.

76. Oakley RH4, Sar M, Cidlowski JA. The human glucocorticoid receptor beta isoform. Expression, biochemical properties, and putative function. J Biol Chem 1996;271:9550-9.

77. Kelsen SG. Ference M, Kapoor S. Effects of prolonged undernutrition on structure and function of the diaphragm. I Appl Physiol 1985;58(4):1354-1359.

78. Prezant DJ, Richner $B_{*}$ Aldrich TK, Valentine DE, Gentry El, Cahill J. Effect of long-term undernutrition on male and female rat diaphragm contractility, fatigue, and fiber types. I Appl Physiol 1994:76:1540-1547. 
79. Prezant $D$, Karwa M, Richner $B$, at al. Short term vs long term dexemethasone travtment: Effects on rat diaphragm structure and function. Lung 1998; $176267-280$.

Bo. Moore BJ, Miller MJ, Feldman MA, Reid MB. Diaphragm atrophy and weakness in corlisoneriated rats. J Appl Physiol 1989;67:2420-2426.

81. Polla $B$, Bottinelli $R$, Sandoli $D$, Sardi $C$, Reggiani $C$. Cortisone-induced changes in myosin heavy chain distribution in respiratory and hindimb muscles. Acta Physibl Scand 1994;151;35361 .

82. Ferguson GT, INin CG. Cherniack RM. Effect of corlicosteroids on diaphragm function and biochemistry in the robbit. Am Rev Respir Dis 1990;141:156-163.

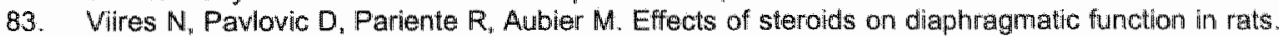
Am Rev Respir Dis 1990; $142: 34-38$.

84. Petrof $B J$, Gottfied SB, Eby J. Lamanca J, Levine S. Growth homone daes nat prevent corticosteroid-induced changes in rat diaphragm structure and function. $J$ Appl Physiol $1995 ; 79: 1571-1577$.

85. Gardiner PF, Edgerton VR. Contractile responses of rat thast-twitch and slow-twitch muscles to gilucocorticoid treatment. Muscle Nerve $1979 ; 2: 274-2811$.

86. Kanda F, Takatani K, OKuda S, Matsushita T, Chihara K. Preventive effects of insulinilke growth factor-l on steroid-induced muscie atrophy. Muscle Nerve 1999;22:213-247.

87. Wilcox PG, Hards JM, Bockhold KK, Bressler B, Pardy RL. Pathologic changes and contractile properties of the diaphragm in corticosteroid myopathy in hamsters: Comparison to peripheral muscle. Am J Respir Cell Mol Biol 1989; $1: 191-199$. 



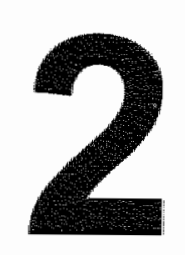

\title{
Contractile properties and histochemical characteristics of the rat diaphragm after prolonged triamcinolone treatment and nutritional deprivation.
}

\author{
E Koerts-de Lanig, AMWJ Schols, EFM Wouters, \\ G Gayan-Ramirez ${ }^{1}$, M Decramer ${ }^{1}$. \\ Journal of Muscle Research and Cell Motility 19: 549-555 (1998)
}

Department of Pulmonology, Maastricht University. The Netherlands.

'Respiratory Muscle Research Unit, Laboratory for Pneumology, University of Leuven. Belgium. 


\begin{abstract}
Absitract
The intuence of decreased muscle mass and reduced food intake on diaphiram structure and contractility in male Wistar rats was determined after triamcinolone acetate treatment (TR: $0.5 \mathrm{mg} / \mathrm{kg}$ /day for 4 weeks) and two degrees of undernutrition (PW: pair-weight, which resulted in a similar $(41 \%)$ reduction of body weight as TR; PF: paitfed, which resulted in a moderate $(13 \%)$ reduction of body weight and a free fed control group (FF, with an increase $(9 \%)$ in body weight). Energy intake of TR decreased but based on daily measurements of food intake and body weight, energy expenditure of the TR rats was increased compared with the other groups. Body (BW) and muscle weights ware reduced in proportion to the extent of undemulition in the nutritionally deprived rats (I.e. BW and diaphragm weight of PF animals were reduced $2 \% 1$ and $16 \%$ respectively compared with FF, versus a $48 \%$ and $41 \%$ reduction in the PW group). Triamcinolone-induced atrophy was limited to type II fibres $130 \%$ of type lla and $45 \%$ of type $\| x j b, p<0,05 \%$. while severe chronic undernutrition (PW) induced a generalised fibre type allophy in the diaphragm (23\% vpe 1, 38\% type Ila and $49 \%$ type $|1| x / b, p<0.05$ ) and moderate undernutrition (PF) caused only significant type lla atrophy $(20 \%, p<0.05)$. A leftward shift of the diaphragmatic tension-frequency relationship and a decreased fatigabillty of the TR and PW bundles were observed $(p \times 0.011)$. while the PF bundles were not significantly different compared with FF. These results suggest that inlamcinolone and severe undernutrition cause similar alterations in in witro contractiity of the diaphragm. The effects of triamcinolone treatment on diaphragm structure may be partly explained by the reduced food intake, but the atrophy pattern induced by severe undemutrition (PW) was different.
\end{abstract}

\title{
2.1. Introduction
}

Previous studies suggest that in patients with chronic obstructive pulmonary disease (COPD) muscle weakness may be the result of muscle wasting associated with weight loss $(1,2)$ and of corticosteroid treatment $(3)$. Weight loss in patients with COPD appears to be primarily the result of increased energy requirements which cannot be restored by increased spontaneous dietary intake (4).

Experimental research in animals (mice, rats) indicates that particularly fluorinated steroids cause myopathies (5) or muscle weakness $(6,7)$, which are accompanied by decreased body weight and muscle mass. A decreased food intake of approximately $42 \%$ was observed with administration of the fluorinated corticosteroid triamcinolone, but the loss of body weight of $51 \%$ could not be only the result of this diminished food intake (6). In another study, Dekhuijzen and colleagues (8) concluded that triamcinolone treatment caused type llb atrophy. while nutritional deprivation, resulting in a comparable body weight reduction, caused a generalised atrophy of all diaphragm fibre types, but these two treatments showed similar changes in in witro diaphragm contractile properties. Based on this study, we questioned to what extent the effects of triamcinolone on muscle structure and in vitro function are related to the effects of nutritional deprivation per se, to the degree of muscle wasting induced by triamcinolone treatment, or to a combination of both. Therefore the present study was designed to compare the effects of triamcinolone treatment with two nutritionally deprived groups; a pair-fed group, with a similar food intake and a pair-meight group, with a comparable body weight, on diaphragm structure and in witro contractility. Corticosteroids are used in low doses as maintenance therapy or in high doses with exacerbations in COPD. In this study, the dose of triamcinolone is within the range of chronic corticosteroid therapy in COPD patients. Furthermore, triamcinolone is used in the present study because muscle wasting occurs, which could be due to glucocorticoid effects or due to 
chronic undernutrition. A possible differentiation between the effects of corticosteroids and chronic undernutrition on muscle structure and function may have clinical relevance in the assessment of (respiratory) muscle weakness in COPD patients.

\subsection{Methods}

\section{Animals}

After 4 days of acclimatisation in metabolic cages, 40 male Wistar rats (aged 14 weeks, body weight (BW) ranged from $287-339 \mathrm{~g}$ ) were randomly divided into four groups to receive during 4 weeks: 1) Triamcinolone (TR: $0.5 \mathrm{mg}^{*} \mathrm{~kg}^{-1}$ "day triamcinolone acetate $\mathrm{lm}$ ), ad libitum food intake $(n=16$ in order to take into account previously described premature death (8)); 2) Pair-weight (PW: $0.05 \mathrm{ml}^{\text {thday }}$ saline i.m.), restricted food intake, daily adjusted to achieve a similar weight loss as TR $(n=8)$; 3) Pair-fed (PF: $0.11 \mathrm{~m}^{*}$ day ${ }^{\text {"i }}$ saline i.m. ( $(\mathrm{BW}>300 \mathrm{~g})$ or $0.05 \mathrm{ml}$ ( $\mathrm{BW}<300 \mathrm{~g})$ ), restricted food intake, dally adjusted to the food intake of TR $(n=8)$; 4) Free fed (FF: $0.1 \mathrm{ml}^{*}$ day" saline $1 . \mathrm{m}$.), ad libitum food intake $(n=8)$. The diet provided to all animals was Muracon-G chow (53\% carbohydrate, $20 \%$ protein, $5 \%$ fat). Water was available ad libitum to all animals. The animals were housed in metabolic cages, at a temperature of $23^{\circ} \mathrm{C}$, with 14 hours light and 10 hours dark. Food intake and body weight of all animals were registered daily. Veterinary oversight, including regular observation of the health of the animals was performed according to the Belgian National Guidelines of Animal Care.

\section{In vitro determination of diaphragm contractility}

Twenty-four hours after the last injection and after 16 hours fasting, the animals were anaesthetised with Nembutal $(6 \mathrm{mg} / 100 \mathrm{~g}$ intraperitoneally), tracheostomized, and mechanically ventilated. Rectal temperature was monitored and adjusted with a heating lamp. The left part of the diaphragm was rapidly excised and two thin strips of muscle were cut from the central tendon to the ribs (in cooled oxygenated $+5 \% \mathrm{CO}_{2} \mathrm{Krebs}$ solution). These diaphragm bundles were each placed in a glass lissue chamber containing oxygenated $+5 \% \mathrm{CO}_{2}$ Krebs solution, maintained at $37^{\circ} \mathrm{C}$. One end of the bundle was tied to a rigid support and the other end was fastened to an isometric force transducer mounted to a micrometer. The optimal length $\left(L_{0}\right)$ of the bundle was determined and thermoequilibration was done for 15 minutes (to $37^{\circ} \mathrm{C}$ ). The bundles were stimulated with a pulse duration of $0.2 \mathrm{~ms}$ and a train duration of $250 \mathrm{~ms}$. From a series of single pulses, the peak twitch tension was determined. Other twitch characteristics, such as the time to peak tension (TPT) and the half-relaxation time $(1 / 2$ RT) were calculated. Maximal tetanic tension was determined at $160 \mathrm{~Hz}$. Tension-frequency relationships were measured at $25,160,50,160$, $80,160,120,160 \mathrm{~Hz}$. Each stimulus was separated by a 2 -min interval. Stimulation at 160 $\mathrm{Hz}$ was interposed between each stimulus frequency during the tension-frequency curve to relate tension output at a certain stimulus frequency to the maximal achievable tension output at that moment (9). Bund les were fatigued by means of $330 \mathrm{~ms}$ stimulations at $25 \mathrm{~Hz}$ and applied every 2 seconds during 5 minutes. Bundle thickness and length were measured at $L_{0 .}$. Afterwards it was blotted $d r y$ and weighed. Cross-sectional area (CSA) was calculated by dividing weight by specific density (11.056) and muscle $L_{a}$. All measured tensions were normalised for CSA of the bundle. 


\section{Muscle fibre histochemistry}

The remaining part of the costal diaphragm was put into "tissue giue" (Tissue-Tek, Elkhard, W) on a cork holder with the muscle fibres oniented perpendicularty to the surface of the cork, then quickly frozen in isopentane, cooled by liquid $N_{2}$. Serial cross sections were cut at $8 \mu \mathrm{m}$ thickness by use of a cryostat kept at $-20^{\circ} \mathrm{C}$. Myofribrillar adenosinetriphosphatase was stained after alkaline ( $\mathrm{pH} \mathrm{9.3)} \mathrm{and} \mathrm{acid} \mathrm{(} \mathrm{pH}$ 4.5) preincubation. Fibre analysis was done with a Leitz microscope, linked up to a digitising board (Quantimet 570 , Leica, United Kingdom). Areas in which fibre orientation was not transverse to the long axis and areas with freezing artifacts, were not analysed. By the use of a computer program, the individual muscle fibres were selected and the fibre CSA was determined from the number of pixels within the outlined fibre. For the diaphragm, CSA was corrected for the shortening occurring from optimal length using a correction factor determined by ourselves in 32 rats, close to that found by Prakash and coworkers (10). At least 250 fibres of each rat were used to calculate the mean CSA of type I, lla and IIx/b fibres.

\section{Statistical analysis}

Two diaphragm bundles were obtained from each animal. The mean of these two was determined and used for analysis. Differences between all groups were assessed using the Mann-Whitriey $U$ test, because of the non-normally distribution of the data. The level of significance was determined as $p \leq 0.05$. Analysis was performed using the SPSSIPC+ program. All data are presented as group means \pm standard error of the mean (SEM). Only significant differences between groups are described.

\subsection{Results}

Animal food intake, body and muscle weights

During the 4 weeks of experiment, 7 rats of the TR group survived (one rat died after 12 days and eight after 20-27 days). In addition, 3 rats of the PW group matched to deceased TR rats and 1 of the PF group died. Triamcinolone treatment caused anorexia after the first injection. Thereafter appetite slowly recovered during the next 5 days, but remained below the ad libitum intake of the rats in group FF $(p<0.05)$. Food intake of PW was significantly lower than that of FF from day 1 onwards $(p<0.01)$ and significantly lower than that of TR from day 6 onwards $(p<0.05)$. Food intake between $P F$ and TR was not significantly different.

Initial body weights of the groups were not significantly different (Figure 1A). During 4 weeks of experiment, the weights of the TR, PW and PF rats were reduced by $47 \%, 48 \%$ and $21 \%$ resp. compared with the FF group $(p<0.01)$, while those of the TR and PW group were significantly lower than those of the PF group $(p<0.01)$.

Adjusted for the differences in body weight, energy intake (food intake in kcal per $100 \mathrm{~g} \mathrm{BW}$ ) of the TR rats decreased and was significantly lower than FF from day 2 until day 8 (Fig $1 \mathrm{~B}$, $p<0.05$ ), but was significantly increased from daly 14 until day 26 (except for day 15,21 and 22) compared with FF (Fig 1B, p<0.05). Energy intake of the TR rats was significantly higher compared with PW (Fig 1B, p<0.05) from day 2 onwards, except for day $4,5,6,9,10,17$, and compared with PF (Fig 1B, $p<0.05$ ) from day 6 onwards, except for day 8,15 and 16. Muscle weight of the diaphragm was significantly decreased in the TR $0.39 \pm 0.02 \mathrm{~g}$. p<0.01), PW $(0.43 \pm 0.01 \mathrm{~g}, p<0.01)$ and $\mathrm{PF}(0.61 \pm 0.03 \mathrm{~g} . \mathrm{p}<0.05)$ groups compared with the FF group $(0.73 \pm 0.04 \mathrm{~g})$ and in the $T \mathbb{R}$ and $P W$ groups compared with the $P F$ group $(p<0.01)$. Both in absolute terms as well as relative to body weight, muscle mass was not significantly different between PW and TR. 

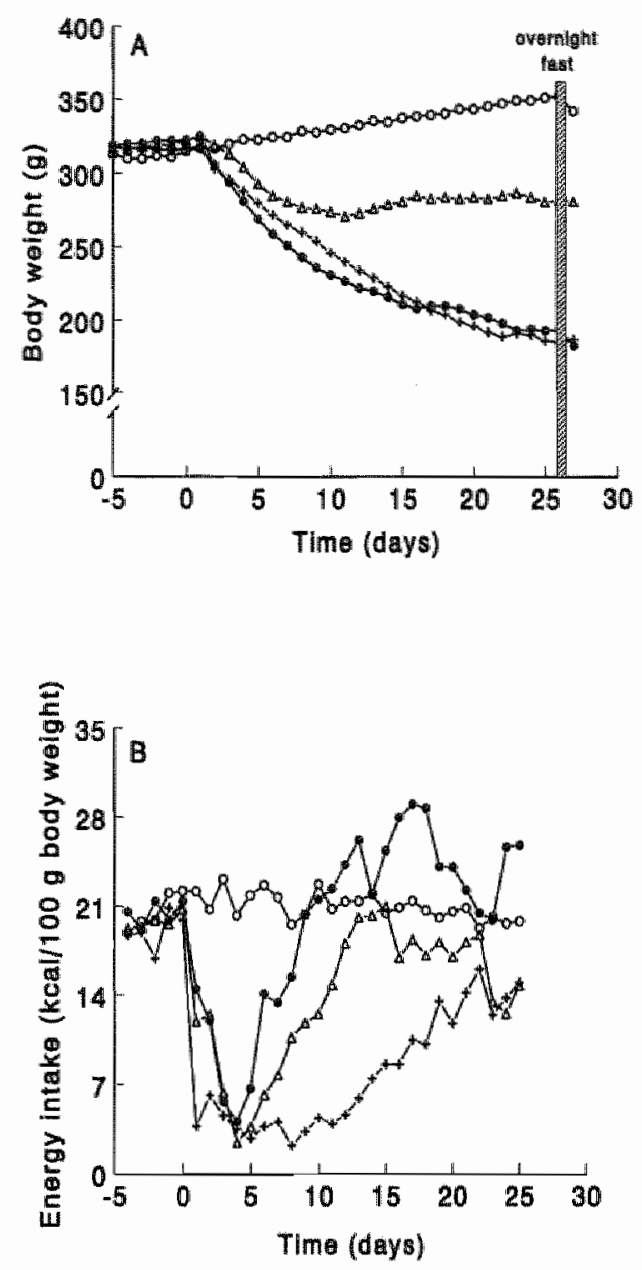

Fig. 1. (A) Body waight of the groups as a result of triamcinolone treatment $(\bullet)$ or pairweight $(+)$, pair-fed $(\Delta)$ or ad libitum food intake (o). TR and 'PW are significantly different from $F F(\rho<0.0 y)$ from day 2 onwards. PF is significant different from $F F$ $(p<0.01)$ from day 4 onwards.

(B) Energy intake of the groups. Seet text for significance.

\section{Peak twitch tension, peak tetanic tension and twitch characteristics}

Tensions and twitch characteristics of the diaphragm are shown in Table 1. Peak wiltch tension ( $\mathrm{Pt}$; at $1 \mathrm{~Hz}$ ) of the PW group was significantly increased compared with PF $(\mathrm{p}<0.05)$ and FF $(p<0.01)$. Peak tetanic $\left(P_{0}\right.$, at $\left.160 \mathrm{~Hz}\right)$ was not significantly different between the groups. The Pt/Po ratio was higher in the TR and PW groups compared with the FF group $(p<0.01)$ and the PF group $(p<0.01)$. Time to peak tension (TPT) of the PW group was prolonged compared with the PF and FF groups (Table $1, p<0.05)$. Half relaxation time (1/2 RT) was longer in the TR and PW groups compared with FF group (Table $1, p<0.05$ ). 
Table 1. Tensions, fatigue and twitch characteristics of the diaphragm

\begin{tabular}{|c|c|c|c|c|}
\hline & Triamcinolone & Palir-welght & Pair-fed & Free-fed \\
\hline $\mathbb{P l}\left(\mathrm{kg} / \mathrm{cm}^{2}\right)$ & $0.8 \pm 0.04$ & $0.9 \pm .010$ 排 & $0.7 \pm 0.02$ & $0.7 \pm 0.02$ \\
\hline Po $\left(\mathrm{kg} / \mathrm{cm}^{2}\right)$ & $2.6 \pm 0.2$ & $2.8 \pm 0.1$ & $2.7 \pm 0.2$ & $2.6 \pm 0.2$ \\
\hline PUPO & $0.31 \pm 0.02$ & $0.34 \pm 0.02$ & $0.26 \pm 0.01$ & $0.25 \pm 0.01$ \\
\hline TPT (ms) & $21.9 \pm 0.3$ & $22.8 \pm 0.2$ & $20.9 \pm 0.4$ & $20.9 \pm 0.4$ \\
\hline $1 / 2 \mathrm{RT}$ (ms) & $28.0 \pm 2.1 *$ & $25.8 \pm 1.4$ & $23.3 \pm 0.5$ & $22.6 \pm 0.7$ \\
\hline
\end{tabular}

Values are means \pm SEM. Pt, peak twitch tension; PO, peak letanic tension; TPT, time to peak tension; Yat, half-relaxation time; " $p<0.05$ compared with pair-fied; $0 p<0.01$ compared with pair-fod; " $p<0.05$ compared with free-fed; $0<0.01$ compared with free-fed.

\section{Tension-frequency relationships}

Figure $2 \mathrm{~A}$ depicts the absolute values of tensions, generated by the diaphragm bundles at different frequencies. The TR and PW group generated significantly higher tensions per CSA than the FF group at $25 \mathrm{~Hz}$ ( $p<0.05$ and $p<0.01$ respectively). When the tensions were expressed as a percentage of interposed $P O$, the curves of the TR and $P W$ groups were significantly shifted to the left compared with that of the FF group (Fig $2 B, p<0.05$ ). The PF
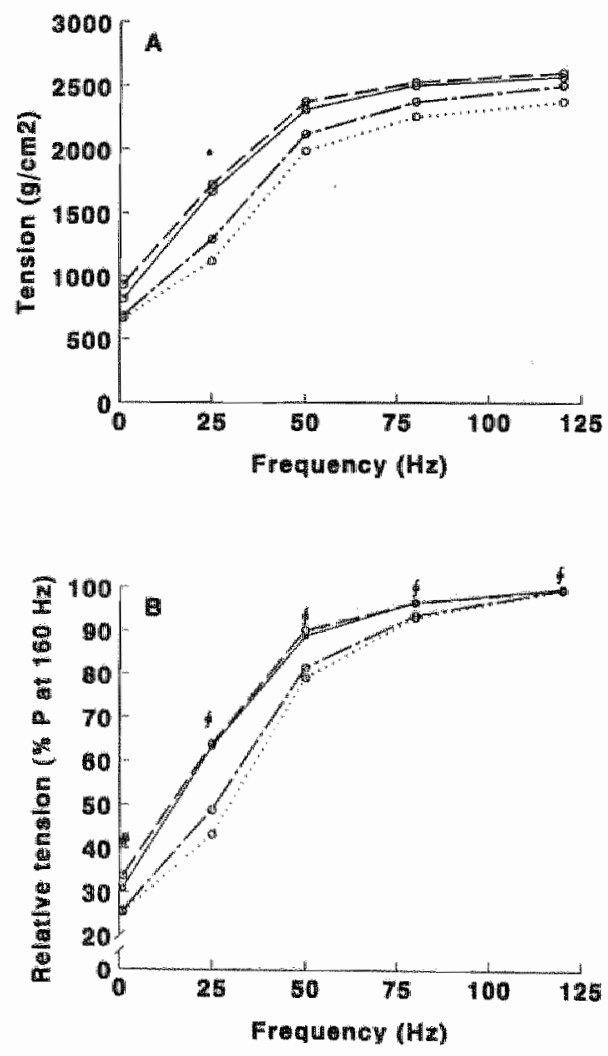

Fig. 2. Tension-frequency relationships in $T R$ (solid line), PW (dashed line), PF (dasheddotted line) and FF (dotted line) groups. (A) Tension-frequency curves aro represented as absolute terisions per cross-sectional area. (B) Tensions were determined as percentages of their maximal tensions. " $p<0.05$ TR compared with FF; \# $p<0.01$ TR compared with FF; $\$$ $p<0.001$ TR compared with FF. 
group showed significantly higher relative tensions only at $25 \mathrm{~Hz}$ compared with the FF group $(p<0.05)$. Fatigue of the interposed $160 \mathrm{~Hz}$ in the TR $(1.9 \pm 1.1 \%)$ and PW $(2.5 \pm$ $0.6 \%)$ rats was significantly less than that of the FF $(11.4 \pm 2.0 \%, p<0.001$ resp. $p<0.01)$ and PF $(7.0 \pm 1.2 \%, p<0.01$ resp. $p<0.05)$ rats.

\section{Fatigue at $25 \mathrm{~Hz}$}

At $25 \mathrm{~Hz}$, the bundles of the TR and PW rats generated significantly higher tensions than those of the FF and PF (after 120 seconds) rats, when expressed in absolute values (Fig $3 \mathrm{~A}$ ). Figure $3 \mathrm{~B}$ depicts the tensions as percentage of their initial values, where TR and $\mathrm{PW}$ bundles showed significantly less fatigue than the FF group $(p<0.05)$, and PW also compared with the PF group after 120 seconds $(p<0.05)$.
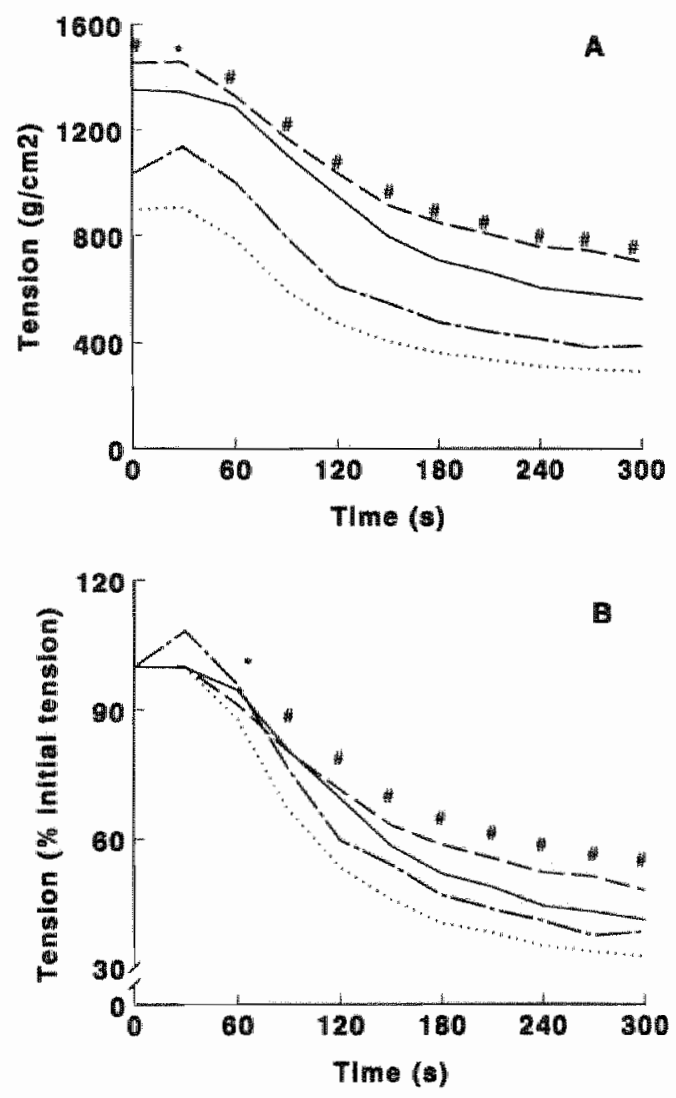

Fig. 3. (A) Fatigue in the bundles of the TR (solid line), PW folashed line), PF (dashed-cotted line) and FF (dotted line) groups. The absolute tenslons per cross-sientional area aria depicted. (B) The relative tension loss is depictied. "is p<0.05 TR comparsd with FF: p<0.01' TR compared with FF. 
Diaphragm fibre cross-sectional area and fibre-type proportions

After triamcinolone treatment, the CSA of type lla and IXXb fibres decreased significantly compared with the FF group by $30 \%$ (Figure $4, p<0.05$ ) and $45 \%(p<0.01$ ) respectively. Severe undernutrition (PW) resulted in a significant reduction of CSA of type I fibres by $23 \%$ $(p<0.05)$ and of both lype $\|$ libres by 38 resp. $48 \%$ (Fig $4, p<0.01$ ). Moderate undernutrition (PF) had no effect on type I fibres but significantly decreased the CSA of lla fibres by $20 \%$ (Fig 4, $p<0.05$ ). Type $\| x / b$ fibres of TR and PW were significantly smaller than those of PF (Fig 4, $p<0.01$ and $p<0.05$ respectively). Significant differences were observed in CSAs of type I fibres between TR and PW rats (Fig $4, p<0.05$ ).
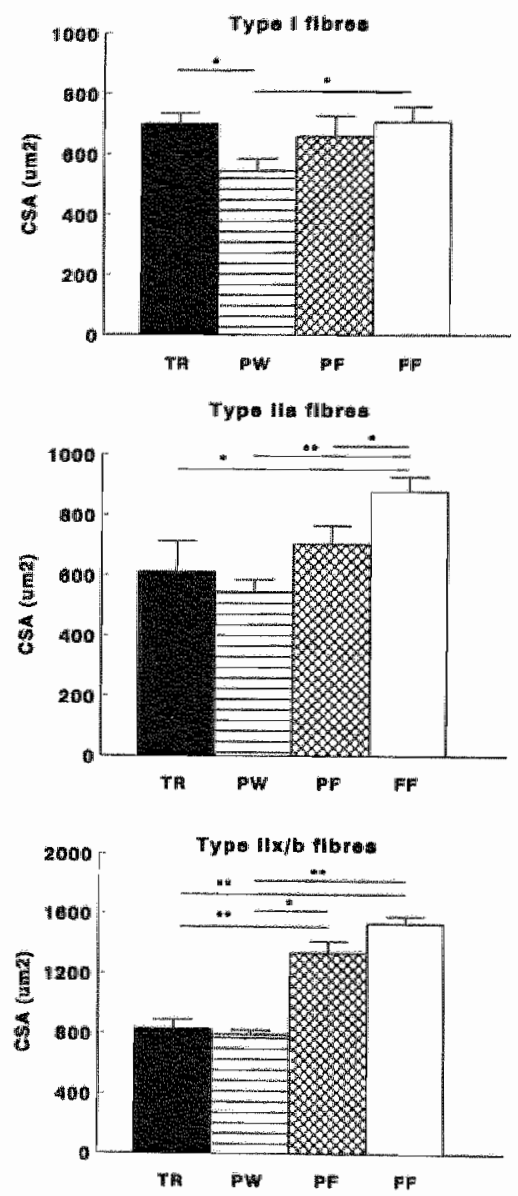

Fig. 4. Fibre cross-sectional area (CSA) in the diaphragm of the different treatment groups. Values are means \pm SEM. * $p<0.05, " p<0.01$.

Figure 5 shows the relative contribution of all fibre type CSAs to the total measured area. Relative type I CSA in TR $(36.5 \%)$ and PW (33.8\%) was increased compared with FF $(22.7 \%, p<0.01)$ and PF $(26.9 \%, p<0.05)$. The relative type Ilx/b CSA of both the TR $(38.3 \%)$ and PW $(37.1 \%)$ groups were significantly reduced compared with the FF $(51.4 \%, p<0.01)$ and PF groups $(50.1 \%, p<0.05)$. Relative type la CSA of the PW group $(29.1 \%)$ was increased compared with the PF group $(23.0 \%, p<0.05)$.

All fibre type proportions remained the same after triamcinolone treatment. On the other hand, after severe chronic undernutrition (PW) a small significant increase in the percentage 
of type lla fibres was found compared with the PF group $(33 \% \mathrm{vs} 29 \%, \mathrm{p}=0.05)$ and a decrease in the percentage of type $1 \mathrm{H} \times \mathrm{b}$ fibres compared with the FF group (29\% ws $35 \%$. $p<0.05$ )

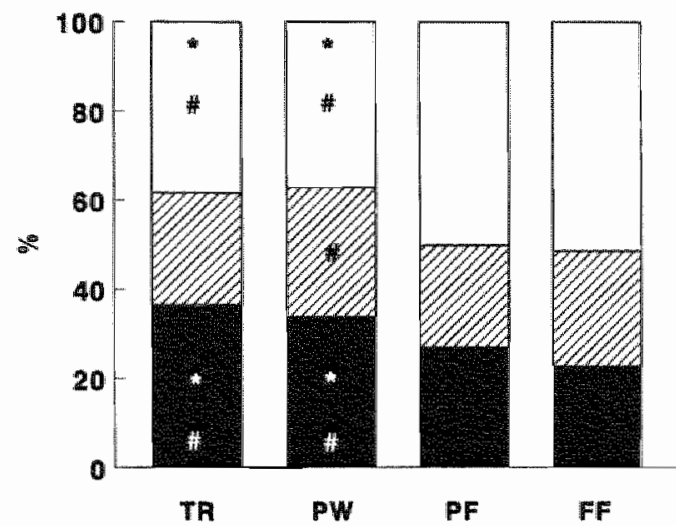

Fig. 5. Relative contributions of different fibre types to total CSA in diaphragm. Solid bars, type I fibres: hatched bars, type lla fibres; opon bars, type $1 / x / b$ fibres." Significant different from FF $p<0.01$; \# significant different from PF $p<0.05$.

\section{Diaphragm bundle dimensions}

The optimal length of the diaphragm bundles of the TR group $(18.2 \pm 0.6 \mathrm{~mm})$ was significantly shorter than that of the FF group $(19.9 \pm 0.4 \mathrm{~mm}, 0<0.05)$. The thickness of the bundles was not significantly different among the groups.

\subsection{Discussion}

The results of this study show a discrepancy between the balance of energy intake and body weight change after triamcinolone treatment, implying that weight loss is a consequence of increased energy expenditure not adequately restored by dietary intake. The diaphragm atrophy pattern of the TR rats was limited to type II fibres, whereas rats with comparable food intake (PF) only showed type lla atrophy and rats with comparable body weight: (PW) showed a generalised atrophy of all fibre types. This suggests a corticosteroid specific effect on diaphragm structure. TR and PW had similarly affected diaphragm muscle mass despite differences in muscle atrophy patterns between these groups, which may suggest atrophy of muscle fibres as well as non-fibre material after triamcinolone treatment. The effect of triamcinolone treatment and severe chronic undernutrition (PW) on diaphragm contractility was comparable, resulting in a decreased fatigue and higher tensions at $25 \mathrm{~Hz}$, but they differed from that of rats with comparable food intake. This suggests that the increased relative contribution of type $\|$ fibres was probably responsible for the alterations noted in contractility.

Chronic severe undernutrition (PW) in this present study showed atrophy of type I fibres $(23 \%)$ but more pronounced atrophy of type $\mathrm{lla}(38 \%)$ and $11 x / b(48 \%)$ fibres. This is in agreement with earlier data on chronic undernutrition to a similar extent in rats, which resulted in $18 \%$ atrophy of type I diaphragmatic fibres and $50 \%$ type II atrophy (11), or $23 \%$ type I and $47 \%$ type II atrophy (12) but in these studies no differentiation was made between type $\| \mathrm{la}$ and $\mathrm{I} \mathrm{x} / \mathrm{b}$. With respect to the effects of undernutrition, the present study design allowed us to differentiate between the effects of moderate (PF) and severe undernutrition (PW) on muscle structure. As expected, moderate undernutrition (PF) caused less effect than severe undernutrition, resulting in only type lla atrophy ( $20 \%$ vs FF).

In general, both triamcinolone and severe chronic undermutrition (PW) caused atrophy of type II diaphragm fibres, most pronounced for type $\| x / b$, whille severe undernutrition also 
caused type I atrophy. Diaphragm weight loss of the TR and PW group was comparable, but total atrophy of the diaphragmatic fibres in the TR group was less than in the PW group. This implies a smaller reduction of fibre material, and may suggest a greater reduction of nonfibre material like extracellular fat stores or connective tissue, after triamcinolone treatment. Moderate undernutrition (PF) resulted in atrophy of type lla fibres approximately to the same extent as caused by triamcinolone, but no significant type $\| x / b$ atrophy. This suggests that the alterations in diaphragm structure after triamcinolone treatment may only be partly explained by their diminished food intake. The atrophy pattern in PW was similar for type II fibres compared to TR, but more pronounced for type I fibres. A similar degree of muscle wasting induced by severe undernutrition resulted in generalised atrophy. Severe undernutrition and triamcinolone treatment resulted in type $\| x / b$ atrophy to the same extent. The contractillty of the diaphragm bundles showed similar alterations for the TR and PW groups compared with the PF and FF group, which were not mutually different. In this study, a prolongation of $1 / 2$ RT and a tendency for TPT to be elevated in the TR group was observed, which is in line with the data of Dekhuijzen and colleagues (8), showing a prolonged $1 / 2 \mathrm{RT}$ after six weeks triamcinolone treatment with the same dose, and a type II $x / b$ fibre atrophy of $51 \%$. After three weeks of dexamethasone treatment in hamsters, Lewis and coworkers (13) reported no change in contraction time and $1 / 2 \mathrm{RT}$, with a type $\|$ atrophy of $33 \%$. Petrof and coworkers (14), after 10 days of triamcinolone treatment in rats, observed a prolongation of the contraction time and a trend toward a prolonged $\%$ RT, with a type $1 \mathrm{x} / \mathrm{b}$ atrophy of $42 \%$. Thus, it seems that the prolongation of $1 / 2 \mathrm{RT}$ after triamcinolone or dexamethasone treatment is related to the extent of type $\| x / b$ atrophy. In the present study, the relative CSA of type | fibres was increased in the diaphragm after severe chronic undernutrition and after triamcinolone treatment, but only the TPT of the pair-weight group was increased, maybe because their type $\| x / b$ atrophy was greater than that of the TR group. The resuits of the tension-frequency stimulation showed a shift to the left of the curves in the TR and PW rats. In earlier studies, this phenomenon was also demonstrated as a result of triamcinolone treatment in hamsters and rats $(8,15,16)$. In the present study, the TR and PW groups demonstrated significantly less fatigue than the FF group, as observed by others in hamsters and rats after triamcinolone treatment $(8,15,16)$. The increased fatigue resistance could be explained by the relatively higher proportion of type I fibres, which are less easily fatiguable than type II fibres.

It seems that the relative decrease in the type $\| x / b$ CSA observed after both TR and PW was primarily responsible for similar alterations in diaphragm contractile properties. This does not exclude the possibility that the observed differences in chronic metabilic effects between TR and PW such as hyperglycaemia and hypermetabolism could well be reflected in in vivo contractility. It appears that the relative decrease in type IIx/b CSA as observed after both triamcinolone treatment and chronic undernutrition was responsible for sirnilar alterations in diaphragm contractile properties. In conclusion, comparable loss of diaphragm muscle mass after triamcinolone treatment and after severe undernutrition resulted in different fibre-type atrophy patterns but similar changes in contractility. in contrast. comparable food intake during triamcinolone treatment and during moderate undernutrition $(P F)$ resulted in differences in diaphragm contractility and structure, while the differences after moderate undernutrition (PF) were less pronounced but in the same direction as after triamcinolone treatment. This suggests that the alterations after triamcinolone treatment may be explained by the diminished food intake in addition to a corticosteroid-specific effect. Furthermore, a discrepancy between the extent of fibre atrophy and muscle mass reduction was observed after triamcinolone treatment and severe chronic undernutrition, which may be caused by a decrease of non-fibre material in the diaphragm muscle after triamcinolone administration. 


\section{Acknowledgements}

The authors wish to express many thanks to $N$ Plaisance-Buts for excellent technical assistance.

\section{References}

1. Lopes $J$, Russell $D$. Whitwell J. Jeejeebhoy KN. Skeletal muscle function in malnutrition. Am J Clin Nutr 1982;36:602-610.

2. Schols AMWJ, Mastert R, Soeters PB, Grewe LH, Wouters EFM. Inwentory of nutritional status in chronic obstructive pulmonary disease. Chest 1989:96:247-249.

3. Decramer M, Lacquet LM, Fagard R, Rogiers P. Corticosteroids contribute to muscle weakness in chronic airflow obstruction. Am J Respir Crit Care Med 1994;150:11-16.

4. Schols AMWJ, Soeters PB, Mostert $\mathrm{R}$, Saris WHM, Wouters EFM. Energy balance in Chronic. Obstructive Pulmonary Disease. Am Rev Respir Dis 1991:143:1248-1252.

5. Faludi $\mathrm{G}$, Gottieb J, Meyers J. Experimentally induced primary myopathies Factors influencing the development of steroid-induced myopathies. Ann NY Acad Sci 1966;138:61-72.

6. Gardiner PF, Montanaro G, Simpson DR, Edgerton VR. Effects of glucocorticoid treatment and food restriction on rat hindlimb muscles. Am J Physiol 1980;238:E124-E130.

7. Viires $N_{s}$ Pavlovic $D$, Pariente $R$, Aubier $M$. Effects of steroids on diaphragmatic function in rats. Am Rev Respir Dis 1990;142:34-38.

8. Dekhuijzen PNR, Gayan Ramirez G, Bisschop A, Bock de $V$, Dom R, Decramer $M$. Corticosteroid treatiment and nutritional deprivation cause a different pattern of atrophy in rat diaphragm. J Appl Physiol 1995;78:629-637.

9. Moore BJ, Miller MJ, Feldman HA, Reid MB. Diaphragm atrophy and weakness in cortisonetreated rats. J Appl Physiol 1989;67:2420-2426.

10. Prakash YS, Fournier $M$, Sieck GC. Effects of prenatal undernutrition an developing rat diaphragm. J Appl Physiol 1993;75:1044-1052.

11. Sieck GC, Lewis MI, Blanco CE. Effects of undernutrition on diaphragm fiber size, SDH activity, and fatigue resistance. J Appl Physiol 1989;66(5):2196-2205.

12. Lewis MI. Sieck $G C$. Fournier M, Belman MJ. Effect of nutritional deprivation on diaphragm contractility and muscle fiber size. J Appl Physial 1986;60:596-603.

13. Lewis MIl, Monn SA, Sieck GC. Effect of corticosteroids on diaphragm fatigue, SDH activity, and muscle fiber size. J Appl Physiol 1992;72(1):293-301.

14. Petrof BJ, Gottfried SB; Eby J, Lamanca J, Levine S. Growth hormone does not prevent corticosteroid-induced changes in rat diaphragm structure and function. J Appl Physial 1995;79:1571-1577.

15. Wilcox PG, Hards $J M_{s}$ Bockhold $K$, Biressler $B$, Pardy RL. Pathologic changes and contractlle properties of the diaphragm in corticosteroid myopathy in hamsters: Comparison to peripheral muscle. Am J Respir Cell Mol Biol 1989;1:191,199.

16. Dekhuijzen PNR, Gayan Ramirez G, Bock de V, Dom R, Decramer M. Triamcinolone and prednisolone affect contractile properties and histopathology of rat diaphragm differently. J Clin Invest 1993;92:1534-1542. 



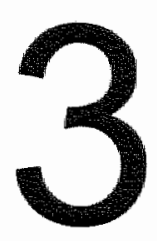

\section{Different effects of corticosteroid-induced muscle wasting compared with undernutrition on rat diaphragm energy metabolism.}

E Koerts-de Lang, AMWJ Schols, OE Rooyackers' "G Gayan-Ramirez², M Decramer', EFM Wouters.

Department of Pulmonology and 'Human Biology, Maastricht University, The Netherlands.

${ }^{2}$ Respiratory Muscie Research Unit, Laboratory for Pneumology, University of Leuven,

Belgium. 


\begin{abstract}
Abstact
An impontant adverse effect of corticasteroid treatment is respiratory muscle weakness and diaphragm musche wasting, but litte is known about the underlying pathophysiological processes. in order to differentiate between the effects of nutritional depletion and corticosteroids on diaphragm muscle metabolism, a study was performed to investigate the effects of triamcinolone (TR) for 2 weeks and of chronic undernutrition in a pair-weight (PW) group on structure and energy metabolism of the diaphragm in male Wistar rats compared with a free-fed (FF) group.

Diaphragm mass was reduced in TR and PW rats to a similar degree, but the extent of type $11 \times / \mathrm{b}$ atrophy was more pronounced in TR rats than in PW rats. No myopalhic features were observed after either treatment. ATP in absolute terms as well as ATP/AOP ratio, total adenine nucleotides, $\mathrm{CrP}$ and $\mathrm{CrP} / \mathrm{Cr}$ ratio were decreased in the diaphragm of both TR and PW rats. In contrast to the PW group, total creatine pool was reduced and pyruwate and lactate levels were elevated in the diaphragm of the TR group compared with the FF group.

In conclusion, the results of this study indicate different metabolic alterations after undernutrition and triamcinolone treatment. Severe undernutrition causes a decrease in muscle energy status resulting in a new melabolic equilibrium while chronic low dose triamcinolone treatment causes a decreased muscle energy status. logeither with a mismatch between glycolysis and oxidative metabolism.
\end{abstract}

\title{
3.1. Introduction
}

Weakness of both peripheral skeletal and respiratory muscles is frequently reported in patients with chronic abstructive pulmonary disease (COPD) (1, 2). Independent of the underlying lung function impairment, peripheral skeletal muscle dysfunction has been associated to exercise intolerance and a decreased health status (2). Weakness of the diaphragm and accessory respiratory muscles furthermore contributes to morbidity by dysfunction of the ventilatory pump and thus can predispose to respiratory faillure. A strong relationship between muscle mass and peripheral muscle function has recently been demonstrated in patients with COPD (3). Muscle weakness associated with muscle atrophy in these patients may be a consequence of corticosteroid treatment (1). undernutrition (4) or inactivity. Studies in anorexia nervosa patients have clearly shown that the effects of muscle wasting are not limited to the peripheral skeletal muscles, but also affect respiratory muscle mass and strength (5).

Especially fluorinated corticosteroids, like triamcinolone and dexamethasone have been shown to induce muscle wasting. In experimental animal studies, triamcinolone-induced diaphragm muscle wasting comprised predominantly atrophy of muscle type $\| x / b$ fibres and myopathic features like an increased amount of connective tissue and excess of nuclei. Furthermore, diaphragm contractility has frequently been studied in vitro and showed in general a decreased fatigue and prolonged contraction time and half-relaxation time of the diaphragm bundle after triamcinolone treatment (6-9). In view of the observed changes in diaphragm morphology and contractility, further analysis of metabolic alterations in muscle cell energy metabolism seems justified. Diaphragm muscle biochemistry has only occasionally been studied in relation to fluorinated corticosteroid treatment. After dexamethasone treatment, a reduction of succinyl dehydrogenase activity in the diaphragm was observed (10). Besides, muscle glycogen stores were found to be increased after triamcinolone treatment (11). To our knowledge, energy-rich phosphates of the diaphragm 
have never been studied in relation to corticosteroid treatment in rats, while they may represent the functional consequences of altered enzyme activities and substrate levels.

The effects of chronic corticosteroid treatment on diaphragm structure and in vitro contractility were frequently compared with the effects of undernutrition, because both freatments may induce muscle wasting. However, the underlying mechanisms of muscle wasting are clearly different. Body and muscle weight reduction after triamcinolone treatment can not be explained by a diminished food intake alone, implying a hypermetabolic state (12). In contrast to triamcinolone treatment, previous studies showed that chronic undernutrition resulted in muscle atrophy which was not restricted to type $\| x / b(6-9)$ and absence of myopathic features. In vitro contractility of diaphragm bundles of undernourished rats however, was comparable of that of rats with the same extent of body weight loss induced by triamcinolone treatment (6-9).

With the knowledge that in contrast to undernutrition, corticosteroids may induce hypermetabolism and hyperglycaemia $(13,14)$ and an increase in muscle glycogen, we hypothesise that triamcinolone treatment will induce other alterations in diaphragm muscle energy metabolism than undernutrition. This study was performed to better clarify the specific effects of triamcinolone treatment on diaphragm muscle "especially on energy metabolism and muscle structure in comparison to undernutrition. This information is important to consider for interpretation of in wivo diaphragm muscle performance and to provide adequate therapy to counteract the muscle wasting as potential side effect of these treatments.

\subsection{Methods}

\section{Animals}

Fourteen week old male Wistar rats were randamly divided into three groups for 14 days of treatment: 1) Triamcinolone treatment (TR: $0.25 \mathrm{mg} / \mathrm{kg} /$ day triamcinolone acetale $\mathrm{i.m}$.), ad libitum food intake $(\mathrm{n}=22)$, 2) Pair weight (PW: $0.05 \mathrm{ml} / \mathrm{day}$ saline $\mathrm{i} . \mathrm{m}$.), restricted food intake daily adjusted to achieve a similar weight loss as TR ( $n=22)$; 3 ) Free fed (FF: 0.1 $\mathrm{m} / \mathrm{d}$ day saline $\mathrm{im}$. , ad libitum food intake $(\mathrm{n}=40)$. Water was avallable ad libitum to all animals. The animals were individually housed in metabolic cages at an ambient temperature of $23^{\circ} \mathrm{C}$ with 14 hours light and 10 hours dark. Food intake and body weight of all animals were registered daily. Regular veterinary inspection of the animals took place to ensure the health and welfare was provided according to the Belgian and Dutch National Guidelines of Animal Care.

\section{Muscle preparations}

After overnight fasting, 10 rats of the TR and PW groups and 20 rats of the FF group were anaesthetised with ether. Rectal temperature was monitored and adjusled using a heating pad. Arterial blood was sampled from the carotid artery and collected in heparinized cups (Lithium-Heparin Micro-sample container CB100, Sarstedt, FRG) on ice.

For hematocrit determinations a micro-hematocrit tube (Modulohm 88302, Herlev, Denmark) was filled with heparinized blood and centrifuged at $10000 \mathrm{~g}$ at room temperature (Micro Hematocrit Centrifuge, Hawksley Ltd, 894481, UK). Hematocrit was read with a Micro Hematocrit Reader (Hawksley Lid, UK).

Plasma was obtained by whole blood centrifugation at $8900 \mathrm{~g}$ at $4^{\circ} \mathrm{C}$ for 5 minutes. For plasma glucose determinations, plasma was vortexed with trichloroacetic acid (TCA, 10\%) $(10: 1)$ and put into liquid nitrogen and stored at $-80^{\circ} \mathrm{C}$

The remaining 44 rats were anaesthetised with Nembutal $(6 \mathrm{mg} / 100 \mathrm{~g}$ intraperitoneally) tracheostomized and mechanically ventilated. Rectal temperature was monitored and body temperature was adjusted using a heating pad. The diaphragm muscie was dissected and weighed. One part was immediately freeze-clamped, frozen in liquid nitrogen and subsequently stored at $-80^{\circ} \mathrm{C}$ until analysis of energy-rich phosphates, lactate and pyruvate. 
The remaining part was put into "tissue glue" (Tissue-Tek, Elkhard, IN) on a cork holder with the muscle fibres oriented perpendicularly to the surface of the cork, then quickly frozen in isopentane and cooled by liquid nitrogen. Serial cross sections were cut at $8 \mathrm{~mm}$ thickness by use of a cryostat kept at $-20^{\circ} \mathrm{C}$. Sections were stained with haematoxylin and eosin to study myopathic changes. The sections were analysed for the presence or absence of the following morphological features: increased amount of central and subsarcalemmal nuclei, increased variation in fibre size, increased amount of split fibres, increased amount of vacuoles, increased amount of necrotic fibres, increased amount of abnormal mitochondria, and increased amount of connective tissue. The other section was stained for myofibrillar adenosine triphosphatase after alkaline $(\mathrm{pH}$ 9.3) and acid $(\mathrm{pH}$ 4.5) preincubation. Fibre analysis was done with a Leitz microscope, linked to a digitising board (Quantimet 570 , Leica, UK). Areas in which fibre orientation was not transverse to the long axis and areas with freezing artifacts were not analysed. By the use of a computer program, the individual muscle fibres were selected and the fibre CSA was determined from the number of pixels within the outlined fibre. CSA was corrected for the shortening occurring from the optimal length using a correction factor determined by ourselves in 32 rats, close to that found by Prakash and colleagues (15). At least 250 fibres of each rat were used to calculate the mean CSA of type I, lla and llx/b fibres.

\section{Biochemical analysis}

Plasma glucose was determined spectrophotometrically on a Cobas Mira $S$ (Roche Diagnostica, Hoffman-La Roche, Basel, Switzerland) by standard enzymatic methods, using commercially available kits as described previously (16).

To determine the dry/wet muscle weight ratio, approximately $200 \mathrm{mg}$ pulverised tissue was freeze dried for 24 hours in a Speedvac (type SC200, Savant Instruments Inc., Farmingdale, NY, USA) connected with a refrigerated condensation trap (type RT 400, Savant Instruments Inc., Farmingdale, NY, USA).

For determination of muscle energy-rich phosphates, lactate and pyruvate, frozen muscle was pulverised using a mortar and pestle precooled in liquid nitrogen and homogenised and deproteinized in ice-cold $1 \mathrm{M}$ perchloric acid (1:5) using an OMNI 1000 mechanical homogeniser (OMNI international). The supernatant was neutralised with $2 \mathrm{M}$ potassium bicarbonate. ATP, ADP, AMP, creatine phosphate (CrP), creatine (Cr), lactate and pyruvate were measured as described by Harris and colleagues (17), using a centrifugal analyser (Cobas-Bio, Roche Diagnostics).

\section{Statistical analysis}

All biochemical measurements were performed in duplicate. Differences between the groups were assessed using the Kruskall Wallis test and the Mann-Whitney $U$ lest. Level of significance was determined as $p \leq 0.05$. Statistical analysis was performed using the SPSS/PC+ program (Wessex, Inc, Winnetka, IL, USA). Data are presented as group mean \pm standard error of the mean (SEM). 


\subsection{Results}

Animal food intake, body weight and muscle mass

After the first injection of triamcinolone, daily food intake of the TR rats significantly decreased ( $\mathrm{p}<0.01$ ) during four days from $18.4 \pm 2 \mathrm{~g}$ to $7.3 \pm 1 \mathrm{~g}$ and then increased slowly to approximately $16 \mathrm{~g}$, but remained below the ad libitum food intake of the FF rats which was approximately $20 \mathrm{~g}(p<0.05)$. From day $6 \mathrm{on}$, dally food intake of the PW rats was significantly lower than that of the TR rats ( $p<0.001)$ and varied from 4 to $7 \mathrm{~g}$ to obtain a comparable body weight as the $T R$ rats. Initial body weights of the groups were not significantly different, while the final body weights (BW) of the TR $(290 \pm 6 \mathrm{~g})$ and PW (295 \pm $5 \mathrm{~g})$ rats were $21 \%$ respectively $20 \%$ lower than of the FF rats $(368 \pm 8 g, p<0.001)$.

Diaphragm muscle mass of the TR rats $(0.49 \pm 0.02 \mathrm{~g})$ and $\mathrm{PW}$ rats $(0.48 \pm 0.02 \mathrm{~g})$ was significantly lower than that of the FF rats $(0.63 \pm 0.02 \mathrm{~g}, p<0.001)$, but diaphragm/body weight ratio was not different between the groups. Dry/wet ratio of the diaphragm was not significantly different between the groups.

\section{Plasma givcase concentrations}

Hematocrit levels were not different between the groups. Plasma glucose levels were significantly increased in the TR rats $(19.9 \pm 2.5 \mathrm{mM}, p<0.01)$ compared with FF $(11.8 \pm 0.5$ $\mathrm{mM})$ and $\mathrm{PW}(10.7 \pm 0.8 \mathrm{mM})$ rats.
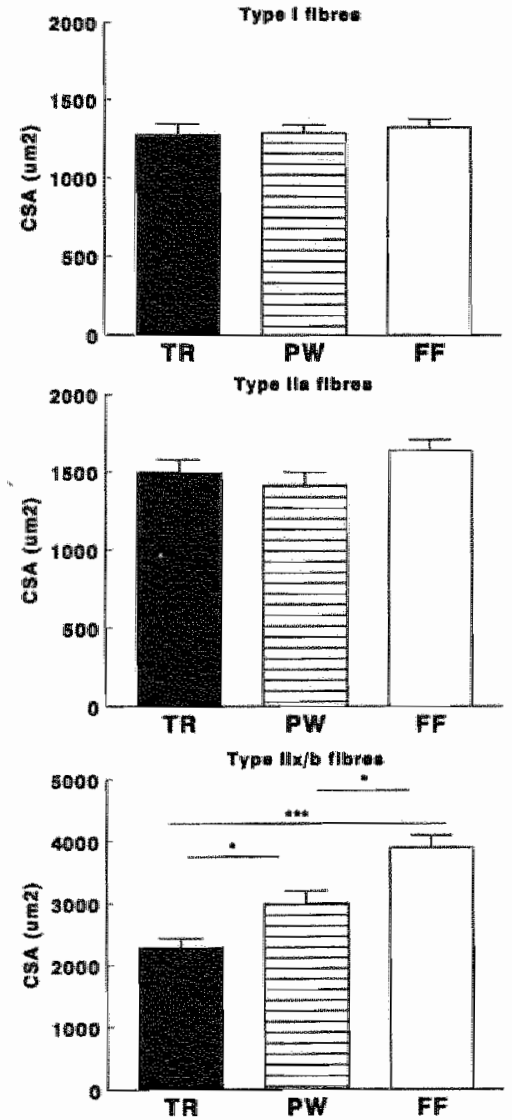

Fig. 1 Cross-sectional area of all fibre types of the diaphragm of the triamcinolone group (TR), the pair-weight group (PW) and the free-fed group (FF). All wallues are means \pm SEM. Significance * $p<0.05, * * 0<0.001$. 


\section{Diaphragm fibre cross-sectional area and fibre-fype proportions}

As shown in Figure 1, triamcinolone resulted in a reduction of type llxib atrophy of the diaphregm of $43 \%$ compared with FF ( $p<0.001$ ) and of $23.5 \%$ compared with $\mathrm{PW}(\mathrm{p}<0.05)$. Related to this, fibre IIx/b diameter was reduced in the TR rats with $20 \%$ compared with FF (p<0.001) and $12 \%$ compared with PW $(p<0.01)$. In the PW group, type IIx/b atrophy was observed compared with FF $(25.1 \% ;$; $<0.05)$, but fibre diameters were not changed. In the TR rats, the relative contribution of type I CSA (26\%) and type Ila CSA $(23.6 \%)$ were increased compared with FF (type 1: $19.8 \%$; $0<0.05$, type Ila: 17.6\%: $p<0.05$ ) and the relative type $1 \mathrm{Hx} / \mathrm{b}$ fibre area $(50.4 \%)$ was decreased compared with $\mathrm{FF}(62.5 \% ; p<0.01)$ and with PW $(57.8 \%, 0<0.05)$. No changes in relative fibre areas were noticed in the PW group compared with FF. Fibre type proportions were not altered in any group.

No evidence for myopathic changes were observed in any of the studied groups, as illustrated by Figure 2. Since, muscle atrophy was present in the diaphragm of the TR and PW rats, the fibre sizes were decreased.

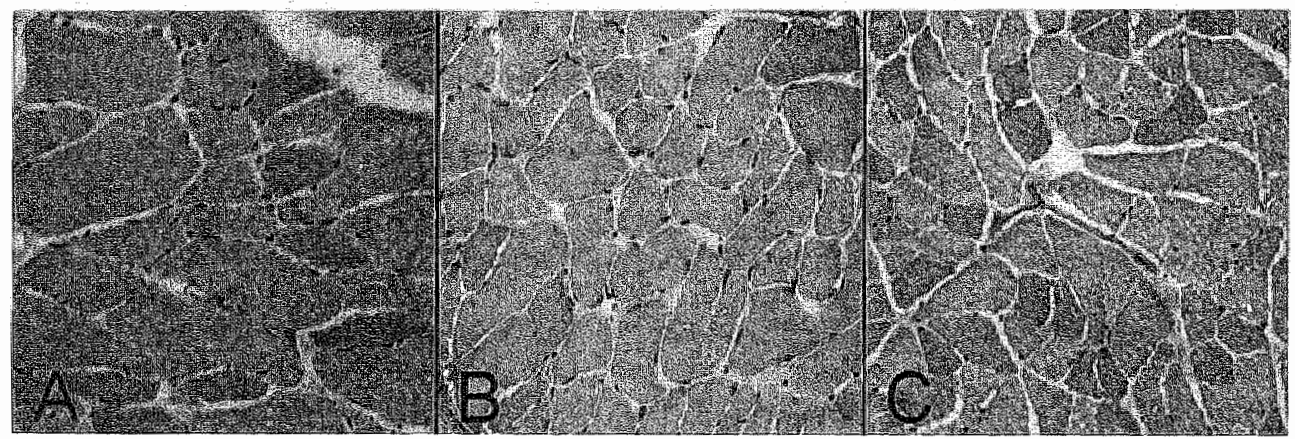

Fig. 2 Haematoxylin and eosh staining of the diaphragm of the frea-fed group (A), the pair-welght group (B) and the triamcinolone group (C). In the PW and TR growp the fores are smaller as a result of muscho atrophy.

\section{Energy metabolites in diaphragm}

Mutual comparisons between all 3 groups are shown in Table 1. Analysis of the pattern of changes revealed that both TR and PW caused a decrease in ATP in absolute terms as well as in ATP/ADP ratio compared with the FF group concentration $(p<0.01$ and $p<0.05$ resp.). Both groups showed a decreased CrP level of the diaphragm ( $p<0.05)$ compared with FF. Only the PW group showed a significantly increased intramuscular creatine level in the diaphragm compared with FF $(p<0.05)$, whereas TR showed a reduced total creatine pool in the diaphragm $(p<0.05$ ) compared with FF. No significant differences were observed in energy-rich phosphates between TR and PW. In contrast to PW, TR demonstrated increased pyruvate and lactate concentrations compared with $F F(p<0.05$ resp. $p<0.001)$. 
Table 1. Concentrations of diaphragmatic energy-rich phosphates.

\begin{tabular}{|c|c|c|c|c|c|}
\hline & Triamcinolone & & Pair-wolght & & Freeted \\
\hline ATP (Mmollg ww) & $4.2 \pm 0.2$ & $\#$ & $4.5 \pm 0.2$ & F & $5.0 \pm 0.1$ \\
\hline ADP (umolig ww) & $1.03 \pm 0.05$ & & $1.02 \pm 0.02$ & & $1.01 \pm 0.02$ \\
\hline AMP (umol/g ww) & $0.074 \pm 0.008$ & & $0.072 \pm 0.004$ & * & $0.061 \pm 0.003$ \\
\hline TAN (umollg ww) & $5.3 \pm 0.3$ & $*$ & $5.6 \pm 0.3$ & * & $6.1 \pm 0.2$ \\
\hline ATPIADP & $4.1 \pm 0.2$ & $H$ & $4.4 \pm 0.2$ & * & $5.0 \pm 0.1$ \\
\hline $\mathrm{CrP}(\mu \mathrm{mol} / \mathrm{g}$ wor $)$ & $14.1 \pm 1.3$ & * & $16.1 \pm 0.9$ & * & $18.0 \pm 0.6$ \\
\hline $\mathrm{Cr}$ (jmollg ww) & $16.0 \pm 0.8$ & & $16.8 \pm 0.5$ & "' & $15.0 \pm 0.5$ \\
\hline $\mathrm{TCr}(\mu \mathrm{mol} / \mathrm{g} w w)$ & $30.1 \pm 1.2$ & $*$ & $32.9 \pm 1.1$ & & $33.0 \pm 0.7$ \\
\hline CrPict & $0.9 \pm 0.10$ & $*$ & $1.0 \pm 0.06$ & \# & $1.2 \pm 0.06$ \\
\hline Pyruwate: & $236 \pm 26$ & $\|^{*}$ & $162 \pm 20$ & & $170+8$ \\
\hline Lactate & $6.9 \pm 0.7$ & H & $4.9 \pm 0.4$ & & $4.4 \pm 0.3$ \\
\hline
\end{tabular}

Values are means \pm SEM. WW: wet weight; TAN, total adenine nucleotides; TCr, fotal creatine pool; CrP, creatine phosphate; Cr, creatine; pyruvate in nmol'g wet weight; lactate in $\mu$ mallg ww; "p<0.05 companed with FF; $p<0.01$ compared with FF; $+p<0.05$ compared with PW.

\subsection{Discussion}

The objective of this study was to differentiate between alterations in diaphragm muscle energy metabolism and muscle morphology after triamcinolone treatment and after a concomitant degree of body weight loss induced by restricted food intake. In spite of the fact that both treatments resulted in type $\| \mathrm{x} / \mathrm{b}$ atrophy without other myopathic changes, differences in muscle energy metabolism were seen between the treatment groups.

Although both triamcinolone treatment and chronic undernutrition caused type $1 / \mathrm{x} / \mathrm{b}$ atrophy of the diaphragm, this was more pronounced in triamcinolone rats. Therefore, a relative increase of oxidative fibre area was only observed in the diaphragm of the triamcinolone rats. The same shift in relative cross-sectional area of the diaphragm was observed by Dekhuijzen and coworkers (6) after triamcinolone treatment but they also noticed myopathy, especially an increased amount of connective tissue and excess of nuclei. This could be caused by differences in treatment, since their triamcinolone dose was 2 times the dose of the present study and the duration of treatment was 3 times the duration of the present study. In the present study, the differences in muscle atrophy between the TR and PW groups were less than expected and differed from some other studies, in which a higher degree of undernutrition resulted in atrophy of all fibre types $(7,18,19)$.

The type $11 \times / b$ atrophy in the present study in the TR and PW groups was accompaniad by decreased ATP and CrP levels which is not surprising in view of the fact that fast-witch muscles contain higher ATP and CrP levels than slow-twitch muscles. These reductions in energy-rich phosplhates after triamcinolone treatment, are probably not only caused by alterations in muscle morphology but also by changes in muscle metabolism. In contrast to undernutrition, triamcinolone treatment resulted in reductions of both total adenine nucleotides and total creatine pool, implying metabolic impairment. The increased AMP levels suggests a contributing role of the adenylate kinase reaction to maintain a sufficiently high ATP level. The increased AMP concentration could also stimulate phosphofructokinase (PFK) activity, which was indeed found to be increased after triamcinolone treatment (11). Furthermore, the observed increased concentration of pyruvate in the diaphragm indicates an increased anaerobic glycolysis. The increased pyruvate concentration could indicate an incapability to oxidise pyruvate in the mitochondria. When pyruvate accumulates, glycolysis will be inhibited. To avoid this, lactate production is increased. Another possibility for an increased lactate level is an incapability to produce NAD+ in the mitochondria. This will lead

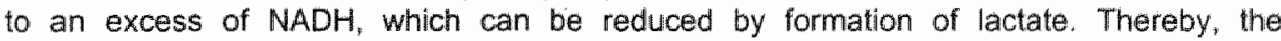
decreased $\mathrm{CrP} / \mathrm{Cr}$ ratio implies a disbalance between the energy flux between ATP production and ATP consumption. These observations and those of an earlier triamcinolone 
study, in which the ratio between PFK and citrate synthase activity was increased, suggest a mismatch between glycolysis and oxidative phosphorylation.

Chronic undernutrition however caused reductions in ATP and CrP levels because of a decreased energy supply as a result of the diminished food intake. In less severe undernourished rats, only $\mathrm{Cr} P$ levels were observed to be reduced (20). In the present study total creatine pool was maintained after chronic undernutrition, suggesting the establishment of a new metabolic equilibrium with lower ATP and CrP levels. Most likely the decreased CrP/Cr ratio reflects an increased creatine and ATP production from CrP, in order to satisfy the need for ATP. Furthermore, as suggested by Pichard and colleagues (20), a transport problem from the cytoplasm to the mitochondria could be present.

Despite different metabolic mechanisms after triamcinolone treatment and after undernutrition, both treatments lead to similar alterations in diaphragm morphology and diaphragm energy-rich phosphates, namely, predominantly type $\| \mathrm{l} / \mathrm{b}$ atrophy and a decrease in ATP and CrP levels. In order to provide adequate therapy to COPD patients with muscle wasting it is important to determine the underlying cause of it. Whereas caloric supply alone could be an adequate therapy for the nutritionally deprived patients to regain muscle mass, this will probably not be effective for patients treated with triamcinolone.

\section{References}

1. Decramer $M$, Lacquet LM, Fagard $R$, Rogiers $P$. Corticosteraids contribute to muscle weakness in chronic airflow obstruction. Am J Respir Crit Care Med 1994;150:11-16.

2. Gosselink R, Troosters T, Decramer M. Peripheral muscle weakness contributes to exercise limitation in COPD. Am J Respir Crit Care Med 1996;153:976-980.

3. Bernard $S$, LeBlanc $P$, Whittom $F$, et al. Peripheral muscle weakness in patients with chronic obstructive pulmonary disease. Am J Respir Crit Care Med 1998;158:629-34.

4. Engelen MPKJ , Schols AMWJ, Baken WC. Wesseling GJ, Wouters EFM. Nutritional depletion in relation to respiratory and peripheral skeletal muscle function in out-patients with COPD. Eur Respir J 1994;7:1793-1797.

5. Murciano D, Rigaud D, Pingleton S, Armengaud MH, Melchior JC, Aubier M. Diaphragmatic function in severely malnourished patients with anorexia nervosa. Am J Respir Crit Care Med 1994; $150: 1569-1574$.

6. Dekhuijzen PNR, Gayan Ramirez $G$, Bisschop $A$, Bock de V, Dom $R$, Decramer $M$. Corticosteroid treatment and nutritional deprivation cause a different pattern of atrophy in rat diaphragm. J Appl Physiol 1995;78:629-637.

7. Koerts-de Lang E, Schols AMWJ, Gayan-Ramirez G, Wouters EFM, Decramer M. Contractile properties and histochemical characteristics of the rat diaphragm after prolonged triamcinolone treatment and nutritional deprivation. J Muscle Res Cell Motility 1998;19:549-555.

8. Petrof $B J$, Gottfriad $S B_{n}$ Eby J, Lamanca J. Levine $S$. Growth hormone does not prevent corticosteroid-induced changes in rat diaphragm structure and function. J Appl Physiol
$1995 ; 79: 157 \%-1577$.

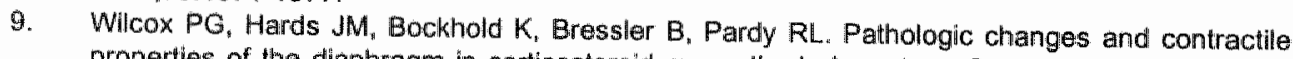
properties of the diaphragm in corticosteroid myopathy in hamsters: Comparison to peripheral muscle. Am J Respir Cell Mol Biol 1989:1:191-199.

10. Lewis MI, Monn SA, Sieck GC. Effect of corticosteroids on diaphragm fatigue, SDH activity, and muscle fiber size. J Appl Physiol 1992;72(1):293-301.

11. Koerts-de Lang $E$. Hesselink $M$, Drost $M$, Van der Vusse $G$, Wouters $E$, Schols A. Enzyme activity of rat tibialis anterior muscle differs between treatment with triamcinolone and prednisolone and nutritional deprivation. Eur J Appl Physiol 1999;79:274-279.

12. Gardiner PF, Montanaro G, Simpson DR, Edgerton VR. Effects of glucocorticold treatment and food restriction on rat hindlimb muscles. Am J Physiol 1980;238:E124-E130. 13. Melby JC. Systemic corticosteroid therapy: Pharmacology and endocrinologic considerations.
Ann Int Med 1974;81:505-512.

14. Peters RF, Richardson MC, Small $M$, White AM. Some biochemical effects of triamcinolone acetonide on rat liver and muscle. Biochem J 1970;116:349-355. 15. Prakash YS, Fournier M, Sieck GC. Effects of prenatal undernutrition on developing rat
diaphragm. J Appl Physiol 1993;75:1044-1052. 
16. Dejong $\mathrm{CH}$, Kampman MT, Deutz NE, Soeters PB. Altered gutamine metabolism in rat portal drained wiscera and hindquarter during hyperammonemia. Gastroenterology 1992:102:936-40.

17. Harris RC, Hultman E. Nordesjo LO. Glycogen, glycolytic intermediates and high-6nergy phosphates determined in biopsy semples of musculus quadriceps femoris of man rest Methods and variance of values. Scand J Clin Lab Invest $1974,33109-120$.

18. Lewis MI, Sieck GC, Fournier Mi, Belman MJ. Effect of nutritional deprivation on diaphragm contractility and muscle fiber size. J Appl Physiol 1986,60:596-603.

19. Sieck GC, Lewis MI, Blanco CE. Effects of undernutrition on diaphragm fiber size, SDH activity. and fatigue resistance. I Appl Physiol 1989;66(5):2196-2205.

20. Pichard $C$, Vaughan $C$, Struk $R$, Amstrong $R L$, Jeejeebhoy $K N$. Effect of dietary manipulations (fasting, hypocaloric feeding, and subsequent refeeding) on rat muscle energetics as assessed by nuclear magnetic resonance spectroscopy. J Clin linvest 1988;82:895-901. 



\section{4}

\section{The effects of corticosteroids and undernutrition on work capacity of skeletal muscle in an in situ rat model.}

E Koerts-de Lang, MKC Hesselink ${ }^{1}$, MR Drost ${ }^{1}$, GJ wan der Vusse ${ }^{2}$, EFM Wouters, AMWJ Schols.

Department of Pulmonology, "Movement Siciences and ${ }^{2}$ Physiology,

Nutrition Toxicology and Environment Research Institute Maastricht and Cardiovascular

Research Institute Maastricht, Maastricht University,

The Netherlands. 


\begin{abstract}
The effects of triamcinolone and prednisolone treatment in an equipotent anti-intlammatory dose were compared on in sifu muscle function in rats, since muscle weakness often occurs with corticosteroid therapy. Furthermore, the effects of corticosteroid-induced muscle wasting were compared with those induced by undemutrition.

Muscle function was performed with a rat dynamometer in the following treatment groups $(\mathrm{n}=10)$; , triamcinolone treatment $10.25 \mathrm{mg}^{\prime \prime} \mathrm{kg}^{-4}$ day ${ }^{-1}$ for 2 weeks) resulting in a $(24 \%)$ reduction of body mass; nutritional deprivation (2 weeks at $30 \%$ of nomal food intake) resulting in a similar $(24 \%)$ decrease of body mass as triamcinolone; prednisolone treatment ( $0.31 \mathrm{mg}^{*} \mathrm{~kg}^{-3}$ dlay ${ }^{-1}$ for 2 weeks), with a $9 \%$ increase in body mass; freefed control group. with a $12 \%$ increase in body mass in 2 weeks. The dorsiflexor hindlimb muscles were tetanized supramaximally during two sessions of 60 isokinetic concentitic contractions.

The decreased body mass after triamicinolone treatment was not only the result of a diminished food intake but implied an increased energy expenditure. In addition, plasma glucose level was increased after triamcinolone treatment $(p<0.01)$, in contrast to the undernourished group. Muscle glycogen was decreased after undernutrition $(p<0.05)$ and was increased both after triamcinolone $(p<0.01)$ and prednisolone ( $p<0.05$ ) treatment. During the firsit session, both triamcinolone and undernutrition showed a decline in absolute external work $(p<0.05)$. Normalised initial extemal work (defined as external work per gram exercising muscle) of triamcinolone was higher than prednisolone $(p<0.05)$ and fatigue (decline in external work) was less in triamcinolone compared to all other groups $(p<0.001)$. Prednisolone and undernutrition did not affect normalised external work. During a 5 minute rest period in between the sessions, the triamcinolone and prednisolone rats fully recovered, in contrast to the undernourished and control rats. In conclusion, the decline in absolute muscle strength is related to muscle wasting independent of the underlying cause. The results show a corticosteroid type specific effect on muscle performance, but recovery of muscle performance was related to cortlicosteroid use per se.
\end{abstract}

\title{
4.1. Intraduction
}

Glucocorticoids are commonly used as anti-inflammatory agents in the treatment of various acute and chronic diseases (1). This treatment is often accompanied by side-effects. The most important adverse effects observed after prolonged treatment with corticosteroids are muscle weakness and wasting (2). In addition, muscle weakness could also be the consequence of nutritional depletion per se, which is often shown in chronic diseases (3-5). The functional and clinical relevance of muscle weakness in chronic disease is shown in the fact that it contributes, independently of the severity of underlying disease, to a decreased exercise capacity and health status (6).

Triamcinolone, a fluorinated corticosteroid which induces also muscle wasting, has frequently been studied in relation to in vitro muscle contractility. It was shown that prolonged daily administration of $0.5 \mathrm{mg} / \mathrm{kg}$ triamcinolone increased fatigue resistance and half-relaxation time of respiratory muscles and caused a leftward shift of the force-frequency relationship $(7,8)$. A prolonged treatment of $0.2 \mathrm{mg} / \mathrm{kg}$ methylprednisolone caused also alterations in in vitro contractility of the diaphragm, like a downward shift of the force-frequency relationship and decreased twitch and tetanic tensions (9). Comparisons of the effects of triamcinolone and predinisolone however, are hampered by differences in dose and in administration protocols between studies. Many studies have investigated the effects of a higher dose of triamcinolone, 
but the occurrence of premature death $(7.8)$ is likely to interfene with the results. Furthemore, in most of these studies muscle performance was investigated under in witro conditions. An obvious disadvantage of in vitro studies upon administration of a drug is that the potential systemic effects that affect muscle contractile performance are surpassed. In vitro studying muscle perfomance is biased by the fact that muscles are studied in an incubation medium lacking the physiological interaction. Muscles studied during in vitro conditions rely on diffusion for substrate metabolism and oxygen supply, both of which will seriously be hampered if muscle size increases (according to Fick's law). In vitro conditions are therefore suboptimal compared to in situ situations, especially when the metabolic rate of the studied muscle is increased due to muscle contraction. Studying exercising muscles is therefore more appropriate in in situ conditions in which interaction with hormones, capillary flow and substrate availability is comparable to the physiological situation.

This study was performed in order to compare the effects of triamcinolone treatment in a non* lethal dose with a similar treatment of prednisolone in an equipotent glucocorticoid dose on in situ muscle work capacity by means of a rat dynamometer. This dose of triamcinolone has previously shown to cause muscle wasting, in contrast to prednisolone treatment in an equipotent dose (10). However this dose of prednisolone treatment has dernonstrated to induce alterations in muscle protein metabolism, like an increased muscle glutamine de novo production (11). Muscle wasting can be a resultant of a diminished energy intake, an increased energy expenditure or both. The cause of weight loss after chronic triamcinolone treatment is primarily related to an increased metabolic rate (8). The second aim of the study was to compare the effects of muscle wasting induced by triamcinolone treatment with those induced by nutritional deprivation on in situ muscle performance.

\subsection{Methods}

\section{Animals}

Forty male Wistar rats, 12 weeks old, were treated during two weeks. The initial body mass of these animals ranged from 314 to $345 \mathrm{~g}$. The animals were randomly allotted to four groups: 1) a triamcinolone treated group (TR: $0.25 \mathrm{mg}^{*} \mathrm{~kg}^{-1 / *}$ day triamcinolone acetate $\left.\mathrm{i} . \mathrm{m}\right)(\mathrm{n}=10$ ) with ad libitum food intake; 2) a nutritionally deprived group (ND: $0.05 \mathrm{ml}^{*}$ day ${ }^{-1}$ saline im.) , with a caloric food intake equivalent to $30 \%$ of normal intake, in order to achieve a similar weight loss as TR $(n=10) ; 3)$ a prednisolone treated group (PR: $0.31 \mathrm{mg}^{* k \mathrm{~kg}^{-1 *} \text { day }} \mathrm{y}^{-1}$ prednisolone i.m.) $(\mathrm{n}=$ 10) with ad libitum food intake; 4) a control group (FF: $0.05 \mathrm{ml}^{*}$ day ${ }^{-1}$ saline i.m.) $(n=10)$ with ad libitum food intake. All animals were injected in the right hindlimb. The diet provided to all animals was SRM-A 1210 pellets (Hopefarms, Woerden, NL). The animals were housed in metabolic cages, at a temperature of $23^{\circ} \mathrm{C}$, with a 12 hour dark light cycle. Food intake and body mass of all animals were registered daily. Veterinary cversight, including regular observation of the health of the animals, was performed according to the Dutch National Guidelines of Animal Care. The experimental protocol was approved by the Ethical Committee of Animal Research of the Maastricht University.

In vivo determination of muscle function of the hindlimb dorsiflexor muscles

Rats were anaesthetised with Nembutal $\left(6 \mathrm{mg}^{*} 100 \mathrm{~g}^{-1}\right.$, intraperitoneally) after short term $(<20$ s) $\mathrm{CO}_{2}$ sedation. This $\mathrm{CO}_{2}$ sedation may prevent excessive rise in plasma cathecholamine levels and thus affecting energy metabolism. In order to electrically stimulate the hindlimb dorsiffexor muscles ( $\mathrm{m}$. tibialis anterior and $\mathrm{m}$. extensor digitorum longus), an incision of the skin was made just distal to the caput fibulae at the lateral side of the left hindlimb and an electrode was placed on the common peroneal nerve. The positive pole of the electrode was placed percutaneousiy, distal to the cathode at the ventral side of the tibialis anterior muscle. The experimental set-up (Figure 1) for assessment of external work performed by the exercised muscles consists of 4 main units: a custom built rat dynamometer (RDM), a control 
unit to adjust RDM settings (e.giv rotational velocity and range of motion) as desired; an Apple Macintosh 7100 PowerPC with an 8 channel, 12 bits Lab-NB analog-to-digital conversion board (National Instruments ) programmed with LabVIEW 3.1 , and a pulse generator for purpose of electrical stimulation and triggering of the RDM (HSE $215 / 1 Z_{\text {. }}$ Freiburg, Germany). The RDM consists of a platform with 6 degrees of freedom, an adjustable fernur fixation, a rotational footplate, a linear motor and a potentiometer.

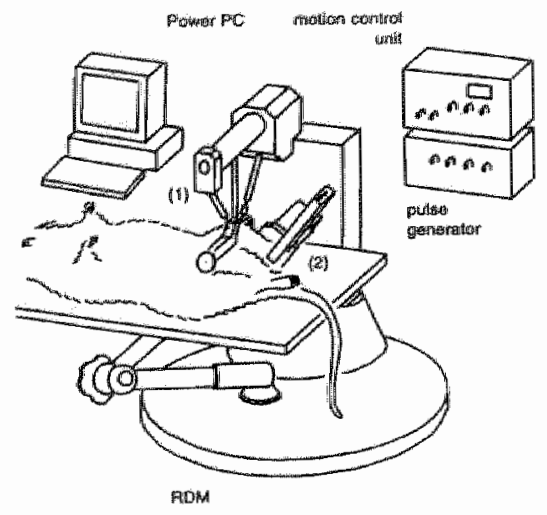

fomur flxatton untl (1) and fiotational footplate (2)

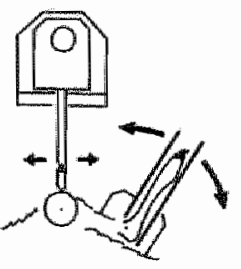

11j

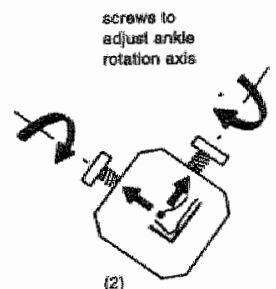

(2)

Fig. 1. Overview of the experimental set-up. The upper panel shows a rat in the rat dynamameter (RDM). The lower panel shows the knee fixation and the rotational foofplate.

The anaesthetised rat is placed in supine position on the heated $\left(37^{\circ} \mathrm{C}\right)$ platform. After positioning the animal in the horizontal plane, the foot is secured to the footplate with twosided adhesive tape while the instep is covered with a narrow fitting thin aluminum plate. The femur is fixed distally with a hinge fixation at a $\sim 90^{\circ}$ flexion in the knee. To induce rotation in the ankle joint, the footplate is secured to the axis of the linear motor.

Fixation of the femur to prevent lateral movement of the knee is achieved by two conical pieces placed on the skin between the femoral and tibial condyles. To prevent force transmission through the tibia towards the femur fixation unit, the femur fixation unit was connected to the body of the RDM by a hinge fixation, enabling small movements parallel to the tibia. The ankle rotation axis was aligned with the rotation axis of the RDM by translation of the footplate relative to the rotation axis of the RDM over $2 \mathrm{~mm}$ in 2 perpendicular directions. Inappropriate alignment of the ankle axis causes visible movement of the femur fixation unit which can be reduced by translation of the footplate. The footplate is rotated using a linear motor with an adjustable isokinetic velocity between $1^{\circ *} \mathrm{~s}^{-1}$ and $1000^{\circ *} \mathrm{~s}^{-1}$. Axis angle, representing the actual ankle angle, is monitored with a precision potentiometer. Active muscle torque is assessed from the voltage through the linear motor of the RDM. External work of the active muscle group is calculated on-line as the integration of active torque over rotation angle. 
The exercise protocol was preceded by determining, for each rat, supramaximal frequency $(110-150 \mathrm{~Hz}$ at square waves of $0.4 \mathrm{~ms})$ and voltage $(0.7-2.0 \mathrm{~W})$ during $4-7$ contractions, followed by a 4 min rest. Two sessions of 60 isokinetic tetanic concentric contractions were performed, separated by a $5 \mathrm{~min}$ recovery period. This exercise protocol was chosen because of the possibility to determine absolute and normalised external work and to study fatigue of the muscles during 60 contractions. Furthemore, recovery of the muscle performance between successive series of 60 contractions can be observed. This intense exercise protocol was chosen since it heavily relies on type $\| x / b$ fibres, known to be atrophied upon corticosteroid treatment $(12-15)$ and undernutrition $(7,16)$. Therefore, we considered this protocol to be sensitive to detect differences between the treatment groups of this study. Whether there are differences between the groups, these will surely be observed during supramaximally exercise. The extensor digitorum longus (EDL) and the tibialis anterior (TA) were tetanized supramaximally every $3 \mathrm{~s}$ for $350 \mathrm{~ms}$, of which the first $200 \mathrm{~ms}$ were isometric followed by $100 \mathrm{~ms}$ rotation (from $30^{\circ}$ plantar flexion to $20^{\circ}$ dorsal flexion at $500^{\circ *} \mathrm{~s}^{-1}$, which is in the plateau of the muscle complex's force-length curve) during which the external work was recorded. With an angle velocity of $500^{\circ / \mathrm{s}} \mathrm{s}^{-4}$, muscle fibre shortening velocity approximates 1.4 fibre lengths per $s(17)$. Initial work was defined as the external work during the first contraction of each session. End work was defined as the external work during the final contraction of each session. Fatigue was defined as the decline in external work as percentage of the initial external work of each session. Immediately after the exercise bout, arterial blood was sampled from the aorta and collected in heparinized cups (Lithium-Heparin Micro-sample container CB100, Sarstedt, FRG) on ice. Finally, the dorsiflexor muscles of the hindlimb were excised and muscle mass was determined in order to normalise external work on exercising muscle mass. Absolute external work is defined as the external work of the whole dorsiffexor muscles, while normalised external work is defined as the external work per gram exercising muscle mass. Recovery during the 5 minute rest period was assessed by comparing end external work of the first session with initial external work from the second session.

\section{Biochemical analysis}

Immediately after weighing the tibialis anterior muscle, it was freeze clamped in liquid nitrogen and stored at $-80^{\circ} \mathrm{C}$ until analysis. Muscle was homogenized (10\% W/V) in SETbuffer by use of an Lltra-Turrax T25 tissue homogenizer (Janke \& Kunkel, GmbH \& CO KG) for four $5 \mathrm{~s}$ intervals. At $0^{\circ} \mathrm{C}$. the homogenizalion process was completed by treatment with ultrasonic sound (Soniprep 150, MSE) for four $15 \mathrm{~s}$ intervals. Total protein was assayed from this homogenate by means of bicinchoninic acid as described eartier $(18,19)$. Part of the muscle was dissolved for 1 h in $1 \mathrm{M} \mathrm{NaOH}\left(37^{\circ}\right)$ " precipitating glycogen with $96 \%$ ethanol (10 min at $80^{\circ} \mathrm{C}$ followed by overnight precipitation at $4^{\circ} \mathrm{C}$. Subsequently the peillet was hydrolyzed using $1 \mathrm{M} \mathrm{HCL}$ at $100^{\circ} \mathrm{C}$ for $3 \mathrm{~h}$ after which $\mathrm{HCL}$ was neutralized with a $\mathrm{KCl}$ saturated $\mathrm{KOH} /$ Tris $(2.1 \mathrm{M} / 0.12 \mathrm{M})$ buffer. Glycogen derived glycosyl units were determined using a glucose kit (hexokinase method "Roche) for a centrifugal analyzer. Glycogen was analyzed on a centrifuglal analyzer (Cobas Fara, Hoffman La-Roche, Basie, Switserland) and expressed as $\mu$ mol glycosyl units per $\mathrm{g}$ wet weight.

Plasma was obtained by whole blood centrifugation at $8900 \mathrm{~g}$ at $4^{\circ} \mathrm{C}$ for 5 minutes. For plasma glucose determinations, plasma was vortexed with trichloroacetic acid (TCA, $10 \%$ ) (10:1) and put into liquid nitrogen and stored at $-80^{\circ} \mathrm{C}$. Plasma glucose was determined spectrophotometrically on a Cobas Mira S. (Roche Diagnostica, Hoffman-La Roche, Basel, Switzerland) by standard enzymatic methods, using commercially avallable kits as described previously $(20)$. 


\section{Statistical analysis}

Differences between all groups were first detected with the Kruskall Wallis test and then assessed using the Mann-Whitney $U$ test. Level of significance was determined as $p \leq 0.05$. Correlation was assessed using the Pearson correlation test. Analyses were performed using the SPSS/PC* program. Data are presented as group mean \pm standard error of the mean (SEM).

\subsection{Results}

Animal food intake, body and muscle mass

Figure $2 \mathrm{~A}$ depicts the daily food intake of the different groups. Food intake of the FF and the PR rats remained stable during the experiment and was not mutually different.
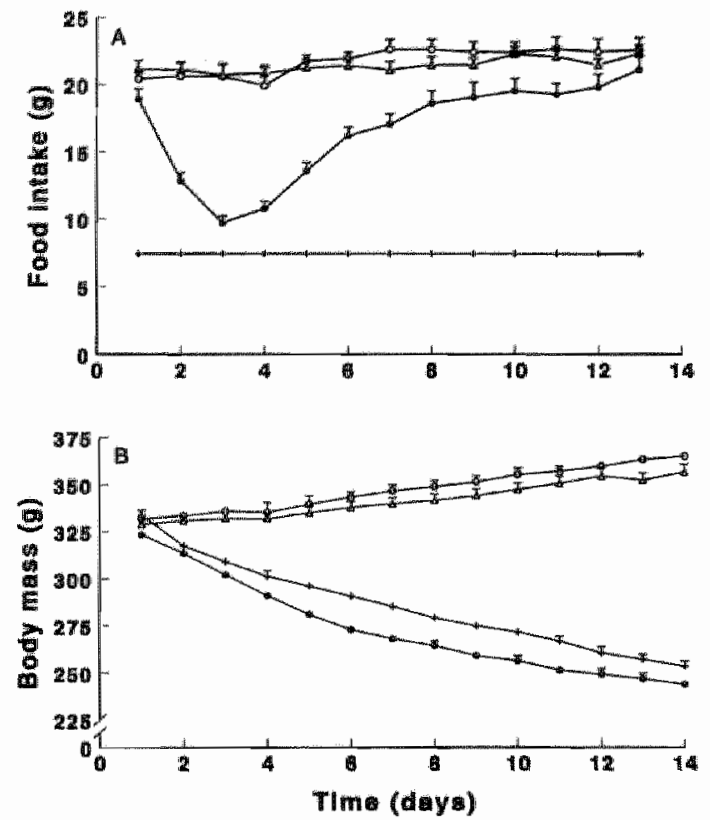

Fig. 2 (A) Mean dally food intake \pm SEM of the triamcinolone ( $\cdot)$, nutritionally deprived $(+)$, prednisolone $(\Delta)$ and freefed (o) groups during experimenta! period. (B) Mean body mass \pm SEM of the groups as a result of triamcinolone (*) or predinisolone ( $\Delta$ ) treatment or nutritional depletion (t) or ad libitum food intake (o).

Food intake of the TR rats declined during two days (at day 3: $p<0.001$ ) and increased gradually until it was not significantly different from FF at day 12 . Daily food intake of the ND rats remained constantly at approximately $7 \mathrm{~g}$ per day $(p<0.001)$, in order to assess as comparable body mass reduction as the TR group.

As shown in Figure 2B, body mass of the FF and PR groups increased, while body mass of the TR and ND groups decreased. During the muscle test, the body mass of the TR (66\% of FF) and ND (69\% of FF) rats were significantly lower than the body mass of the FF and PR rats. $(p<0.001)$ and were mutually not significantly different. Body mass of the PR rats was slightly but significantly lower than that of the FF rats $(97 \%$ of $F F, p<0.05$ ).

Table 1. Muscle weights

\begin{tabular}{lcccccc}
\hline & Triamcinolone & Nutritional deprived & Prednisolone & Free-fed \\
\hline TA + EDL (mg) & $562 \pm 13$ & $+\$ \#$ & $701 \pm 11$ & $\$$ & $931 \pm 18$ & $895 \pm 13$ \\
$\%$ muscle mass & $0.23 \pm 0.003+\$$ & $0.28 \pm 0.003 \pm$ & $0.26 \pm 0.006$ & $*$ & $0.24 \pm 0.003$ \\
\hline
\end{tabular}

Values are means I SEM. TA, tibialis anterior; $E D$, extensor digitorum longus; \% muscle mass, muscle massibody mass $\times 100 ; t, p<0.001$ compared to ND; $\neq, \S, p<0.05$ and $p<0.001$ compared to $P R_{;}$ 
Muscle mass of the EDL and TA was significantly decreased in the TR and ND groups compared to the FF and PR groups (Table 1, p<0.001). It was significantly lower in the TR group compared to the ND group ( $p<0.001)$. Muscle mass as a percentage of body mass was significantly decreased in the TR group compared to the PR and ND groups $(p<0.001)$, increased in the PR group compared to the FF group $(\rho<0.05)$ and even further elevated in the ND group compared to the FF and PR groups ( $p<0.001$ and $p<0.05$ resp.).

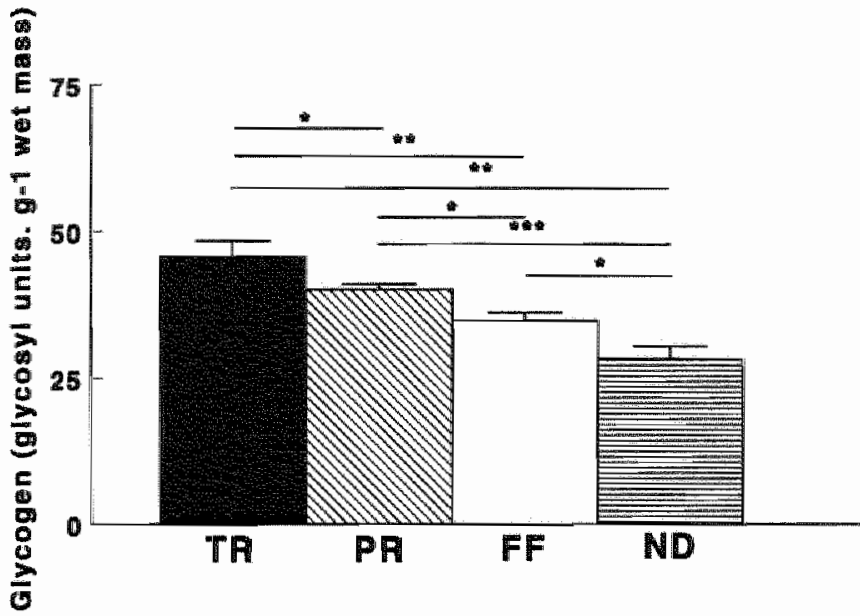

Fig. 3 Moan glyoogen contern (SEM) in the tibialis anterior muscle of tho triamcinolone (TR). prednisolone (PF). nutritional deprived (ND) and free-fad (FF) group. $p<0.05$, w $p<0.001$ $p<0.0 \%$

\section{Muscle protein and glycogen content}

Protein contents per gram muscle wet weight were not significantly different between the groups for the dorsiflexor muscles. Glycogen levels in TR and PR were higher than in FF and ND (Figure $3, p<0.05)$, while glycogen content in TR was significantly higher than in $P R(p<0.05)$. Glycogen content in the ND group was significantly lower than in all other groups $(p<0.05$ ). Plasma glucose level was significantly increased in the TR group ( $33 \pm 4 \mathrm{mM}$ ) compared to $\mathrm{FF}$ $(11 \pm 1 \mathrm{mM}), \mathrm{PF}(11 \pm 1 \mathrm{mM})$ and $\mathrm{PR}(12 \pm 3 \mathrm{mM})(\mathrm{p}<0.01)$

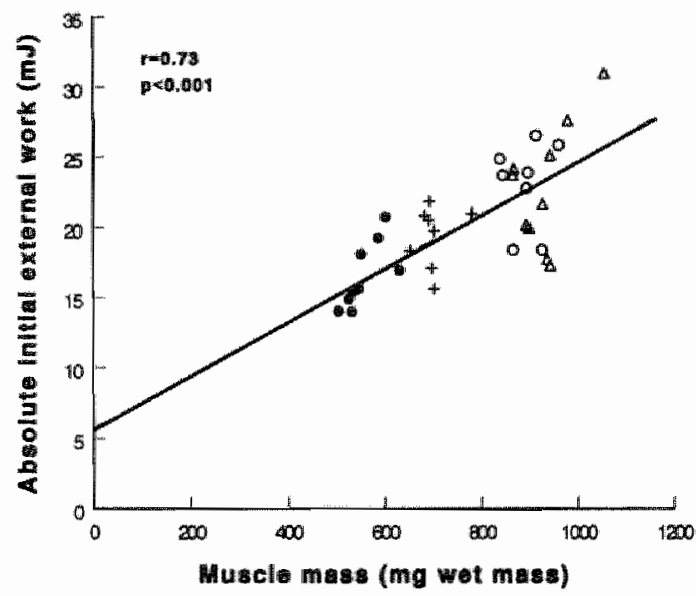

Fig. 4 Correlation between active muscle mass (EDL+TA) and its absolute initial external work during the first session for triamcinalone (*), nutritionally deprived $(+)$, precinisolone $(\Delta)$ and free-fed (o) groups. 


\section{Extemal muscle work of tibialis anterior and extensor digitorum longus}

Muscle mass (EDL+TA) and absolute initial external work during the first session showed a correlation of 0.73 , with $p<0.001$ (Fig.4). Figure 5 A depicts the pattern of normalised external work ( $\mathrm{mJ}^{*} \mathrm{~g}^{-4}$ muscle) for all animal groups during the first session of stimulation. In the FF rats; external work gradually declined during the first exercise session. The patterns of normalised external work of the prednisolone and nutritionally deprived rats resembled that of the FF rats, while that of the triamcinolone rats declined much less.

During the second session, external work of the FF, ND and PR rats declined but reached a plateau after approximately 20 contractions (Fig. 5B). Normalised initial and end external work of the TR rats were higher than the other groups. In Table 2, extemal work of dorsiflexors is quantified at different moments of the exercise bout. TR rats showed significantly higher external work compared to PR rats when normalised on the mass of the exercising skeletal muscles $(p<0.05)$. The TR rats showed significantly higher normalised initial external work compared to the FF, ND ( $p<0.001)$ and PR rats $(p<0.01)$ during the second session. Normalised end external work of the TR rats was significantly higher than the other groups (Table 2, $p<0.001$ ) in each session. Fatigability, defined as the decline in external work as percentage of the initial external work, was significantly smaller in the TR group compared to all other groups (Table 2, $p<0.001$ ).

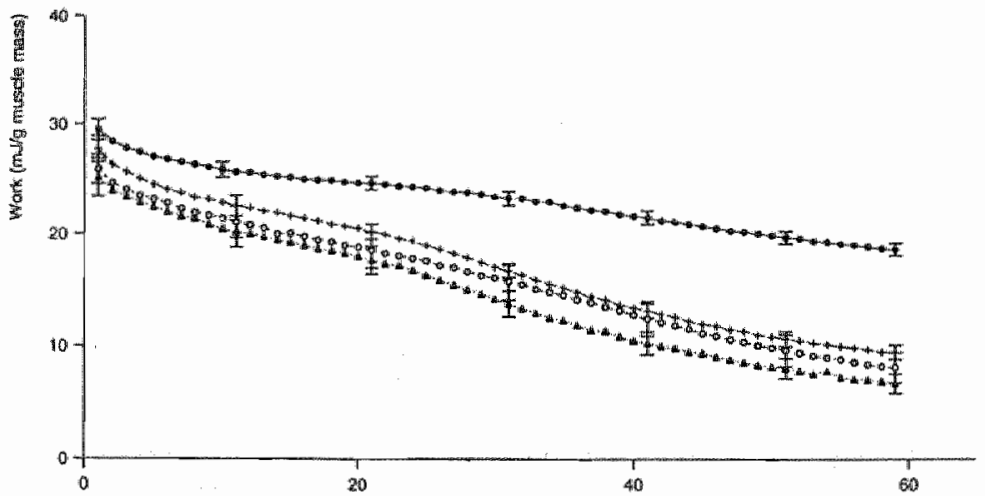

Fig.5 (A) Normalised external work during the first session of the triamcinolone $\quad(\cdot)$ nutritionally deprived $(+)$, prednisolone

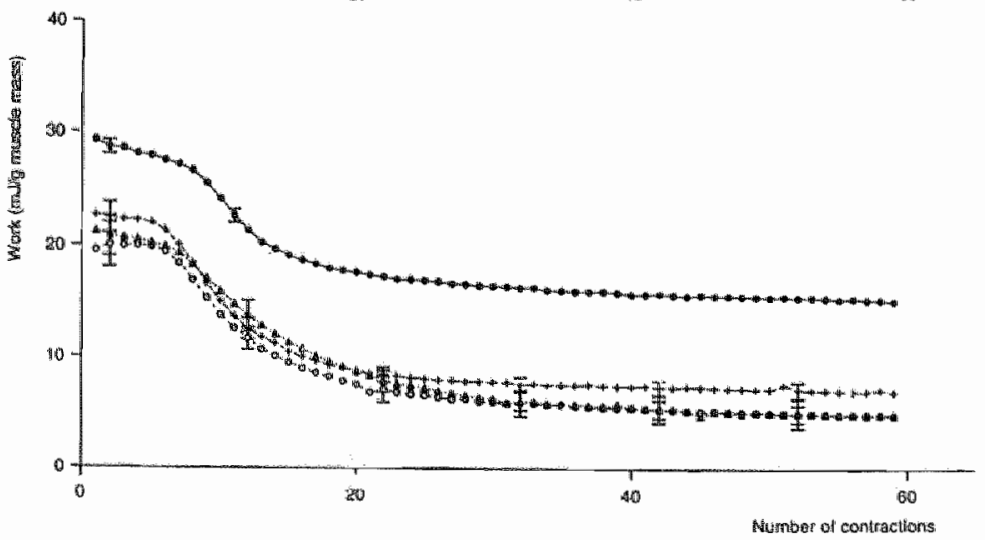
and free-fed (o) groups \pm SEM. (B) Normalised external work during the second session of the triamcinolone nutritionally deprived $(+)$ prednisolone and free-fed (o) groups \# SEM.

Information of the recovery of the dorsiflexor muscles was obtaineo by companing inutual external work of the second session with end external work of the first session. This showed a full recovery of the TR and PR rats, whereas the recoveries of the ND and FF rats were not adequate. 
Table 2. External work of donsflexors

\begin{tabular}{|c|c|c|c|c|c|c|}
\hline & \multicolumn{2}{|c|}{ Triamcinolone } & \multicolumn{2}{|c|}{ Nutritional deprived } & Prednisolone & Freesed \\
\hline nor init ext work 1 & $29.5 \pm 0.9$ & $t$ & $27.7 \pm 1.1$ & & $25.1 \pm 1.6$ & $25.9 \pm 1.3$ \\
\hline nor init ext work 2 & $29.2 \pm 0.6$ & +15 & $22.7 \pm 1.3$ & & $21.2 \pm 1.7$ & $19.6 \pm 1.9$ \\
\hline nor end ext work 1 & $18.5 \pm 0.5$ & - $11 \S$ & $9.4 \pm 0.6$ & $t$ & $6.6 \pm 0.8$ & $8.0 \pm 1.3$ \\
\hline nor end ext work 2 & $15.1 \pm 0.4$ & - I 5 & $6.9 \pm 0.6$ & & $4.8 \pm 0.7$ & $4.9 \pm 1.2$ \\
\hline fatigue 1 & $37 \pm 2$ & - II & $66 \pm 2$ & $t$ & $74 \pm 2$ & $70 \pm 4$ \\
\hline fatigule 2 & $48 \pm 1$ & - $\pi \xi$ & $69 \pm 3$ & + & $78 \pm 2$ & $77 \pm 5$ \\
\hline
\end{tabular}

All values are means \pm SEM. nor init ext work, narmalised initial extemal work (in mU/gram exercising muscle); fatigue, decline in external work as percentage of initial external work; 1 , during first session of stimuli: 2, during second session of stimuli; $-p<0.001$ compared to ND; $t, 1 . q, p<0.05, p<0.01$ and $p<0.001$ compared to $P R_{;} \$, p<0.001$ compared to FF.

\subsection{Discussion}

The results of this study clearly demonstrate a corticosteroid type specific effect on in situ muscle work performance. Although both triamcinolone and prednisolone treatment resulted in an increased muscle glycogen store, muscle performance was not comparable. In contrast to prednisolone in an equipotent dose, triamcinolone treatment showed an increase in external work when normalised on skeletal muscle mass. Moreover, dorsiflexor muscles of triamcinolone treated animals were less prone to fatigue than prednisolone treated rats. The observed hyperglycaemia after triamcinolone treatment could play a role in this. Prednisolone treatment showed no changes compared to control. Contrary to in witro contractility, where friamcinolone treatment and chronic undernutrition showed similar alterations (8), in this in situ set-up, changes in external work of the TR rats were also significantly different from ND and could therefore not be exclusively attributed to the muscle wasting per se.

Balance between energy intake and bady weight change showed a clear discrepancy after triamcinolone treatment, mplying that weight loss is a consequence of increased energy expenditure not adequately restored by dietary intake. This phenomenon was not observed after prednisolone treatment, and was triamcinolone-specific. No quantative analysis of total body composition was performed. However, muscle mass was significantly decreased in comparison to body mass reduction after triamcinolone treatment, implying relatively more muscle degradation. Undernutrition however, showed a relatively sparing of muscle mass.

In vitro contractility studies demonstrated that triamcinolone treatment in a higher dose and nutritional deprivation with a comparable body mass reduction, resulted in similar changes in respiratory muscle function, such as a reduced fatigability and an increased half-relaxation time $(7,8)$. In the present in situ study, triamcinolone treatment and nutritional deprivation both resulted in a decrease of absolute initial external work of the dorsiflexor hindilmb muscles. However, when external work was corrected for the exercising muscle mass, triamcinolone treated rats showed an increased extemal work, whereas nutritional deprivation showed no alterations compared to control rats. How can this discrepancy between these two different contractility studies be explained? The decrease in in vitro fatigability after triamcinolone treatment as well as after nutritional deprivation is suggested to be related to a relative increase in cross-sectional area of oxidative muscle fibres $(7,8)$. In earlier studies, triamcinolone treatment has demonstrated to induce no differences in fibre type distributions, but predominantly type $11 \times / b$ fibre atrophy of both the diaphragm $(7,8,21)$ and the gastrocnemius muscle (7). Corticosteroid treatment has shown in the EDL to cause both type 11 a and 116 atrophy (12). Both the EDL and anterior digitorum longus muscles are stimulated in the rat dynamometer in the present study. The dorsiflexor muscles consist mainly of type Ila and Ilb fibres. It is to be expected that triamcinolone treatment will cause type $1 / x / b$ attrophy of the dorsiflexor muscles. Prolonged treatment of low-dose methylprednisolone has demonstrated to cause a decrease in distribution of type lib fibres and atrophy of both type I Ila and IIx fibres, 
resulting in a relatively increase of type $11 x$ fibres and a decrease of type lib fibres of the diaphragm muscle. In the present study, no structural changes are to be expected after prednisolone treatment, at least not resulting in any changes in muscle performance. Undernutrition has demonstrated to cause atrophy of all fibre types, but proportionally of mostly type $11 x / \mathrm{b}$ fibres $(7,8,22)$. In contrast to corticosteroid treatment, Kelsen and colleagues found that undernutrition lead to alterations in muscle fibre composition of the diaphragm muscle, resulting in relatively more oxidative fibres (22). We assume that this will not be found in the present study, since nutritionally deprivation did not show an improved fatigability. The results of the present study however indicate that in in situ conditions not only the relative fibre contribution determines muscle fatigue but other factors, like intermediary metabolism also may contribute. Most likely the observed typerglycaemia, which was also demonstrated by others after fluorinated conticosteroids (23-25), will play a significant role. We would like to hypothesise that the combination of exercise-induced increase in skeletal muscle glucose transport capacity (26) and hyperglycaemia in TR rats, most likely results in an elevated supply of glucose during contraction compared to rats with nomal plasma glucose levels, and subsequently in a decreased fatigability of the muscles. Obviously, the increased muscle glycogen concentration does not contribute to an increased muscle performance, since the muscle performance in the prednisolone rats was not altered.

Opposite to muscle wasting observed after triamcinolone treatment, prednisolone treatment did not lead to alterations in body and muscle mass compared to FF, and even in a small but significant increase in muscle mass relative to body weight. This implies even a relative conservation of muscle mass after prednisolone treatment in contrast to the muscle wasting observed after an equipotent triamcinolone dose. In line with the absence of a catabolic response, prednisolone treatment in the present study was not associated with alterations in in situ muscle function when compared to free-fed animals. The full recovery of both the triamcinolone and prednisolone rats may imply that in corticosteroid-treated rats energy stores are not fully exhausted after the first session or that energy stores are better restored. Muscle glycogen concentrations were indeed found to be increased after either corticosteroid treatment.

Corticosteroids are commonly used in low doses as maintenance therapy or in high doses during disease exacerbations. In clinical practice, triamcinolone is not used extensively, in contrast to other fluorinated corticosteroids. The rationale for studying this corticosteroid is the clear body wasting, not only caused by a decreased food intake (16). The dose of triamcinolone in the present study is within the range of those given to patients with chronic diseases $(27,28)$. Prednisolone however is a frequently used corticosteroild in clinical practice. In the present study, the dose of prednisolone was within the range of those given to patients (29), but somewhat higher than maintenance therapy. The results of this study point out that triamcinolone, in contrast to prednisolone treatment in a comparable anti-infiammatory potency, causes muscle wasting. Despite the muscle wasting effect of triamcinolone, the functional properties of the remaining muscle tissue are superior to that in the other groups: less fatigable and almosit complete recovery within 5 minutes after a strenuous exercise bout. The differences in systemic effects between different glucocorticoid treatment may be important to consider in the choice of corticosteroids type as medical therapy.

\section{References}

1. Horber FF, Zurcher RM, Herren H, Crivelli MA, Robotti G, Frey FJ. Altered body fat distribution in patients with glucocorticoid treatment and in patients on long-term dialysis. Am $\mathrm{J}$ Clin Nutr 1986:43:758-769.

2. Decramer M, Stas KJ. Corticosteroid-induced myopathy involving respiratory muscles in patients with chronic obstructive pulmonary disease or as thma. Am Rev Respir Dis 1992; 146:800-802.

3. Coles GA. Biody composition in chronic renal failure. Quart J Med 1972;41:25-

4. McPariand $M_{r}$ Krishnan $B_{n}$ Wang $Y$, Gallagher $C$. Inspiratory muscle weakness and dyspnea in chronic heart failure. Am Rev Respir Dis 1992;146:467-472. 
5. Schols AMWJ, Mostert R, Soeters PB, Greve LH, Wouters EFM. Imwentory of nutritional status in chronic obstructive pulmonary disease. Chest 1989;96:247-249.

6. Gosselink R, Troosters T, Decramer M. Peripheral muscle weakness contributes to exercise limitation in COPD. Am J Respir Crit Care Med 1996; 153:976-980.

7. Dekhuilzen PNR, Gayan Ramirez $G$, Bisschop $A$, Bock de $V_{\text {, Dom }} R$, Decramer M. Corticosteroid treatment and nutritional deprivation cause a different pattern of atrophy in rat diaphragm. I Appl Physiol 1995;78:629-637.

8. Koerts-de Lang $E_{1}$ Schols AMWJ, Gayan-Ramirez G, Wouters EFM, Decramer M. Contractile properties and histochemical characteristics of the rat diaphragm after prolonged triamcinolone treatment and inutritionall deprivation. I Muscle Res Cell Molility 1998:19:549-555.

9. Balkom VRHH, Dekhuijzen PNR, Folgering HTM, et al. Anabolic steroids in part reverse glucocorticoid-induced alterations in rat diaphragm. J Appl Physiol 1998;84:1492-1497.

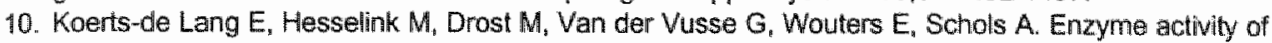
rat tibialis anterior muscle differs between treatment with triamcinolone and predinisolone and nutritional deprivation. Eur J Appl Physiol 1999;79:274-279.

11. Koerts-de Lang E, Schols AMWJ, Deutz NEP, Wouters EFM. Attenuated effects of prednisolone ireatment on muscle glutamine and protein metabolism during nutritional deprivation in rats. Am $\mathrm{J}$ Resp Crit Care Med 1997:155:A921.

12. Polla $B_{1}$ Bottinelli $R$, Sandoli $D$, Sardi $C_{4}$ Reggiani $C$. Cortisone-induced changes in myosin heavy chain distribution in respiratory and hindlimb muscles. Acta Physiol Scand 1994;151:353-61.

13. Balkom $\mathrm{VRHH}$, Zhan $W$. Prakash $Y$. Dekhuijzen $P$, Sieck $G$. Conticosteroid effects on isotonic contractile properties of rat diaphragm muscle. $₫$ Appl Physiol 1997;83:1062-1067.

14. Kanda $F$, Takatani $K$, Okuda $S$, Matsushita $T$, Chihara K. Preventive effects of insulinlike growth factor-I on steroid-induced muscle atrophy. Muscle Nerve 1999;22:213-217.

15. Wilcox PG, Hards JM, Bockhold K, Bressler B, Pardy RL. Pathologic changes and contractle properties of the diaphragm in corticosteroid myopathy in hamsters: Comparison to peripheral muscle. Am J Respir Cell Mol Biol 1989;1:191 199.

16. Gardiner PF, Montanaro $G_{*}$ Simpson DR, Edgerton VR. Effects of glucocorticoid treatment and food restriction on rat hindlimb muscles. Am I Physiol 1980;238:E124-E130.

17. Hesselink M. Structural, functional and metabolic aspects of shortening and lengthening muscle contractions. Maastricht: Maastricht Universitary Press, 1998.

18. Brown $R$, Jarvis $K$, Hyland $K$. Protein measurement using bicinchoninic acid: eliminatlon of interfering substances. Anal Biochem 1989;180:136-139.

19. Smith PK, Krohn RI, Hermanson GT, et al. Measurement of protein using bicinchoninic acid. Anal Biochem 1985; 150:76-85.

20. Dejong $\mathrm{CH}$, Kampman MT, Deutz NE, Soeters PB. Altered glutamine metabolism in rat portall drained viscera and hindquarter during hyperammonemia. Gastroenterology $1992 ; 102: 936-48$.

21. Petrof BJ, Gottfied SB. Eby J "Lamanca J, Levine S. Growth hormone does not prevent corticosteroid-induced changes in rat diaphragm structure and function. J Appl Physiol 1995;79:1571 . 1577 .

22. Kelsen $\mathrm{SG}_{4}$ Ference $M$, Kapoor $\mathrm{S}$. Effects of prolonged undemulrition on structure and function of the diaphragm. I Appl Physiol 1985;58(4):1354-1359.

23. Mayer M, Rosen F. Interaction of glucocorticoids and androgens with skeletal muscle. Metaboilism $1977 ; 26: 937-962$.

24. Melby JC. Systemic conticosteroid therapy: Pharmacology and endocrinologic considerations. Ann fint Med 1974;81:505-512.

25. Haber RS, Weinstein SP. Role of glucose transporters in glucocorticoid-induced insulim resistance GLUT4 isoform in rat skeletal muscle is not decreased by dexamethasone. Diabetes 1992;41:728735.

26. Ren JM, Youn $J H$, Gulve EA, Henriksen EJ, Hollosizy JO. Effects of alkaline $\mathrm{pH}$ on the stimulation of glucose transport in rat skeletal muscle. Biochim Biophys Acta 1993;1145:199-204.

27. Askari A, Vignos PJ, Moskowitz RW. Steroid myopathy in connective tissue disease. Am J Med 1976:61:485-492.

28. Decramer $M_{*}$ Lacquet LM, Fagard R, Rogiers P. Corticosteroids contribute to muscle weakness in chronic airflow obstruction. Am J Respir Crit Care Med 1994:150:11-16.

29. Perez $T$, Becquart LA, Stach $B$, Wallaert $B$, Tonnel $A B$. Inspiratory muscle strength and endurance in steroid-dependent asthma. Am J Respir Crit Care Med 1996;153:610-615. 



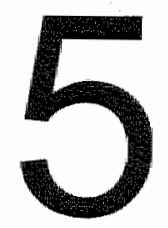

\section{Enzyme activity of rat tibialis anterior muscle differs between triamcinolone and prednisolone treatment and nutritional deprivation.}

E Koerts-de Lang, MKC Hesselink', MR Drost ${ }^{1}$ "GJ van der Vusse ${ }^{2}$, EFM Wouters, AMWJ Schols.

European Journal of Applied Physiology 79: 274-279 (1999)

Department of Pulmonology " Movement Sciences and ${ }^{2}$ Physiology, Nutrition Toxicology and Environment Research Institute Maastricht and Cardiovascular Research Institute Maastricht Maastricht University, The Netherlands. 


\begin{abstract}
The maximal activity of a selection of enzymes involved in muscle carbohydrate handling, citric acid cycle and fatty acyl $\beta$-oxidation respectively were studied after treatment with the fluorinated corticosteroid triamcinolone and compared to a similar treatment of the non-fitorinated conticosteroid prednisolone in an equipotent ant-inflammatory dose. Furthermore, because triamcinolone causes loss of mass and muscle wasting, the effects of triaminolone were investigated relative to a control group, with the same loss of mass, due to nutritional deprivation. The study was performed in male Wistar rats in the following treatment groups; $T R$, trlamcinolone treatment $10.25 \mathrm{mg} / \mathrm{kg} /$ day for 2 weeks), which resulted in a reduction of body mass $(24 \%)$; $N D$, nutritional deprivation ( $30 \%$ of normal daily food intake for 2 weeks) resulting in a similar (24\%) decrease of body mass as TR; $\mathrm{PR}_{\mathrm{u}}$ prednisolone treatment $(0.31 \mathrm{mg} / \mathrm{kg} / \mathrm{day}$ for 2 weeks), with a $10 \%$ increase in body mass; FF, free-fed control group, with a $12 \%$ increase in body mass in 2 weeks. Compared to FF, TR induced an increase in phosphofructokinase (PFK) activity $(p<0.01)$. glycogen synthase $[G S(i+d)]$ activity $(p<0.05)$ and glycogen content $(p<0.011)$ in the tiblalis anterior muscle. The PR and ND caused no alterations in PFK or citrate synthase (CS) activity compared to FF. Compared to $\mathrm{PR}$, $\mathrm{TR}$ induced an increase in PFK $(p<0.01), \operatorname{CS}(p<0.05)$ and $G S(1+d)$ activity $(p<0.01)$. Both TR and PR caused an increased muscle glycogen concentration, being more pronounced in TR $(p<0.05)$. Compared to ND, TR induced an increased CS $(p<0.05)$ and $G S(i+d)$ activity $(p<0.01)$ and glycogen content $(p<0.01)$. The ND resulted in a decreased glycogen content compared to FF $(p<0.05)$. None of the treatments affected the activity of glycogen phosphorylase, $\beta$ hydroxyacyl COA dehydrogenase and lactate dehydrogenase. It was concluded that corticosteroids led to an increased muscle glycogen content. However, the changes in the enzymes of carbohydrate metabolism were corticosteroid type specific and did not relate to undernutrition, which accompanied the triamcinolone treatment.
\end{abstract}

\title{
5.1. Introduction
}

Glucocorticoids have been commonly used as anti-inflammatory agents in the treatment of chronic obstructive pulmonary disease (COPD)(1). It has been found that patients with COPD often suffer from respiratory and peripheral skeletal muscle weakness (2-4). The cause of this muscle weakness in COPD is not yet clear, but among others, muscle wasting related to nutritional depletion (5) and corticosteroids (6) have been suggested as contributing factors. Corticosteroids can be fluorinated to increase their anti-inflammatory potency. However, it has been shown that this results in more severe systemic effects than non-fluorinated corticosteroids (7).

It has been demonstrated in studies on experimental animal, that the fluorinated corticosteroid triamcinolone causes muscle wasting and predominantly type lix/b atrophy (8-10). In addition to histochemical changes, triamcinolone exerts many alterations in muscle energy metabolism, which can also be associated with alterations in muscle function. If has been noticed that triamcinolone caused an increase in glycogen concentration in muscle but the exact mechanism of action of triamcinolone on muscle carbohydrate handling is still a matter of debate. Evidence for increased glycogenesis after triamcinolone treatment has been found, associated with increased lactate concentrations (11). In addition, glutamine release of the rat hindquarter has been observed to be increased $(12,13)$, which implies protein catabollism. 
Furthermore, triamcinoione has even been shown to cause in witho uncoupling of oxidative phosphorylation and respiration (14). which will probably be reflected in changed muscle enzyme capacities.

The question that remains to be addressed is whether changes in muscle metabolism after triamcinolone treatment are induced by 1) muscle wasting, related to loss of mass, or induced by 2) corticosteroid treatment per se, as studied in a prednisolone group. We hypothesized that triamcinolone-induced muscle atrophy and increased glycogen content is associated with alterations in the activity of muscle enzymes, involved in carbohydrate and $\beta$-oxidation. In an earlier study we have demonstrated that a similar administration of the non-fluorinated corticasteroild prednisolone in an equipotent glucocorticoid dose (15) did not affect muscle mass (16). Since triamcinolone has been shown to cause type $/ 1 \times / b$ atrophy, a muscle with predominantly type II fibres was studied: the tibialis anterior muscle.

\subsection{Methods}

\section{Animais}

Forty male Wistar rats were treated during two weeks. The initial body mass (BM) of these animals, aged 12 weeks, ranged from 314 to $345 \mathrm{~g}$. The animals were randomly allotted to four groups, a triamcinolone treated group (TR: $0.25 \mathrm{mg} / \mathrm{kg} /$ day triamcinolone acetate $1 . \mathrm{m}$., which had an ad libitum food intake, $n=10$ ) and 3 reference groups. Because in previous studies, the amount of muscle wasting after triamcinolone treatment could not be explained by the diminished food intake (17) but also by an increased energy expenditure (9), we did not introduce a pair-fed group, but introduced a nutritionally deprived group (ND: $0.05 \mathrm{~m}^{*} \mathrm{day}$ saline $\mathrm{i} . \mathrm{m}$.), receiving a food intake of $30 \%$ of normal, resulting in a calculated comparable body mass reduction $(n=10)$. A prednisolone treated group was included which recelved an equipotent anti-inflammatory dose to triamcinolone (PR: $0.31 \mathrm{mg}^{*} \mathrm{~kg}^{-1 /}$ day ${ }^{-1}$ prednisolone $1 . \mathrm{m}$.) $(n=10)$, with an ad libitum food intake. Thirdly, a free fed group (FF: $0.05 \mathrm{ml}^{*}$ day ${ }^{-1}$ saline $1 . \mathrm{m}$.) was included which had an ad libitum food intake $(n=10)$. The chosen corticosteroids dose is comparable to what is used in patients with COPD as maintenance therapy or during acute exacerbations. The diet provided to all animals was SRM-A 1210 pellets (Hopefarms. Woerden, NL). Water was available ad libitum to all animals. The animals were housed in metabolic cages at a temperature of $23^{\circ} \mathrm{C}$ with a 12 hour dark light cycle. Food intake and body mass of all animals were registered daily. Veterinary oversight, including regular observation of the health of the animals was performed according to the Dutch National Guidelines of Animal Care. The experimental protocol was approved by the Ethical Committee of Animal Research of the Maastricht University.

\section{Muscle preparation and enzyme determination}

Rats were anaesthetized with Nembutal $6 \mathrm{mg} / 100 \mathrm{~g}$ body mass, intraperitoneally) after short term $\left(<20\right.$ s) $\mathrm{CO}_{2}$ sedation. Tibialis anterior muscle was dissected, immediately weighed and freeze clamped in liquid nitrogen and stored at $-80^{\circ} \mathrm{C}$ until analysis. Muscle was homogenized (10\% W/V) in SET-buffer by use of an Ultra-Turrax 125 tissue homogenizer (Janke \& Kunkel, $\mathrm{GmbH} \& \mathrm{CO} \mathrm{KG}$ ) for four $5 \mathrm{~s}$ intervals. At $0^{\circ} \mathrm{C}$, the homogenization process was completed by treatment with ultrasonic sound (Soniprep 150, MSE) for four 15 $s$ intervals. Total protein was assayed from this homogenate by means of bicinchoninic acid as described earlier $(41,42)$. For enzyme determination, the homogenate was centrifuged $\left(4^{\circ} \mathrm{C}\right)$ for $10 \mathrm{~min}$ at $2100 \times \mathrm{g}(3500 \mathrm{rpm})$ and supernatant was assayed for lactate dehydrogenase (LDH; EC 1.1.1.27) (18), phosphofructokinase (PFK; EC 2.7.1.11) (19), citrate synthase (CS; EC 4.1.3.7) (20) and 3-hydroxyacyl CoA dehydrogenase (HAD; EC 1.1.1.35) (21) activities by use of the Cobas Bio centrifugal analyzer (La Roche. Basie. Switzerland). Glycogen synthase (GS) activity was assessed on a centrifugal analyzer (Cobas Fara, Hoffman La-Roche, Basle, Switserland) in the muscle homogenate at $30^{\circ} \mathrm{C}$. To 
discriminate between the active GS(1) part of GS and total GS activity GS(i+d), GSi activity was assayed in absence of glucose-6-phosphate (G6P) while $\mathrm{G} 6 \mathrm{P}$ (10 mM) was added to the homogenate to assay total GS activity.

UDP-glucose was used as starting reagents and formation of UDP was measured according to Danforth (22). Glycogen phosphorylase (GP) activity was assayed according to Schreiber (23) on a centrifugal analyzer and expressed as jumoliminig ww. Both the total GP(a+b) and active form $\mathrm{GP}(\mathrm{a})$ of glycogen phosphorylase were assessed. Part of the muscle was dissolved for thin $1 \mathrm{M} \mathrm{NaOH}\left(37^{\circ}\right)$, precipitating glycogen with $96 \%$ ethanol (10 min at $80^{\circ} \mathrm{C}$ followed by overnight precipitation at $4^{\circ} \mathrm{C}$ ). Subsequently the pellet was hydrolyzed using $1 \mathrm{M}$ $\mathrm{HCL}$ at $100^{\circ} \mathrm{C}$ for $3 \mathrm{~h}$ after which $\mathrm{HCL}$ was neutralized with a $\mathrm{KCl}$ saturated $\mathrm{KOH} / \mathrm{Tris}(2.1 \mathrm{M} /$ $0.12 \mathrm{M})$ buffer. Glycogen derived glycosyl units were determined using a glucose kit (hexokinase method, Roche) for a centrifugall analyzer. Glycogen was analyzed on a centrifugal analyzer (Cobas Fara) and expressed as $\mu$ mol glycosyl units per $g$ wet weight.

\section{Statistical analysis}

Differences between all groups were first detected with the Kruskall Wallis test and then assessed using the Mann-Whitney $U$ test, because of the non-normal distribution. Level of significance was determined as $p \leq 0.05$. Analysis were performed using the SPSS/PC+ program. Data are presented as group mean standard error of the mean (SEM).

\subsection{Results}

Animal food intake, body and muscle mass

Food intake of all rats was comparable before the experimental period ( $\pm 21 \mathrm{~g} /$ day). During treatment, food intake of the FF and PR rats remained stable and was approximately 100 $\mathrm{kJ} / 100 \mathrm{~g}$ body mass.

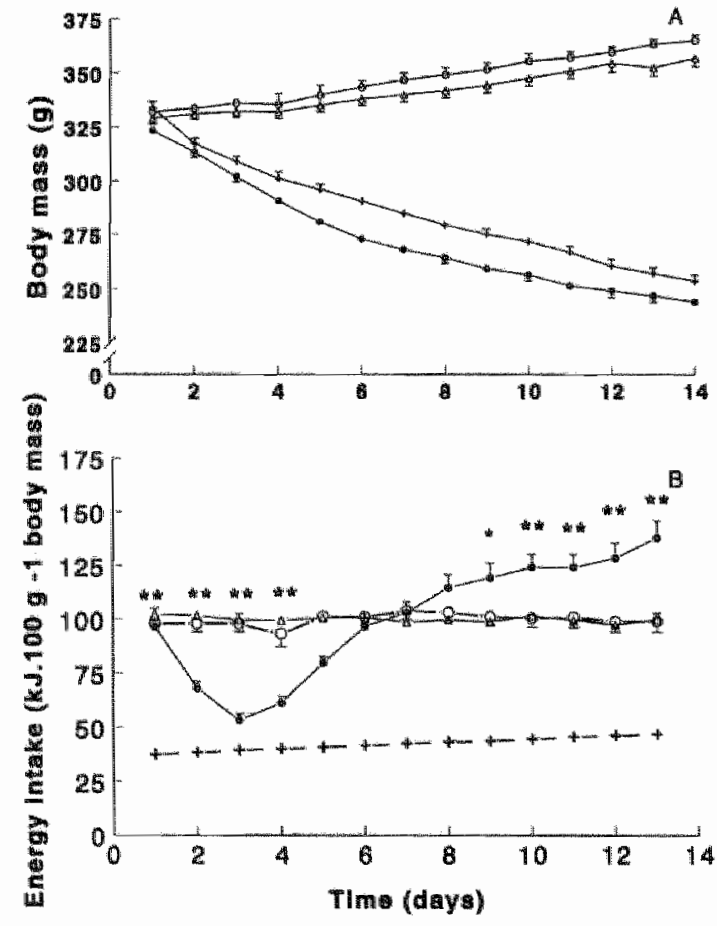

Fig. 1.(A) Mean body mass of the groups as a result of triamcinolone ( $\omega)$ or prednisolone $(\Delta)$ treatment or nutritional depletion $(+)$ or ad libitum food intake (o). (B) Mean energy intake per $100 \mathrm{~g}$ body mass \pm SEM of the triamcinolione (*). nutritionally deprived (+). prednisolone ( $\Delta$ ) and free-fed (o) groups during experimental period. Significant difference between TR and FF: ", $p<0.05 ; * * 0<0.01$. 
Food intake of the TR rats decreased after the first injection to $9.7 \pm 0.5 \mathrm{~g}$ at day 3 and then slowly increased until it was not significantly different from that of the FF rats at day 12 (TR: $19.8 \pm 1.0 \mathrm{~g}$. FF: $21.5 \pm 0.5 \mathrm{~g}$ ). Food intake of the ND rats remained stable at approximately 7 $g$ per day. As shown in Figure $1 A$, body mass of the FF and PR group increased, while body mass of the TR and ND groups decreased. After two weeks treatment body mass of the TR and ND rats were significantly lower than those of the FF and PR rats (Table 1, p<0.001). Body mass of the TR rats was slightly lower than of the ND rats $(p<0.05)$. Figure $1 B$ depicts the energy intake per $100 \mathrm{~g}$ body mass. There was no significant change in energy intake per body mass during treatment period for the FF. PR and ND rats. Energy intake per body mass of the TR rats was decreased during the first days and was even increased compared to all other groups after 9 days on $(p<0.05)$.

Table 1. Body and muscle weights

\begin{tabular}{|c|c|c|c|c|}
\hline & Trilamcinolane & Prednisolone & Nutritional deprived & Froo-fod \\
\hline Body mass (g) & $244 \pm 2 \quad 108$ & $357 \pm 4$ & $254 \pm 3 \quad \S$ & $365 \pm 2$ \\
\hline Tibialis anterior (mg) & $438 \pm 12$ & $748 \pm 18$ & $564 \geq 14$ & $708 \div 12$ \\
\hline$\%$ Muscle mass & $1.8 \pm 0.03 \%$ & $2.1 \pm 0.06$ & $2.2 \pm 0.038$ & $1.9 \neq 0.03$ \\
\hline
\end{tabular}

Values are mean \pm SEM. \% muscle mass, muscle mass of tibialis anterior/body mass $\times 100$;

If $p<0.001$ compared to $P R ; 0,0, p<0.05, p<0.001$ compared to $N D ; " \$, p<0.05, p<0.001$ compared to $F F$.

Muscle mass of the tibialis anterior was significantly decreased in the TR and ND group compared to FF and PR (Table 1, $p<0.001$ ). Muscle mass was significantly lower in the TR group compared to the ND group $(p<0.001)$. Muscle mass percentage of body mass was significantly decreased in the TR group compared to $P R$ and $N D(p<0.001)$, increased in the PR group compared to FF $(p<0,05)$ and even further elevated in the ND group compared to FF $(p<0.001)$.

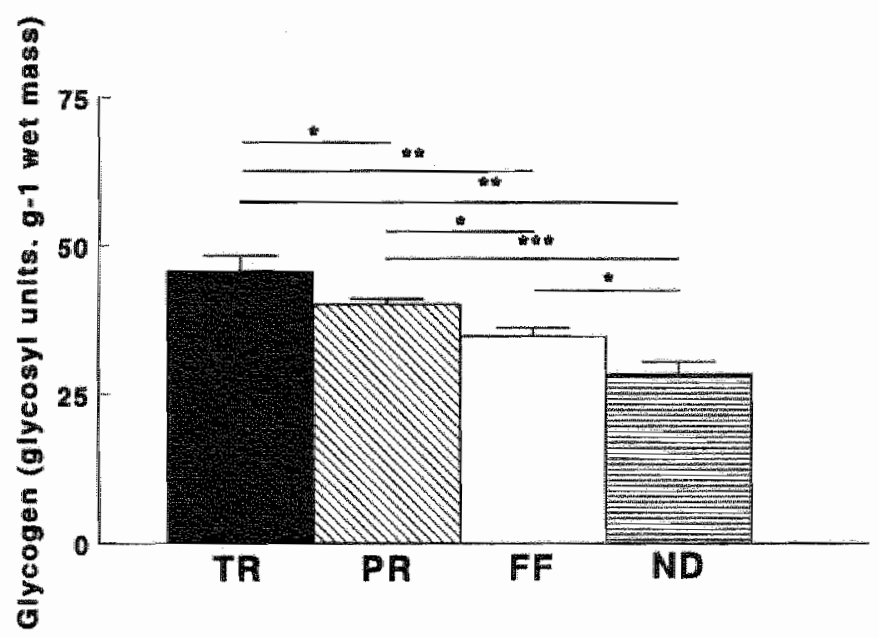

Fig. 2. Mean glycogen content \pm SEM in the tibialis anterior of the triamcinolone (TR), prednisolone (PR). nutritional deprived (ND) and control (FF) group. * $p<0.05$; ** $p<0.01 ;, p<0.001$.

Muscle glycogen stores and enzyme activities in tibialis anterior

Protein contents per gram muscle wet weight were not significanlly different between the groups. Glycogen levels in TR and PR were higher than in FF and ND (Figure 2, $p<0.05$ ), while glycogen content in TR was significantly higher than in PR $(p<0.05)$. Glycogen content in the ND group was significantly lower than in all other groups $(p<0.05)$. Total glycogen synthase activity [GS(i+d)] was significantly increased in the TR group compared to all other groups (Table 2, p<0.05). Maximal activity of glycogen synthase (d) was calculated and significantly increased in TR compared to PR and ND $(p<0.001)$ and FF $(p<0.01)$. Glycogen phosphorylase 
activity was not different between the groups. Phosphotructokinase (PFK) activity was significantly increased in the tibialis anterior of the TR rats compared to the FF and PR rats (Table 2, $0<0.01$ ). Lactate dehydrogenase (LDH) and 3-hydroxyacyl CoA dehydrogenase (HAD) activities were not significantly different between the groups (Table 2). Activity of citrate synthase (CS) was significantly increased in the TR rats compared to the PR and ND rats (Table $2, p<0.05$ ). The ratio of CS over PFK activity was significantly decreased in the TR

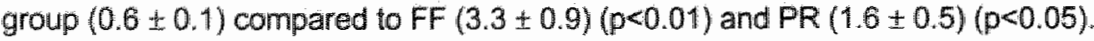

Table 2. Muscle enzyme activities in tibialis antenior

\begin{tabular}{|c|c|c|c|c|c|c|c|c|c|c|}
\hline \multirow[b]{2}{*}{$\mathrm{QP}(\mathrm{a}+\mathrm{b})$} & \multicolumn{3}{|c|}{ Triamcinolone } & \multicolumn{2}{|c|}{ Predmisolone } & & \multicolumn{2}{|c|}{ Nutritional deprived } & \multicolumn{2}{|c|}{ Free-fed } \\
\hline & $263 \pm$ & 12 & & $269 \pm$ & 12 & & $240 \pm$ & 14 & $258 \pm$ & 16 \\
\hline QP(a) & $94 \pm$ & 8 & & $96 \pm$ & 7 & & $78 \pm$ & 8 & $83 \pm$ & 6 \\
\hline $\mathrm{GS}(i+d)$ & $38+$ & 3 & $+0^{\circ}$ & $30 \pm$ & 1 & 0 & $25 \pm$ & 2 & 28 & 3 \\
\hline $\operatorname{SS}(1)$ & $17 \pm$ & 1 & & $17 \pm$ & 1 & & $15 \pm$ & 1 & $16 \pm$ & 1 \\
\hline PIFK & $507+$ & 127 & \pm & $155 \pm$ & 40 & & $217 \pm$ & 44 & $117 \pm$ & 40 \\
\hline $\mathrm{LDH}$ & $10.0 \pm$ & 0.8 & & $12.5 \pm$ & 1.5 & & $10.2 \pm$ & 1.0 & $10.3 \pm$ & 0.8 \\
\hline$H A D$ & $118 \pm$ & 15 & & $109:$ & 15 & & $87 \pm$ & 8 & $89 \pm$ & 12 \\
\hline $\operatorname{css}$ & $225 \pm$ & 29 & 10 & $167 \pm$ & 31 & & $168 \pm$ & 14 & $194 \pm$ & 29 \\
\hline
\end{tabular}

All walues are means \pm SEM; GP, glycogen phosphorylase in U/mg protein, (a) is the active form and $(a+b)$ the total gilycogen phosphorylase; $G S$, glycogen synthase in U/mg protein, (i) is the active form and $(i+d)$ the tolal glycogen synthase; $P F K_{1}$, phosphofructokinase in U/g protein; $L D H$, lactate dehydrogenase in U/mg protein; HAD, 3-hydroxyaCyl COA dehydrogenase in U/g protein; CS, citrate synthase in U/g protein; $t, t$, II $p<0.05, p<0.01, p<0.001$ compared to PR; $0,0, p<0.05, p<0.01, p<0.001$ compared to ND; ", tH, p<0.05, p<0.01 compared to FF.

\subsection{Discussion}

This study demonstrated that the triamcinolone-induced effects on muscle enzyme capacity were not related to the reduction in muscle mass per se, or corticosteroid treatment per se, but to underiying metabolic alterations different from nutritional deprivation or prednisolone treatment.

Triamcinolone treatment caused a relative increase in energy intake after 9 days, considering the food intake per $100 \mathrm{~g}$ body mass. However muscle mass reduction was even more pronounced in TR rats than in ND rats. This would imply an increased energy expenditure and an increased net protein degradation in the TR rats. The ND caused a reduction in body mass, but the reduction in muscle mass was relatively small, which could be expected in view of the metabolic adaptations to starvation, that is increase fat oxidation instead of net protein degradation. In contrast to triamcinolone, prednisolone caused no alterations in energy intake or inuscle mass. Tibialis anterior muscle mass relative to body mass was even increased similar to nutritional deprivation. These findings were in line with earlier studies, in which it has been shown that in contrast to oral treatment or subcutaneous administration of prednisolone (24-26), intramuscular treatment of prednisolone has appeared to cause no catabolism (27, 28).

The observed increase in muscle glycogen content would seem to be induced by corticosteroids per se, since enhanced glycogen levels were observed in the tibialis anterior muscle of both TR and PR treated animals. However, the increase was significantly higher after treatment with the fluorinated corticosteroid triamcinolone than after prednisolone administration. The substantially increased glycogen content after triamcinolone treatment was accompanied by an increased glycogen synthase (i+d) activity, which was caused by an increase of the inactive form GS(d). When this enzyme is dephosphorylated, it becomes active (GS(i)). After triamcinolone treatment, the supply of phosphorylated GS is increased, which may be surplus. The observation of increased GS activity corroborates earlier findings of Peters and colleagues (29), who have not distinguished between the active and inactive forms. 
In contrast, the increased glycogen content after prednisolone treatment was not accompanied by alterations in the maximal activity of GP or GS. These findings would suggest that glycogen synthesis is regulated by factors other than the content (i.e. maxtmal activity) of GS or GP. which supports the allosteric activity of GS by glucose. Nutritional deprivation resulted in an expected decrease of glycogen content in the tibialis anterior muscle (30-33), without alterations in the maximal activity of glycogen handling enzymes.

Both PFK and CS enzyme capacities were increased in tibialis anterior muscle after triamcinolone treatment, implying an increase in both glycolyfic and oxidative enzyme capacity. This could also have been an indirect result of muscle wasting with a marked loss of contractile proteins and a relative preservation of metabolic proteins, but in that case, all muscle enzyme capacities would have had to be increased, which was not observed in this study. The fact that the increase of PFK was more pronounced than that of CS would indicate that the glycolytic pathway was more sensitive to triamcinolone treatment than the citric acid cycle. In the present study, oxidative phosphorylation was not studied, but earlier studies have shown that oxidative phosphorylation and respiration in isolated mitochondria obtained from muscle tissue were less tightly coupled after triamcinolone treatment $(14,34)$. The consequence of relative uncouping is most likely upregulation of enzyme activities irwolved in the rate determining steps of glycolysis and citric acid cycle activity as observed in the present study, in order to obtain sufficient ATP.

In contrast to the increase of PFK activity after triamcinolone treatment, we observed after prednisolone treatment no alterations in PFK activity in the muscle, while Lieu and coworkers have even found a decrease of PFK activity (26). The resuits of these studies are difficult to compare because of the differences in treatment and types of muscles under investigation. Lieu and colleagues (26) have injected higher doses of prednisolone than in the present study and injected it subcutaneously, which induced catabolism. Nutritional deprivation in the present study caused no alteration in PFK, while Russell and colleagues (33) fed rats $25 \%$ of their normal diet over 3 weeks after which they observed a decrease in PFK capacity in the gastrocnemius muscle. Despite a decreased glycogen level and wasting of the tibialis anterior after nutritional deprivation, no alterations in the maximal activity of enzymes involved in carbohydrate and $\beta$-oxidation were observed in the present study.

It has been suggested that several factors may contribute to muscle wasting and muscle weakness in patients with COPD, including nutritional depletion (5), corticosteroid medication (6), acute respiratory failure (35) and inactivity (36). In this study we found that corticosteroids led to increased muscle glycogen contents and may have induced a type specific upregulation of enzymes of carbohydrate metabolism. Undernutrition was associated wilth glycogen depletion but not to major changes in these enzymes. Both increased muscle glycogen levels (37) and decreased glycogen contents (38) have previously been reported in patients with COPD. Altered PFK and CS activities have also been demonstrated in muscles of COPD patients $(36,39)$, but the pattern of changes has not been consistent among the studies. Furthermore, a very recent study showed in skeletal muscle of COPD patients an upregulation of the activity and gene expression of cytochrome oxidase (40). Further studies are needed to determine whether biochemical analysis of peripheral muscle biopsies could be useful in differentiating between the specific contributions of nutritional depletion and corticosteroids in patients with COPD, aimed at targeted intervention strategies.

\section{References}

1. Ferguson GT. Corticosteroids and respiratory muscies. Does if matter? Chest 1993;104:16491650 .

2. Gosselink R, Troosters $T$, Decramer M. Peripheral muscle weakness contributes to exercise limitation in COPD. Am $\Downarrow$ Respir Crit Care Med 1996;153:976-980 
3. Hamiton AL, Killian KJ, Summers E, Jones ML. Muscle strength, symptom intensity, and exercise capacity in patients with cardiorespiratory disorders. Arn J Respir Crit Care Med $1995 ; 152: 2024-203 \%$.

4. Tobin MJ. Respiratory muscles in disease. Clin Chest Med 1988,9:263-286.

5. Engelen MPKJ, Schols AMWJ, Baken WC, Wesseling GJ, Wouters EFM. Nutritional depletion in relation to respiratory and peripheral skeletal muscle function in out-patients with COPD. Eur Respir J 1994:7:1793-1797.

6. Decramer $M_{s}$ Lacquet $L M_{4}$ Fagard $R_{*}$ Rogiers $P$. Corticosteroids contribute to muscle weakness in chronic airflow obstruction. Am J Respir Crit Care Med 1994;150:11\%16.

7. Thalen A, Brattsand R, Andersson PH. Development of glucocorticosteroids with enhanced ratio between topical and systemic effects. Acta Derm Venereol 1989;69 (suppl 151):11-19.

8. Dekhuijzen PNR, Gayan Ramirez G, Bisschop $A$, Bock de $V$, Dom $R_{x}$ Decramer $M$. Corticosteroid treatment and nutritional deprivation cause a different pattern of atrophy in rat diaphragm. J Appl Physiol 1995;78:629-637.

9. Koerts-de Lang E, Schols AMWJ, Gayan-Ramirez G, Wouters EFM, Decramer M. Contractile properties and histochemical characteristics of the raf diaphragm after prolonged triamcinolone treatment and nutritional deprivation. J Muscle Res Cell Motility 1998:19:549-555.

10. Polrof BJ, Gottfried SB, Eby $\mathrm{J}_{\text {, Lamanca }}$. Levine $S$. Growth harmone does not prevent corticasteroid-induced changes in rat diaphragm structure and function. J Appl Physiol $1995 ; 79: 1571-1577$.

11. Shoji $S_{*}$ Takagi A, Sugita $H$, Toyokuria $Y$. Muscle glycogen metabolism in steroid-induced myopathy of rabbits. Exp Neurol 1974;45:1-7.

12. Koerts-de Lang E, Schols AMWJ, Deutz NEP, de Blaauw I, Wouters EFM. Effects of combined prolonged corticosteroid treatment and undernutrition on muscle glutamine metabolism in rats. Am J Resp Crit Care Med 1995;151:A812.

13. Welbourne TC. Role of glucocorticoids in regulating interorgan glutamine flow during chronic metabolic acidosis. Metabolism 1988;37:520 525.

14. Peter JB, Verhaag DA, Worsfold M. Studies of steroid myopathy. Examination of the possible effect of triamcinolone on mitochondria and sarcotubular vesicles of rat skeletal muscle. Biochem Pharmacoll 1970;19:1627-1636.

15. Goodman LS, Gillman A. Adrenocortical steroids. The pharmacological basis of therapeut. New York: Pergaman Press, 1990:1436-1462.

16. Koerts-de Lang E, Schols AMWJ, Deutz NEP, Wouters EFM. Attenuated effects of prednisolone treatment on muscle glutamine and protein metabolism during nutritional deprivation in rats. Am J Resp Crit Care Med 1997;155:A921.

17. Gardiner PF, Montanaro G, Simpson DR, Edgerton VR. Effects of glucocorticoid treatment and food restriction on rat hindlimb muscles. Am J Physiol 1980;238:E124-E130.

19. Bergmeyer H. In: Bergmeyer $H$, ed. Methods of Enzymatic Analysis, 1974:480-482.

19. Ling K, Peatkau V, Marcus F, Lardy H. Phosphofructokinase. I. Skeletal muscle. Methods in Enzymology 1966:5:425-429.

20. Shepherd $D_{11}$ Garland $P B$. Citrate synthase from rat liver. Methods Enzymology 1969;13:11-16.

21. Bergmeyer $H$. In: Bergmeyer $H$, ed. Methods of Enzymatic Analysis, 1974:474.

22. Danforth W. Glycogen synthetase activity. Inferconversion of two forms and control of glycogen synthesis. J Biol Chem 1965:240:588.593.

23. Schreber WE, Bowling S. An automated assay of glycogen phosphorylase in the direction of phosphorolysis. Ann Clin Biochem 1990;27:129-132.

24. Dodd SL, Powers SK, Vrabas IS, Eason JM. Interaction of glucocorticoids and activity patterns: affect muscle function. Muscle Nerve 1995;18:190-195.

25. Kelly FJ, McGrath JA, Goldspink DF, Cullen MU. A morphological / biochemical study on the actions of corticosteroids on rat skeletal muscle. Muscle \& Nenve 1986;9:1-10.

26. Lieu FK, Powers SK, Herb RA, et al. Exercise and glucocorticoid-induced diaphragmatic myopathy. J Appl Physiol 1993;75:763-774.

27. Dekhuijzen $P_{N R}$ Gayan Ramirez $G$, Bock de $V$, Dom $R$, Decramer $M$. Triamcinolone and prednisolone affect contractile properties and histopathology of rat diaphragm differently. $J$ Clin Invest 1993;:92:1534-1542.

28. Faludi G, Gotlieb J, Meyers J. Experimentally induced primary myopathies Factors influencing the development of steroid-induced myopathies. Ann NY Acad Sci 1966;138:61-72. 
29. Peters RF. Richardson MC, Small M. White AM. Some biochemical effecis of triancinolone acetonide on rat liver and muscle. Biochem $J 1970 ; 116: 349-355$.

30. Brown DH. Glycogen metabolism and glycolysis in muscte. In. Engel $A_{1}$ Banker B, eds. Myology. basic and clinica: McGraw-Hill Inc, 1986:673-696.

31. Conlee RK Rennie MJ, Winder WW. Sketetal muscle glycogen content: dilumal variation and effects of fasting. Am J Physiol 1976,231:614-618.

32. Russell DM, Walker PM, Leiter LA, al Metabolic and structural changes in sketetal muscle during hypocaloric dieting. Am J Clin Nutr 1984;39:503-51 3.

33. Russell DM, Atwood HL. Whitaker JS, et al. The effect of fasting and hypocaloric diets on the functional and metabolic characteristics of ral gastrocnemis muscie. Clin Sct 1984;67:185-194.

34. Vignos $P J_{1}$ Greene R. Oxidative respiration of skeletal muscle in experimental corticosteroid myopathy. J Lab Clin Mled 1973;81:365-378.

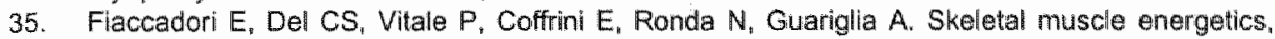
acid-base equilibrium and lactate melabolism in patients with severe hypercapnia and hypoxemia. Chest $1987 ; 92: 883-887$.

36. Maltais F. Simard A Simard C. Jobin J Desgagnes P. LeBlanc P. Oxidative capacity of the skeletal muscle and lactic acid kinetics during exercise in nornal subjects and in patients with COPD. Am J Respir Crit Care Med 1996;153:288-293.

37. Pouw $E$, Schols $A$, vanderVusse $G_{\text {}}$ Wouters $E$. Elevated inosine monophosphatte luvels in resting muscle of patients with stable chironic obstructive pulmonary disease. Am $\sqrt{ }$ Respir Crit Care Med 1998;157:453-457.

38. Jakobsson P. Jorfeldt L. Long-term oxygen therapy may improve skeletal muscie metabolsm in advanced chronic obstructive pulmonary disease patients with chronic hypoxaemia. Respir Med $1995 ; 89: 471 \% 476$

39. Jakobsson $P$. Jlorfeldt L, Henriksson J. Metabolic enzyme activily in the quadriceps femoris muscle in patients with severe chronic obstructive pulmonary disease. Am J Respir Crit Care Med 1995;151:374-377.

40. Sauleda J, GarciaPalmer $F$, Wiesner $R_{\text {, }}$ et al. Cytochrome oxidase actiwity and mitochondrial gene expression in skeletal muscle of patients with chronic obstructive pulmonary diseatse. Am $\mathrm{J}$ Respir Crit Care Med 1998;157:1413-14\|17. 



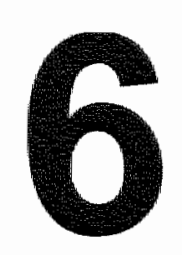

\section{Effects of corticosteroids and undernutrition on glutamine metabolism in rat skeletal muscle.}

E Koerts-de Lang, I de Blaauw', NEP Deutz", EFM Wouters, AMWJ Schols. 


\begin{abstract}
Corticosteroid treatment affects muscle glutamine metabolism. We have investigated to what extent undemutrition contributes to these alterations and whether acute and chronic corticosteroid treatment exert comparable meiabolic atterations. The study was performed in Wistar rats in the following treatment groups: $T R_{s}$ triamcinolone treatment $(0.25 \mathrm{mg} / \mathrm{kg} / \mathrm{day} \mathrm{im}$ ) for 3 days $(n=8)$ or for 14 days $(n=10)$; PF, pair fed (similar food intake as TR) for 3 days $(n=8)$ or for 14 days $(n=10)$; $P$ W, pair weight (comparable body weight reduction as TR) for 14 days $(n=10)$ : $F F$, free fed for 3 days $(n=8)$ or 14 days $(n=10)$.

in contrast to undernutrition, acule corticosteroid treatment increased intramuscular glutamine concentration and glutamine shunting and decreased intracelfular disposal and production of glutarnine in the muscle. Chronic corticosteroid treatment however, was accompanied by an increased muscle glutamine efflux, an increased glutamine de novo production and increased glutamine membrane transport rates, which were also observed (although less pronounced) after chronic undernutrition. Glutamate is likely to be the precursor for glutamine production after chronic triamcinolione treatment, but after chronic undernutrition influx of possible precursors for glutamine production. fike glulamate or branched chain amino acids was not altered.

in conclusion, chronic weight loss either induced by triamcinolone or by undernutrition is associated with similar alterations in muscle glutamine metabolism.
\end{abstract}

\title{
6.1. Introduction
}

Corticosteroids are commonly used as anti-inflammatory agents in the treatment of various diseases including chronic obstructive pulmonary disease (COPD) (1). Muscle weakness and wasting are frequently reported after a prolonged treatment with corticosteroids $(2,3)$. It is not clear to what extent this is related to the metabolic effects of corticosteroids or to the associated undernutrition. Muscle wasting is the result of a disturbed protein balance. Protein metabolism was indeed found to be disturbed in COPD patients $(4,5)$. Of the metabolic alterations, particularly glutamine metabolism was found to be changed. Alterations in glutamine efflux (4) and intramuscular glutamine concentrations were found $(5$. $6)$. The results are however inconsistent, which could be related to differences in patient characteristics, muscles studied and corticosteroid use.

Glutamime is an important nitrogen and ammonia carrier in interorgan metabolism (7). It is a non-essential amino acid and can be synthesised from glutamate and ammonia with the means of the enzyme glutamine synthase (GS).

During metabolic stress, glutamine is considered to be a conditionally essential amino acid, as metabolic fuel for the gut and other rapidly dividing cells e.g. the immune system. Intramuscullar concentrations were observed to be decreased after chronic starvation (8) or corticosteroid treatment $(9)$. In addition, it has been observed that the activity of glutamine synthetase is increased in muscle and lung in response to various catabolic disease states $(10,11)$ and after corticosteroid treatment (12).

To discriminate between the effects of corticosteroid treatment per se and those of undernutrition on muscle glutamine metabolism a rat study was conducted. The fluorinated corticosteroid triamcinolone was used, since this corticosteroid induces besides a hypermetabolic state, also an abrupt drop in food intake.

First aim of the study was to compare the effects on muscle glutamine metabolism after corticosteroid treatment or undernutrition. Second aim was to study possible differences in glitamine metabolism between acute and chronic effects of corticosteroid treatment, when dietary intake is normalised. 


\subsection{Methods}

\section{Animals}

Fifty four male Wistar rats ( $\pm 350 \mathrm{~g}$, Harlan-Winkelmann, Borchen, Germany) were studied. The diet provided to all animals was standard laboratory rat chow (SRM-A 1210, Hopefarms, Woerden, The Netherlands) and water ad libitum. They were subjected to standard 12 hour light-dark cycle periods (7:30 A.M. to 7:30 P.M.) whereas room temperature was maintained at $25^{\circ} \mathrm{C}$. The experiments were performed in accordance with the recommendations of the Guide for the Care and Use of Laboratory Animals (13) and approved by the Ethical Committee of Animal Research of the Maastricht University.

\section{Experimental groups}

Rats were randomly divided into four groups. The first group (TR) received a daily injection of triamcinolone $(1.25 \mathrm{mg} / \mathrm{ml})$ of $0.25 \mathrm{mg} / \mathrm{kg}$ body weight (approximately $0.06 \mathrm{mll}$ ) intramuscular (i.m.) for 3 days $(n=8)$ and 2 weeks $(n=10)$ and ad libitum food intake. The second group (pair-fed; PF) had a similar food intake as. TR, and received daily $0.05 \mathrm{ml} 450$ $\mathrm{mM} \mathrm{NaCl}$ i.m. for 3 days $(n=8)$ and 2 weeks $(n=10)$. The third group (pair-weight; PW) had a comparable body weight as TR by reducing daily food intake and received daily $0.05 \mathrm{ml} 150$ $\mathrm{mM} \mathrm{NaCl}$ i.m. for 2 weeks ( $n=10)$. The fourth group was free fed (FF) for 3 days $(n=8)$ and for 2 weeks $(n=10)$, and received daily $0.05 \mathrm{ml} 150 \mathrm{mM} \mathrm{NaCl}$ i.m. All injections were given in the hamstrings of the left leg.

\section{Study and sampling procedure}

Rats were randomly assigned to metabolic cages, taking an adaptation period of 4 days prior to the experiment into account. Food intake and body weight (BW) of all animals were registered daily at 8:00 A.M., before the injections. All infusion and sampling experiments were performed as described previously $(14,15)$. In brief under anaesthesia a laparotomy was performed. The inferior caval vein, the right vena renalis, the aorta and the left carotid artery were cannulated. To study amino acid membrane transport kinetics, a primed (1.1 $\mu \mathrm{Ci} / 100 \mathrm{~g}$ BW) continuous infusion $(1 \mu \mathrm{Cl} / 100 \mathrm{~g} \mathrm{BW} / \mathrm{h})$ of $\mathrm{L}-[3,4-3 \mathrm{H}]$-Glutamine (OLN) and L[2,6-3H]-Pheny/alanine (PHE) was given into the right renal vein. For flow measurements, the indicator dilution method with para-aminohippuric acid $(\mathrm{PAH})$ was used $(\mathrm{pH} 7.4$, isoosmolar, Sigma A 1422, St Louis, MO, USA). A primed (0.15 m/100 g BW; $50 \mathrm{mM})$ continuous infusion $(0.75 \mathrm{ml} / 100 \mathrm{~g} \mathrm{BW} / \mathrm{h}, 5 \mathrm{mM})$ of PAH was infused in the aorta.

After 30 minutes, blood (1.2 $\mathrm{ml}$ per catheter) was sampled from the caval vein and carotid artery at a maximum rate of approximately $500 \mu / / \mathrm{min}$. All blood was collected in heparinized cups (Lithium-Heparin Micro-sample container CB100, Sarstedit, Germany) on ice. Hereafter, the right gastrocnemius muscle was dissected freely, directly freeze-clamped, put in liquid nitrogen and stored at $-80^{\circ} \mathrm{C}$ until further analysis. Gastrocnemius muscle from the left leg was dissected freely and weighed.

For PAH determinations, $50 \mu$ l heparinized blood was added to $500 \mu l$ Trichloroacetic acid GR 10\% (w/v) (TCA 10\%) (Merck 807, Darmstadt, Germany), vortexed and centrifuged at $8,900 \mathrm{~g}$ at $4^{\circ} \mathrm{C}$. The supernatant was frozen in liquid nitrogen and stored at $-80^{\circ} \mathrm{C}$ until further analysis. For hematocrit determinations a micro-hematocrit tube (Modulohm 88302 , Herlew, Denmark) was filled with heparinized blood and centrifuged at $10,000 \mathrm{~g}$ at room temperature. Plasma was obtained by whole blood centrifugation at $8,900 \mathrm{~g}$ at $4^{\circ} \mathrm{C}$ for 5 minutes. For arterial and wenous glucose determinations, $200 \mu$ plasma was vortexed with $20 \mu$ of $50 \%$ TCA, put into liquid nitrogen and stored at $-80^{\circ} \mathrm{C}$. For plasma amino acid determinations $200 \mathrm{\mu l}$ plasma was added to $8 \mathrm{mg} 5$-Sulfosalicylic acid (SSA 5\%) (Brunschwig, 10346, Amsterdam, The Netherlands) for deproteinization, vortexed, frozen in liquid nitrogen and stored at $-80^{\circ} \mathrm{C}$. 
For the determination of tissue free amino acid concentrations and specific activity, frozen muscle tissue was pulverised using a mortar and pestle precooled in liquid nitrogen and homogenised and deproteinized using a Mini-beater (Biospec products, Bartlesville) Approximalely $100 \mathrm{mg}$ tissue was added to 500 ul SSA $(5 \%)$ plus glass beads $(1 \mathrm{~mm})$. This was put in the mint-beater for 30 seconds. The homogenate was frozen in liquid nitrogen and stored at $-80^{\circ} \mathrm{C}$ until further deteminations of the supernatant.

To determine the tissue dry weight approximately $200 \mathrm{mg}$ pulverised tissue was freeze dried for 24 hours in a Speedvac (type SC200, Savant Instruments Inc., Farmingdale, NY, USA) connected with a refrigerated condensation trap (type RT 400, Savant Instruments Inc., Farmingdale, NY, USA).

\section{Biochemical analysis}

Plasma glucase and PAH were determined spectrophotometrically on a Cobas Mira $S$ (Roche Diagnostica, Hoffman-La Roche, Basel, Switzerland) by standard enzymatic methods, using commercially avalable kits as described previously $(15,16)$. Amino acids and specific activity were determined by fully automated high performance liquid chromatography (HPLC) using 2-3 $\mu \mathrm{M}$ spherisorb ODS II packing material and pre-column derivatization with ortho-phthaldialdehyde as described previously (17).

\section{Calculations}

Plasma flow across the hindquarter using PAH in the indicator dilution method is calculated as follows:

Plasma flow = IPAH / \{[PAHIven-[PAH]art $\}$

in (m/100 g BW/min), IPAH is the infusion rate of PAH ( $\mu$ mol/100 $\mathrm{g} \mathrm{BW/min)}$ and [PAH]ven or art the venous or arterial plasma PAH concentration $(\mu \mathrm{M})$.

Hindquarter substrate fluxes are calculated by multiplying the inferior caval vein-arterial concentrations differences with the mean hindquarter plasma flow of the group and are expressed in nmol/100 $\mathrm{g} \mathrm{BW} / \mathrm{min}$. A positive flux indicates net release, a negative flux reflects a net uptake. Tissue concentrations of amino acids are expressed in $\mathrm{mmol} / \mathrm{L}$ and derived by the multiplication of tissue homogenate amino acid concentration (mmol/kg wet weight) and the percentage tissue water content. Branched-chain amino acids were calculated as the sum of valine, leucine and isoleucine.

\section{Glutamine turnover}

Three compartment modelling was used to calculate glutamine turnover $(18,19)$. The model divides an organ in two vascular compartments and a tissue compartment. Plasma-tissue membrane transport rates are calculated as the glutamine flux in vivo from the arterial pool to the intracellular muscle pool ( Fm,a) and from the intracellular pool to the venous pool $(F v, m)$. Metabolic shunting can be derived from the flux entering the venous pool from the arterlal pool bypassing the intracellular free glutamine pool ( $\left.F v_{,}, a\right)$. Whole body glutamine and phenylalanine rate of appearance $(\mathrm{Ra})$ were calculated from the arterial dilution of the tracer amino acid at steady state (20). Glutamine can be incorporated in muscle protein (intracellular disposal). Production of glutamine can be obtained by protein breakdown (intracellular production) and by the transamidation of glutamate. Knowing the relative amino acid concentration of phenylalanine and glutamine in protein (21) enables us to calculate glutamine $\mathrm{Ra}$ derived from protein breakdown and non-protein derived glutamine $\mathrm{Ra}$ (de novo production).

\section{Statistics}

All data are presented as group means \pm SEM. Kruskal-Wallis Oneway ANOVA was used to test significant differences. Differences between all groups were assessed using a nonparametric test (Mann-Whitney U). A significance level of $p \leq 0.05$ was selected. 


\subsection{Results}

Animal food intake, body and muscle weights

The daily food intake of the different groups treated during 2 weeks, is depicted in figure $1 \mathrm{~A}$. The TR rats showed a reduced intake during the first days of the experiment. After this acute response, food intake gradually returned to normal levels. Initial body weights of the groups (Fig. 1B) were not significantly different.
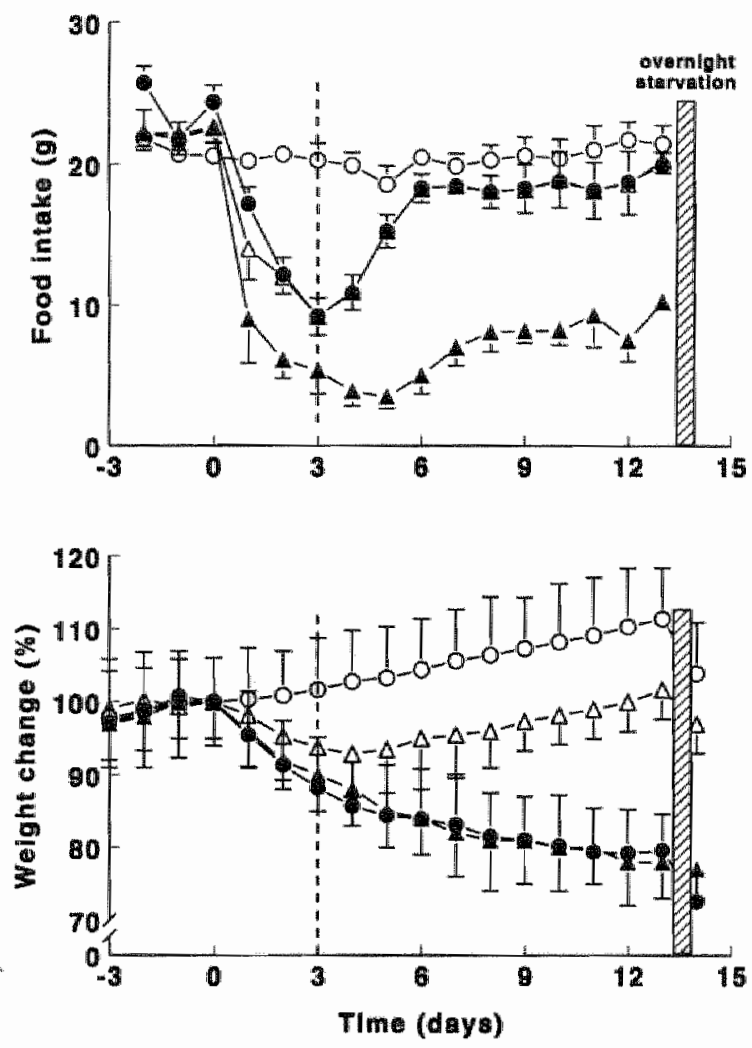

Fig. 1. (A) Food intake of the groups as a result of triamcinolone treatment (-) or pair-weight ( $\Delta)$, pair-fed $(\Delta)$ or ad libitum food intake (0).

(B) Weight change during triamcinolone treatment (-) or pairwaight ( $\Delta$ ), pair-fed ( $\Delta$ ) or ad libilum food intake (o).

After 3 days, body weight of the TR group was significantly decreased compared to the FF group. while body weight of the PF group was not significantly different from FF (Table 1). During the 2 weeks treatment, the weights of the TR and PW rats decreased by $20 \%$ and $22 \%$, while body weight of the PF and FF rats increased: values at the end of treatment period were not significantly different (Figure 1B). As shown in table 1, gastrocnemius weight decreased after triamcinolone treatment, but also after 2 weeks severe undernutrition (PW). Totall gastrocnemius weight expressed as percentage of body weight was significantly decreased after 14 days in the TR group compared to all other groups (Table 1). No difference in relative muscle weight was observed between the PW, PF and FF groups. 
Table 1. Booy and mustere wethots.

\begin{tabular}{|c|c|c|c|c|c|c|c|}
\hline & & $\mathrm{FF}$ & PF & PW & & TR & \\
\hline Final BW & 30 & $354 \pm 9$ & $337 \pm 9$ & & & $315 \pm 8$ & $\mathrm{a}$ \\
\hline (g) & $14 d$ & $343 \pm 7$ & $334 \pm 4$ & $266 \pm 4$ & $\mathrm{c}$ & $251 \pm 5$ & of $g$ \\
\hline Weight gastro & $3 d$ & $1.90 \pm 0.06$ & $1.85 \pm 0.07$ & & & $1.67 \pm 0.06$ & \\
\hline (g) & $14 d$ & $1.89 \pm 0.0 .5$ & $1.88 \pm 0.03$ & $1.55 \pm 0.02$ & $\mathrm{c}$ & $1.26 \pm 0.05$ & c f i \\
\hline \multirow[t]{2}{*}{ Gastro/BW } & $3 d$ & $0.54 \pm 0.01$ & $0.55 \pm 0.01$ & & & $0.53 \pm 0.01$ & \\
\hline & $14 d$ & $0.56 \pm 0.01$ & $0.56 \pm 0.01$ & $0.58 \pm 0.01$ & & $0.50 \pm 0.01$ & a e \\
\hline
\end{tabular}

Vaves are mean \pm SEM. BW, body weight; Gastro, gastrocnemius. $a, b, c, p<0.05, p<0.01, p<0.001 \mathrm{vs}$ FF; $d, e, f, p<0.05, p<0.01, p<0.001$ ws PF; $g, h, i, p<0.05, p<0.01, p<0.001$ vs PW.

Intramuscular and artenial concentrations and hindquarter fluxes after 3 days

Hematocrits and muscle weVdry weights were not significantly different between the groups. When we compare the TR with the FF group, an increased arterial glucose concentration was observed in the TR rats $(42 \pm 2 \mathrm{mM})$ compared to FF rats $(12 \pm 1 \mathrm{mM}, \mathrm{p}<0.01)$. Comparing TR with PF, the TR rats had higher arterial glucose levels than the PF rats (PF: $11 \pm 1 \mathrm{mM}, p<0.001$ ). As shown in Table 2, intramuscular glutamine (GLN) concentration was increased in the TR rats $(p<0,05)$ and glutamate (GLU), phenylalanine (PHE) and branched chain amino acid (BCAA) concentrations were unchanged. Efflux of PHE and BCAA were increased in the TR rats (Table 3, p<0.05), while GLU influx and GLN efflux were unchanged.

Table 2. Intramuscular substrate concentrations in the gastrocnemius.

\begin{tabular}{|c|c|c|c|c|c|c|c|}
\hline & & $F F$ & PF & PW & & TR & \\
\hline \multirow[t]{2}{*}{ GLU } & $3 d$ & $448+33$ & $431 \pm 22$ & & & $354 \pm 43$ & \\
\hline & $44 d$ & $685 \pm 35$ & $700+70$ & $743 \pm 69$ & & $721 \pm 63$ & \\
\hline \multirow[t]{2}{*}{ GLN } & $3 d$ & $2113 \pm 78$ & $2188+92$ & & & $2517 \pm \| 53$ & $a$ \\
\hline & $14 d$ & $2414 \pm 51$ & $2517 \pm 99$ & $3143 \pm 99$ & $c$ & $2423 \pm 190$ & $h$ \\
\hline \multirow[t]{2}{*}{ PHE } & $3 d$ & $108 \pm 3$ & $99 \pm 8$ & & & $116 \pm 5$ & \\
\hline & $14 d$ & $68 \pm 7$ & $52 \pm 3$ & $54 \pm 3$ & & $42 \pm 3$ & $B \odot g$ \\
\hline \multirow[t]{2}{*}{$\mathrm{BCAA}$} & $3 d$ & $386 \pm 19$ & $430 \pm 29$ & & & $430 \pm 33$ & \\
\hline & $14 d$ & $349 \pm 18$ & $317 \pm 26$ & $321 \pm 21$ & & $251 \pm 12$ & $b d g$ \\
\hline
\end{tabular}

Values are mean \pm SEM. Concentrations are in $\mu$ mol/kg wet weight. GLU, glutamate; GLN, glutamine; PHE, phenylalanine; $B C A A$, branched chain amino acids (the sum of valine, leucine and isolevicine). a, $b, c, p<0.05, p<0.01, p<0.001$ vs FF; $d, \theta, p<0.05, p<0.01$ vs PF; $g, h, p<0.05, p<0.01$ vs PW.

Table 3. Hindquarter substrate nuxes

\begin{tabular}{|c|c|c|c|c|c|c|c|}
\hline & & $\mathrm{FF}$ & PF & PW & & TR & \\
\hline \multirow[t]{2}{*}{ Flow } & $3 d$ & $37 \pm 1.0$ & $2.7 \pm 0.9$ & & & $3.9 \pm 1.1$ & \\
\hline & $14 \mathrm{~d}$ & $3.1 \pm 0.5$ & $3.9 \pm 1.2$ & $3.0 \pm 0.9$ & & $4.0 \pm 0.8$ & \\
\hline \multirow[t]{2}{*}{ Glucose } & $3 \mathrm{~d}$ & $-479 \pm 969$ & $-2052 \pm 564$ & & & $-2993+2280$ & \\
\hline & $14 d$ & $-1638 \pm 1298$ & $-18 \pm 1446$ & $-1345+700$ & & $-6993 \pm 2085$ & a d \\
\hline \multirow[t]{2}{*}{ GLU } & $3 d$ & $-28 \pm 20$ & $-34: 20$ & & & $-16 \pm 8$ & \\
\hline & $14 \mathrm{~d}$ & $19 \pm 4$ & $-23 \pm 8$ & $-20 \pm 3$ & & $-85 \pm 18$ & $b e h$ \\
\hline \multirow[t]{2}{*}{ GLN } & $3 \mathrm{~d}$ & $151 \pm 44$ & $116 \pm 23$ & & & $127 \pm 48$ & \\
\hline & $14 d$ & $160 \pm 39$ & $204 \pm 53$ & $324 \pm 68$ & $a$ & $494 \pm 65$ & $\operatorname{cog}$ \\
\hline \multirow[t]{2}{*}{ PHE } & $3 \mathrm{~d}$ & $-4 \pm 3$ & $1 \pm 4$ & & & $14 \pm 6$ & a \\
\hline & $14 d$ & $5 \pm 4$ & $9 \pm 3$ & $14 \pm 3$ & & $19 \pm 2$ & $b d$ \\
\hline \multirow[t]{2}{*}{ BCAA } & $3 d$ & $-61 \pm 33$ & $-47 \pm 32$ & & & $27 \pm 24$ & $a$ \\
\hline & $14 \mathrm{~d}$ & $-72 \pm 13$ & $-59 \pm 21$ & $-71 \pm 11$ & & $-13 \pm 14$ & $a$ \\
\hline
\end{tabular}

Vaiues are mean $\$$ SEM. Flow in mU/100 $\mathrm{g}$ BW/min. Fluxes in nmol/100 $\mathrm{g}$ bady weight/min. BCAA is the sum of valine, loucine and isoleucine. $a, b, c, p<0.05, p<0.01, p<0.001$ vs $F F ; d, a, p<0.05, p<0.01$ vs PFi $g, h, p<0.05, p<0.01$ ws PW. 
Intramuscular and arterial concentrations and hindquarter fluxes after 2 weeks

Comparing the TR with the FF group, an increased arterial glucose concentration was observed in the TR rats (TR: $20 \pm 3 \mathrm{mM}, \mathrm{FF}: 12 \pm 1 \mathrm{mM}, \mathrm{p}<0,01)$. Arterial glucose of the PW and PF groups were unchanged (11 $1 \mathrm{mM}$ and $10 \pm 1 \mathrm{mM}$ resp.) and were therefore significantly lower than the TR group $(p<0.01)$. Intramuscular concentrations of PHE and BCAA were decreased in the TR rats (Table 2). The PW group showed an increased concentration of GLN in the gastrocnemius and GLN, PHE and BCAA concentrations in the gastrocnemius were significantly higher than in the TR group (Table 2). Intramuscular concentrations of PHE and BCAA were also higher in the PF rats than in the TR rats (Table 2). Glucose and GLU influx and PHE and GLN efflux were increased in the TR group (Table 3), while BCAA influx was decreased. The PW group showed an increased GLN efflux from the hindquarter (Table 3). Influx of glucose and GLU was higher in the TR group than in the PW group (Table 3), while influx of BCAA was lower. Efflux of GLN was also higher in the TR group than in the PW group. Influx of glucose and GLU and efflux of GLN and PHE were higher in the TR rats than in the PF rats (Table 3).

Table 4. Muscle membrane transport rates of giviamine.

\begin{tabular}{|c|c|c|c|c|c|c|c|c|}
\hline & & $\mathrm{FF}$ & PF & & PUN & & TR & \\
\hline \multirow[t]{2}{*}{$\mathrm{Fm}, \mathrm{a}$} & $3 d$ & $730 \pm 117$ & $593+79$ & & & & $728+145$ & \\
\hline & $14 d$ & $393=79$ & $818+219$ & & $628 \pm 75$ & $a$ & $1099+92$ & ch \\
\hline \multirow[t]{2}{*}{ Fv,m } & $3 d$ & $788 \pm 85$ & $683 \pm 99$ & & & & $822 \pm 143$ & \\
\hline & $14 d$ & $524 \pm 71$ & $1011 \pm 270$ & & $952 \pm 97$ & $b$ & $1616 \pm 166$ & $6 h$ \\
\hline $\mathbb{F v}, a$ & $\begin{array}{r}3 d \\
14 d\end{array}$ & $\begin{array}{l}1768 \pm 90 \\
1332 \pm 105\end{array}$ & $\begin{array}{l}1190 \pm 68 \\
1641 \pm 271\end{array}$ & $b$ & $1319+113$ & & $\begin{array}{l}2020 \div 239 \\
1184 \div 100\end{array}$ & $d$ \\
\hline
\end{tabular}

Values are mean \pm SEM. In nmol/100 g body weight/min; Fm, a plasma membrane rate from the arterial to the free amino acid muscle pool; FV, m, plasma membrane rate from the free amino acid muscle pool to the venous pool: $F v, a$, plasma membrane rate from the arterial to the venous pool; $3 d$, 3 days: $14 d, 14$ days, $a, b, c, p<0.05, p<0.01, p<0.001$ vs FF; $d^{\prime} p<0.05$ vs PF; $h, p<0.01$ vs PW.

Intracelfular gluttomine iurnover
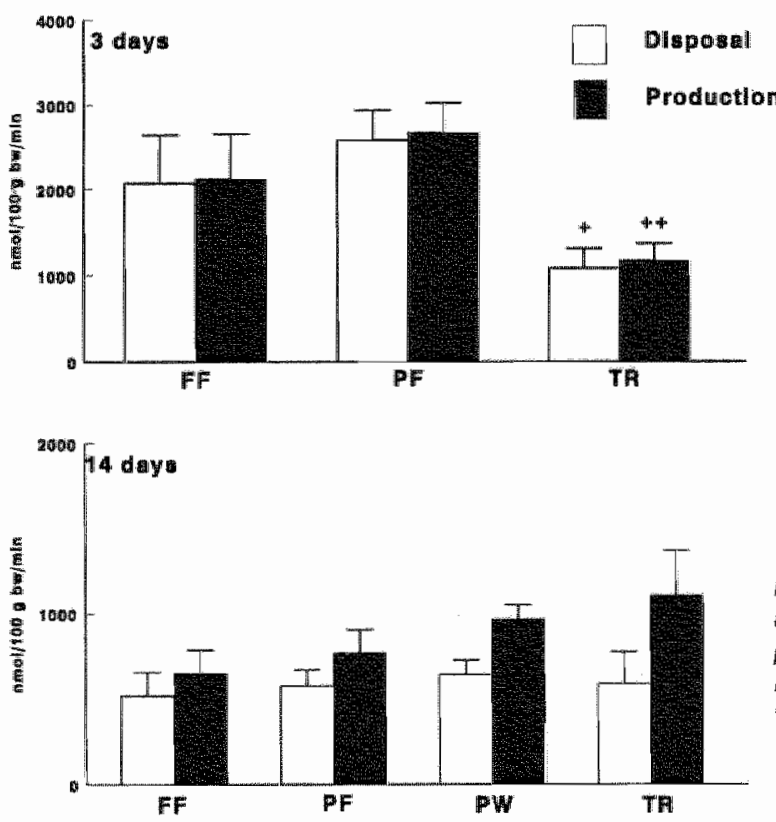

Flg. 2. Intracellwar glutarmine disposal and production from the fres amino acid pool in the musclo after 3 and 14 days. FF, fres fed; PF, pair fed; PW, pair weight; $T R$, triamcinolone treated, ,$+ p<0.05 ;+, p<0.01$ ws PF. 


\section{Glutamine turnover over the hindquarter}

Acute triamcinolone treatment resulted in no significant changes in glutamine turnover compared to the FF group, but glutamine shunting ( $F v$, a) was increased compared to the PF group (Table 4, p<0.05). Furthermore, both intracellular disposal and production of glutamine were decreased in the TR group compared to the PF group (Fig.2). After 2 weeks, membrane transport rates from the arterial to the intracellular free amino acid pool (Fm,a) and from the intracellular pool to the venous pool (Fv,m) were increased in TR compared to FF $(p<0.001)$.
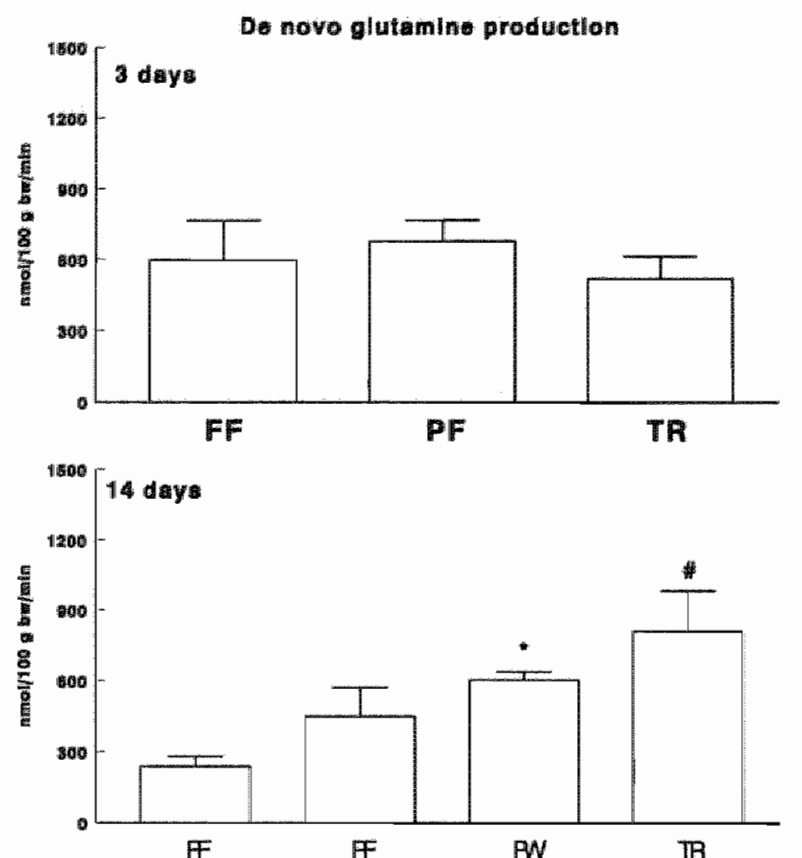

Fig. 3. De novo glutamine production in the hindquarter of the rat affer 3 and 14 days. FF froe fod; PF, pair fed; PW, pair weight; TR, thamcinolone treated; p<0.01; : $p<0.001$ vs FF.

Furthermore de novo glutamine production was increased (Fig.3, $p<0.01$ ). After 2 weeks, the PW group showed both an increased $\mathrm{Fm}, \mathrm{a}$ and $\mathrm{Fv}, \mathrm{m}$ and also an increased glutamine de novo production. The increases in $\mathrm{Fm}$, a and $\mathrm{Fv}, \mathrm{m}$ were significantly higher in the TR group than in the PW group $(p<0.01)$.

\subsection{Discussion}

In contrast to undernutrition, the present study indicates that acute triamcinolone treatment caused hyperglycaemia and an increased intramuscular glutamine concentration associated with an increased glutamine shunting in the muscle and decreased glutamine disposal and production. Chronic triamcinolone treatment on the other hand showed similar alterations in muscle glutamine metabolism as undernutrition (PW), like an increased glutamine de novo production, an increased glutamine efflux and increased glutamine membrane transport rates into and from the free amino acid pool in the muscle. These alterations were nevertheless more pronounced in the TR group, as reflected in a higher reduction in muscle mass relative to the body mass reduction. Glutamate is a likely precursor for de novo glutamine production induced by $T R_{n}$ but after undernutrition precursors of glutamine production are not clear. 
The effects of triamcinolone treatment on muscle glutamine metabolism were compared with those of undernutrition after 3 days treatment, since triamcinolone treatment caused after 3 days the most dramatic decrease in food intake (22). In the present study, this resulted only in the triamcinolone group in a decreased body weight and muscle mass, which probably was the result of an increased muscle protein degradation, as indicated by the increased phenylalanine efflux. Otherwise, data of the pair fed grcup showed that after this short period of time undernutrition per se did not result in a significantly decreased body weight or muscle mass, and revealed unchanged net protein degradation of the hindquarter muscles.

Three days triamcinolone treatment caused an intramuscular increase of glutamine concentration despite unaltered fluxes. This is in contrast to the majority of earlier reports, in which intramuscular glutamine concentrations were found to be decreased after approximately 1 wreek of treatment with corticosteroids $(9,23-25)$ or unchanged after 3 days treatment in old rats (25). Otherwise, two days hydrocortisone acetate has also showin to cause an increased intramuscular glutamine concentration in the diaphragm (26). Glutamine efflux from the muscle was consistently found to be increased after 1 to 2 weeks treatment with corticosteroids $(9,23,27)$, while in the present study glutamine efflux was not altered after 3 days triamcinolone treatment. In general, an increased muscle glutamine concentration could be caused by an increased de novo glutamine production (induction of glutamine synthase), by an increased net muscle protein degradation, or by both. The tracer data in the present study showed acutely no de novo glutamine production; increased muscle protein degradation on the opposite seems more likely in line with the increased phenylalanine efflux. A recent study of Minet-Quinard and colleagues has demonstrated that glutamine synthase activity was increased in the extensor digitorum longus (EDL) after 3 days dexamethasone treatment, but in the gastrocnemius this increase was only shown after 5 days dexamethasone treatment (25). Therefore, the differences in glutamine metabolism of the present study with earlier studies could be due to different muscles studied and different treatment periods.

A short period of food restriction in the present study had no significant effect on glutamine concentration or efflux from the muscle. Earlier reports showed decreased intramuscular glutamine levels in the gastrocnemius (28) and increased intramuscular glutamine levels in the diaphragm and EDL (26) or in the gastrocnemius (14) after starvation. However, in the present study, food intake of the PF rats was not totaly reduced to zero as in these earlier studies. Therefore, these PF rats should be compared with semistarved rats. Seven days of undernutrition showed an unchanged glutamine efflux from the hindquarter and an increased gilutamine concentration in the gastrocnemius (29). Remarkably, the changes in glutamine shunting over the hindquarter in the pair fed group were opposite to those of the TR group, possibly related to an expected adaptive decreased metabolism during undernutrition.

The observed initial decrease in daily food intake in the TR group was restored completely after 2 weeks, while energy intake per gram body weight was even increased compared to the free fed group. This phenomenon and the changes in body mass indicates that the TR group was still hypermetabolic after 2 weeks. After 2 weeks, the pair fed group was not catabolic, since energy intake per gram body weight was not decreased and body weight was increasing. This implies that the PW group was the only nutritionally deprived group after 2 weeks, resulting in a similar body weight reduction as the TR group. However, the comparison between the TR and the PW group is also somewhat limited since muscle mass reduction was not comparable due to the fact that muscle wasting relative to body wasting was more pronounced in the TR group.

Chronic triamcinolone treatment did not alter intramuscular glutamine concentration in the gastrocnemius. As mentioned above, earlier animal studies have found decreased intramuscular glutamine concentrations after 3-9 days treatment with corticosteroids. However, in patients, chronically treated with corticosteroids, increased intramuscular glutamine levels were reported. It is very difficult to compare several studies, because of the 
different corticosteroids used, the different treatment periods, the different muscles studied and the different ages of the animals, which are also important to consider (25).

In the present study, an increased muscle glutamine efflux was showm, in line with earlier studies after nine or eight days treatment with dexamethasone $(9,23)$. The increased glutamate influx of the present study implies that glutamate could be the precursor for this glutamine production. This is confirmed by the observed increased de novo glutamine production. Earlier studies have indeed demonstrated an increased glutamine synthase mRNA expression and activity after corticosteroid treatment $(12,25,30)$. Undernutrition also showed an increased muscle glutamine efflux, which was earlier reported after 4 days starvation (14). Interestingly, undernutrition showed also an increased de novo production, but here the precursors for glutamine are not clear. It has been demonstrated earlier that starvation could increase the maximum activity of glutamine synthase in muscle (31)or in the lung (11), which is in line with the observed increased de novo glutamine production in the present study. Despite striking similarities in muscle glutamine metabolism, the remaining amino acids (glutamate, phenylalanine and branched chain amino acids) and other substrates showed a clearly different response. After TR treatment an increased muscle influx of glucose and glutamate and effux of phenylalanine was found while undernutrition did not induce any of these changes. This discrepancy between the two treatment groups is in line with an earlier study, where glycolytic and oxidative muscle enzyme capacities were found to be increased in the peripheral skeletal muscle of rats treated with triamcinolone. while undernourished rats did not show any of these alterations (22).

It is important to consider the similar effects of triamcinolone treatment and severe undernutrition (PW) on muscle glutamine metabolism. It is possible that both treatments could enhance these effects on glutamine metabolism. Therefore, it is important to prevent undernutrition in patients chronically treated with corticosteroids. The present experimental rat model could be an interesting model to discriminate between the acute and chronic effects of glutamine suppletion on corticosteroid treatment and to investigate the reversibility of the effects of metabolic stress relative to undernutrition on glutamine metabolism. This may provide new perspective to the treatment of cachexia associated with chronic corticosteroid dependent disorders.

\section{Acknowledgements}

The authors wish to thamk Mrs GAM Ten Have for biotechnical assistance and Mr HMH van Eijk and Mr DR Rooyakkers for analytical help.

\section{References}

1. Horber FF, Zurcher RM "Herren H, Crivelli MA, Roboti G. Frey FJ. Altered body fat distribution in pationts with glucocorticoid troatment and in patients on long-torm dialysis. Am J Clin Nutr $1986 ; 43: 758-769$

2. Decremer M. Stas $\mathrm{KJ}$. Corticosteroid-induced myopathy involving respiratory musches in patients with chronic obstructive pulmonary disease or asthma. Am Rev Respir Dis 1902;146:800-802.

3. Mak VHF, Buglar JR, Spiro SG. Sternomastoid muscle fatigue and twitch maximum relaxation rate in pattents with steroid dependent asthina. Thorax 1993,48:979-984t.

4. Morrison WL, Gibson JNA, Scrimgeour $C$, Rennie M. Muscle wasting in emphysema. Clin Sci $1988: 75: 415-420$.

5. Pouw EM, Schols AM, Deulz NE. Wouters EF. Plasma and muscle amino acid levels in relation to resting energy expenditure and inflammation in stable chronic obstructiwe pulmonary disease. Am J Respir Crit Care Med 1998; 158:797-801.

6. Engelen MPKJ, Schols AMW., Does JD, Deutz NEP, Woulers EFM. Altered glutamate metabolism is associated with reduced muscle glutathion levels in patients with emphysema. Am $₫$ Respir Crit Care Med 1999 ; in press.

7. Max SR, Mill J. Mearow K, ef al. Dexamethasone regulates glutamine symthetase expression in rat skeletal muscles. Am J Physiol 1988;255:E397-E403. 
8. Legaspi $A$, Roberts J. Abert J, Tracey $K$, Shires $G$, Lowry 5 . The effect of starvation mnd lotal parenteral nutrition on skeletal muscle amino acid content and membrane potarial difference in normal man. Surg Gyn Obst 1988:166:233-240.

9. Hundal HS, Babij P. Taylor PM, Wat PW, Rennie M.l. Effects of cortlcosteroid on the transport and metabolism of glutamine in rat skeletal muscle. Biochim Blophys Acta 1991;1092:376-383.

10. Austgen $\mathbb{T}$, Chakrabarti $\mathbb{R}_{\mathrm{s}}$ Chen $M$. Souba $W$. Adaptive regulation in skeletal muscle glutamine rnetabolism in endotoxin-treated rats. I Trauma 1992;32;600 6.

41. Ardawi MSM. Glutamine-synthesizing activity in lungs of fed, starved, acidotic, diabetic, injured and septic rats. Biochem J 1990;270:829-832.

12. Max SR. Glucocorticoid-mediated nduction of glutamine synthetase in skeletal muscie. Med Sci Sports Exerc 1990;22:325-330.

13. Bayne K. Revised Guide for the Care and Use of Laboratory Animals available. American Physiological Society. Physiologist 1996,39:208-11.

14. de Blaauw I, Deutz NE, von Meyenfeld MF. Muscle protein and amino acid tumover in rats in wiw: effects of short-term and prolonged starvation. Clin Sci Colch 1996:90:457-66.

15. Dejong $\mathrm{CH}$, Deutz NE, Soeters PB. Renal ammonia and gutamine metabolism during liver insufficiency-induced hyperammonemia in the rat. J Clin Invest $1993 ; 92 ; 2834-40$.

16. Heeneman $S$, Deutz $N$. Effects of decreased glutamine supply on gut and liver metabolism in vivo in rats. Clin Sci 1993;85:437-444.

17. van Eijk HM, Rooyakkers DR, Wagenmakers Ad, Soeters PB. Deutz NE. Isolation and quantitation of isotopically labeled amino acids from biological samples. J Chromatogr B Biomed Scl Appl 1997;691:287-96.

18. de Blaauw I, Heeneman S, Deutz NEP, von Meyenfeld MF. Increased whole body protein and glutamine turnover in advanced cancer is not matched with increased muscle protein and glutamine turnower. Am J Physiol 1996.

19. Biolo $G$, Chinkes $D$, Zhang $X$, Wolfe RR. A new model to determine in vivo the relationship between amino acid transmembrane transport and protein kinetics in muscle. J $P E N$ $1992 ; 16: 305-315$

20. Thompson GN, Pacy PJ, Merritt H, et al. Rapid measurement of whole body and forearm protein turnover using a [2H5]phenylalanine model. Amm J Physiol 1989;256:E631-E639.

21. Kominz DR, Hough $A$, Laki $K$. The amino acid composition of actiri, myosim, tropomyosin and the meromyosins. Arch Biochem Biophys 1954;50:148-159.

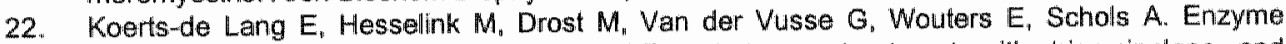
activity of rat tibialis anterior muscle differs between treatment with triamcinolone and prednisolone and nultritional depriwation. Eur J Appl Physiol 1999:79:274-279.

23. Ardawi MSM, Jamal YS. Glutamine metabolism in skeletal muscle of glucocorticoid-treated rats. Clin Sci 1990;79:139-147.

24. Hickson RC, Czerwinski SM, Wegryn LE. Gutamine prevents downregulation of myosin heavy chain synthesis and muscle atrophy from glucocortlcoilds. Am J Physlol 1995:268: $\mathrm{E} 730 \times 734$.

25. Minet Qunard $\mathbb{R}$, Moinard $C$, Vilie $F$, all. Kinetic irnpainment of nutrogen and muscle glutamine metabolisms in old glucocorticoid-treated rats. American Joumal Of Physiology Endocrinology And Metabolism. Mair 1999,39:E558-E564.

26. Tischler ME, Henriksen Eע, Cook PH. Role of glucoconticolds in increased muscle glutamine production in staryation. Muscle \& Nerve 1988; 1 1,752-756.

27. Muhbacher F, Kapadia CJ. Colpoys MF, Smith R., Wilmore DW. Effects of glucocorticoids on glutamine metabolism in skeletal muscle. Am J Physiol 1984,247 E75 E83.

28. Millward DJ, Jepson MM. Omer A. Muscle glutamine concentration and proten tumover in vivo in malnutrition and in endotoxemia. Metabolism 1989;38(5):6-13.

29. Dejong $\mathrm{CH}_{\text {, Deutz NE }}$ Soeters PB. Musche ammonia and glutamine exchange duning chronic liver insufficiency in the rat. J Hepatol 1994;21:299-307.

30. Abcouwer SF, Bode BP, Souba WW. Gluicocorticoids regulate rat glutamine synthetase expression in a tissue-specific manner. J Surg Res 1995;59:59-65.

31. King P, Goldstein L, Newshome E. Glutamine synthetase activity of muscle in acidosis. Biochem J 198; $3 ; 216: 523-525$. 



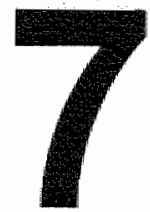

\title{
$\alpha$ and $\beta$ Glucocorticoid receptor mRNA expression in skeletal muscle.
}

\author{
SH Korn, E Koerts-de Lang, GEJ Engel" "JWW Arends", \\ EFM Wouters, FBJM Thunnissen!.
}

Joumal of Muscle Research and Cell Motility 19: 757-765 (1998)

Department of Pulmonology and "Pathology, Maastricht University"

The Netherlandis.

This sludy was supported in part by ASTRA Pharmaceutica, the Netherlands. 


\begin{abstract}
The aim of the preserit study was to inwestigate the occurrence and autoregulation of both glucocorticoild receptor mRNAs in rat gastrocremis muscle. The expression of both receptor forms was studied at 1,4 or 12 hours after inlra-tracheal instiflation of a high dose (100 $\mathrm{\mu g}$ ) of budesonide; muscular expression was compared with glucocorticoid receptor expression in lung tissue. After Northem blot analysils, hybridtation was performed with glucocorticoid receptor. glyceraldethyde-3-phosphate dehydrogenase and glutamine synthetase probes. In the gastrocnemius muscle, both the and $\beta$ glucocorticoid receptor mRMA forms were detected and found to be downiregulated four hours after the budesonide instillation. afp glucocorticoid receptor ratios were lower in the gastrocnemus (1.4 10.2$)$ than in the lungs (2.6 0.6$)$. In the lungs, all all the points, the average o gucocorticoid receptor mRMA levels did not differ from contro/s, although glutamine synthetase MRNA levels were upregulated. The $\beta$ glucocorticold receptor mRNA was slightly reduced at 1 and 4 hours. In conclusion. after intra-tracheal instilation of budesonide, both $\alpha$ and $\beta$ glucocorticoid receptor forms were downregulated in muscle tissue. The difference in $\alpha / \beta$ glucocorticoid receptor mRNA ratios and concentrations between lung and gastrocnemius muscle supports the hypothesis of differential gene regulation by glucocorticoids in different cell types.
\end{abstract}

\title{
7.1. Introduction
}

The use of glucocorticoids, the mainstay of treatment in a wide variety of chronic inflammatory diseases, can have severe systemic side-effects, although the severity and frequency are reduced when glucocorticoids are applied topically (Barnes, 1995; Hanania et al., 1995; Kamada et al. , 1996). One of the reported side-effects that may occur after glucocorticoid use is skeletal muscle atrophy (Khaleeli et al., 1983; Seene, 1994). The fasttwitch muscles in particular are sensitive to the catabolic action of glucocorticoids (Kelly et al. 1986; Picado et al., 1990; Burtea et al., 4992). A centrall role in the action of glucocorticoids is played by the glucocorticoid receptor (GR), and GR levels have been investigated in slow and fast-twitch skeletal muscles. Higher concentrations of GR have been demonstrated in the slow twitch muscles (Almon \& Dubois, 1990; Dubois \& Almon, 1984; Saartok, 1984; Sauerwein et al. 1991). Therefore, a higher response to glucocorticoids may be expected in slow-twitch muscles, but in contrast, fast-twitch muscles are affected to a greater extent by glucocorticolds. At present, no studies have been performed regarding the response of the GR after exposure to glucocorticoids in fast-twitch skeletal muscles like the gastrocnemius.

The GR is present in the cytoplasm of cells as an inactive protein bound to a complex of different heat shock proteins (Pratt et al., 1992). After binding of the ligand, the receptor becomes activated by dissociation of the heat shock proteins. By binding as a dimer to glucocofticoid responsive elements (GRE) in the DNA, the GR regulates the transcription of genes. The activated GR can also modulate gene transcription by binding to other transcription factors, such as activator protein-1 (AP-1) (Yang-Yen et al., 1990), nuclear factor $\mathrm{kB}$ (NFkB) (Brostjan et al., 1996), cAMP-responsive element binding protein (CREB) (Peters et al., 1995) and signal transducer and activator of transcription 5 (Stat5) (Stocklin et al. 1996). Glucocorticoid hormone receptors contain a ligand binding $\mathrm{C}$-terminal end, a central DNA binding domain, and a transactivating $N$-terminal end. Owing to alternative splicing. two functionally distinct receptors $\alpha$ and $\beta$ are formed, differing at their carboxyterminal end (Hollenberg et al., 1985). The presence of both GR mRNAs has been demonstrated in humans in several tissues (Bamberger et al., 1995; Oakley et al., 1996), but 
on a protein levell no clear separation between the $\alpha$ and $\beta$ form has been made. Recently an antibody recognizing the $\alpha$ form has become commercially avallable; however, this has not yet been the case for the $\beta$ GR (Lee et al., 1996). In a recent study by Oakley and colleagues (Oakley et al., 1996), three GR mRNA isoforms were described. With Northern blot analysis, an a 1 of $7 \mathrm{~kb}$, an $\alpha 2$ of $5.5 \mathrm{~kb}$, and a $\beta$ GR MRNA form of $4.3 \mathrm{~kb}$ was demonstrated. Translation of the $\alpha_{1}$ and $\alpha 2$ forms results in the same protein, which has ligand-binding capacity. In contrast, the $\beta$ GR has no steroid-binding domain and is

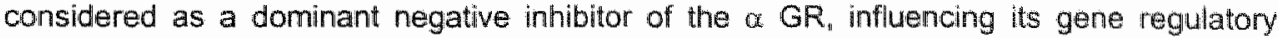
function after activation by glucocorticoids (Bamberger et al "1995; Oakley et al., 1996). In view of this inhibitory function it is of interest to study $\beta$ GR form, its relationship to the o GR form and transcriptional regulation by different modulators.

Because of the direct correlation between glucocorticoid receptor number and cellular responsiveness to glucocorticoids (Pui et al., 1984; lida et al., 1985; Vanderbilt et al., 1987) and because of the inhibitory effect of the $\beta \mathrm{GR}$ on the $\alpha \mathrm{GR}$, it is important to understand thoroughly the mechanisms responsible for maintaining $\alpha$ and $\beta$ receptor levels and ratios. Several studies (Dong et al., 1988; Kalinyak et al., 1989; Silva et al. 1994; Sweezey et al., 1995; Meyer \& Schmidt, 1994; Knutsson et al., 1995; Schlecte et al., 1982) have shown that the $\alpha \mathrm{GR}$ is downiregulated after exposure to glucocorticosteroids. Thus far, little information is available on the autoregulation of the $\beta$ form. In a recent study (Korn el al., 1997) we demonstrated a downregulation of the $\beta$ GR mRNA after exposure to budesonide in human bronchial epithelial cells and alveolar macrophages. In rats, no information is available about the existence of the $\beta$ GR in skeletal muscles. Also no information is available about the regulation of $\alpha$ and $\beta$ GR forms by glucocorticoids.

The aim of this study was to investigate the presence of both $\alpha$ and $\beta$ GR mRNAs and their autoregulation by budesonide in rat skeletal muscle (gastrocnemius). Also, $\alpha / \beta$ GR ImRNA ratios were determined. Because of the known effects of glucocorticoids on the GR mRNA levels in the lung, this tissue served as a positive control. Furthermore, glutamine synthetase, upregulated by glucocorticoids, was investigated as a positive control.

\subsection{Methods}

\section{Animals and tissues}

Sixty-five male Wistar rats weighing 200-250 g (Harlan-Winkelmann, Borchen, Germany) were anaesthetised by subcutaneous injection of $0.2 \mathrm{ml}$ of $100 \mathrm{mg}$ per mi ketamin (Nimattek, AUV Cuijk, the Netherlands) and $0.2 \mathrm{ml}$ of 5 times diluted $23 \mathrm{mg}$ per ml Sedamun (AUV Cuijk, the Netherlands) in the neck. Five animals were used to optimise the instillation technique by aerosolation of black ink. The other 60 rats mere included in the study. After intubation the animals were ventilated mechanically with $\mathrm{O}_{2}$ and $\mathrm{N}_{2} \mathrm{O}$ at a frequency of 40 breaths per minute. Under visual inspection the tube ending was localised a few millimetres above the carina. Owing to the increasing use of local application of glucocorticoids in chronic inflammatory airway diseases, intra-tracheal exposure to glucocorticoids was chosen. To this end, a small tube was inserted within the ventilation tube, through which the budesonide solution was administered. $10 \mathrm{mg}$ Budesonide was dissolved in $250 \mu 1$ of $70 \%$ alcohol and diluted in $50 \mathrm{ml}$ phosphate buffered saline (PBS) to a final concentration of 200 $\mu \mathrm{g}$ per $\mathrm{ml}$. Either $0.5 \mathrm{ml}$ budesonide solution or $0.5 \mathrm{ml}$ dilutant (control) was injected in aliquots of $50 \mu$, administered during the inspiratory phase. Since the animals were similar in weight, the budesonide dosage was equal in all rats: $100 \mu \mathrm{g}$ of budesonide intra-tracheally $(400 \mathrm{\mu g} / \mathrm{kg})$. Animals regained consciousness and were sacrificed 1, 4, or $12 \mathrm{~h}$ later with 1.5 $\mathrm{ml} 60 \mathrm{mg} / \mathrm{ml}$ pentobarbital administered intraperitoneally. The right gastrocnemius muscle and both lungs of each animal were sampled. The gastrocnemius muscle was put into $4 \mathrm{ml} 4$ $M$ guanidinium isothiocyanate (GTC) and frozen immediately to $-70^{\circ} \mathrm{C}$ withoul homogenisation. The lungs were embedded in tissue-tek (Miles Imc., Elkhart, IN, USA) and 
immediately frozen in liquid nitrogen. The whole animal experiment was performed in two days, and control and budesonide exposed animals were handled simultaneously (10 per group).

\section{Histology}

From the frozen lung specimens $6 \mu M$ sections were cut and mounted on gelatinechromium(III)-potassium sulfate coated slides. Sections were stained with hematoxylineosin. Morphologic examination on sections from right and left lung was performed to investigate possible traumatic or inflammatory changes in all animals.

\section{RNA*isolation}

For part of the samples the method of total RNA extraction was similar as described before (Korn et al., 1997). In brief; tissues were homogenized in GTC, and after CsCluitracentrifugation total RNA was recovered. The second, faster approach was based on the method described by Chomczynski et al. (Chomczynski \& Sacchi, 1987), using an RNA isolation kit, TRIzol Reagent (Life Technologies, Breda, the Netherlands). Tissue samples were homogenized in $1 \mathrm{ml}$ TRlzol Reagent per $100 \mathrm{mg}$ tissue. After adding $0.2 \mathrm{ml}$ chloroform, the tubes were vigorously shaken, incubated at room temperature for 3 minutes and centrifuged at $4{ }^{\circ} \mathrm{C}$ and $12,000 \mathrm{~g}$ for 15 minutes. The aqueous phase was mixed with $0.5 \mathrm{ml}$ 2-propanol per $1 \mathrm{ml}$ TRlzol and RNA was recovered by centrifugation at $12,000 \mathrm{~g}$ and $4{ }^{\circ} \mathrm{C}$ for 10 minutes. The pellet was washed with $75 \%$ ethanol and recovered again by centrifugation for 5 minutes at $7,500 \mathrm{~g}$ and $4{ }^{\circ} \mathrm{C}$. This wash step was repeated once. RNA pellets were dissolved in $10 \mu \mathrm{l}$ distilled water. Total RNA concentration was determined visually, by comparison to RNA samples with known concentrations on a $1 \%$ agarose gel.

\section{Northern blot analysis}

Northern blot analysis was performed as described before (Korn et al., 1997) with slight modifications. Total RNA $(20 \mu \mathrm{g})$ was dissolved in sample buffer (1.3xMOPS, $0.5 \mathrm{M}$ formaldehyde ( $\mathrm{pH} \mathrm{6.5)}$ and $16.3 \mathrm{M}$ formamide) and fractionated by electrophoresis on an $1.2 \%$ agarose gel $(1.2 \mathrm{mg} / \mathrm{ml}$ agarose in $1 \times M O P S$ and $1 \mathrm{M}$ formaldehyde $(\mathrm{pH} 6.5)$ with a $1 \times$ MOPS running buffer) at $110 \mathrm{~V}$ at room temperature for $2 \mathrm{~h}$ The gel was rinsed $3^{\prime} 15$ minutes in RNAse free water, colored with ethidium bromide, washed in RNAse free water 3.15 minutes in RNAse free water, 20 minutes in $0.05 \mathrm{M} \mathrm{NaOH}$, rinsed shortly in water and finally washed 30 minutes in $1 \mathrm{M}$ ammonium acetate. The RNA was transferred onto a Nytran membrane (Schleicher and Schuell, Dassel, Germany) by overnight (17 h) capillary blotting with $1 \mathrm{M}$ ammonium acetate. After blotting the RNA was fixed to the membrane by UV-crosslinking and $1 \mathrm{~h}$ baking at $80^{\circ} \mathrm{C}$. Since a maximum of 14 samples could be loaded onto the gel, the 20 animals used for each time point had to be separated over 2 geis. 10 Samples/gel were loaded, 5 budesonide exposed animals and their simultaneously handled controls. All 6 gels necessary for this experiment were poured from the same agarose stock, loaded and run at the same time.

\section{Hybridization}

Northern blots were hybridized simultaneously with the rat GR, human glyceraldehyde-3phosphate delnydrogenase and rat glutamine synthetase (a generous gift from Prof. Dr. W.H. Lamers, AMC. Amsterdam, the Netherlands) probes in similar order as described before (Korn et al., 1997). Since glutamine synthetase is upregulated by glucocorticoids (Feng et al., 1990; Abcouwer et al., 1995), this probe (2800 bp) was used as a positive control. The GR probe was 2800 bp long and detected both $\alpha$ and $\beta$ GR forms (Ko \& Takano "1989). The glyceraldehyde-3-phosphate dehydrogenase (GAPDH) probe was $1007 \mathrm{bp}$ long. The probes were labelled with the random primed labelling method using [a- ${ }^{32}$ P]-dCTP (Amersham, Buckinghamshire, England). All 6 Northern blots were hybridized simultaneously at $65^{\circ} \mathrm{C}$ in $0.5 \mathrm{M}$ phosphate, $1 \mathrm{mM}$ EDTA, $70 \mathrm{mg} / \mathrm{ml}$ SDS and $5 \mathrm{mg} / \mathrm{ml}$ BSA at the same probe specific 
activities. The blots were washed at room temperature with $2 \times S S C, 3.5 \mathrm{mM}$ SOS and $0.5 \times$ SSC $_{3} 3.5 \mathrm{mM} \mathrm{SDS}$ and at $65^{\circ} \mathrm{C}$ with $0.1 \times S S C, 3.5 \mathrm{mM}$ SDS for 15 minutes each. The sample signals were analysed visually as well as semiquantitatively with a phosphorimaging system (Molecular Dynamics, Sunnyvale, CA, USA). GR and glutamine synthetase mRNA expression levels were determined relative to the control gene GAPDH to correct for the amounts of total RNA loaded onto the gel. These relative expression levels were compared to the relative expression levels of the control animals $(100 \%)$ receiving only dilutant, resulting in 10 outcomes per timepoint. So the percentages were the result of the comparison of 1 exposed animal with the mean expression of the control animals.

\section{Statistics}

For all studies mean \pm standard deviation (SD) was calculated and the Mann-Whitney U test performed. A difference of $p<0.05$ was considered statistically significant.

\subsection{Results}

\section{Aerosol instillation and lung morphology}

In a pilot study (5 rats), optimisation of glucocorticoid distribution was carried out by aerosoling black ink into the lungs. By staining $6 \mu \mathrm{M}$ sections of frozen lung specimens, the distribution of the ink was visualised and shown to be present throughout lungs, until into the alveoli. With morphologic examination of the treated and control rats no signs of bleeding or inflammation were found in the lungs. During the experiment 2 rats died after being anaesthetised, one in the budesonide exposed group (12 h), and one in the control group (1 h). which reduced the total number from 60 to 58 .

\section{Northern blot hybridization}

The GR mRNA expression levels in the gastrocnemius were 5-8 times lower than in the lungs. Therefore, GR mRNA signals from the gastrocnemius of 17 rats, evenly distributed over the treated and control animals, were too weak for a reliable quantification. Only the $\alpha 1$ and $\beta$ GR mRNA bands were observed. No $\alpha 2$ band was demonstrated in the lung or gastrocnemius muscle.

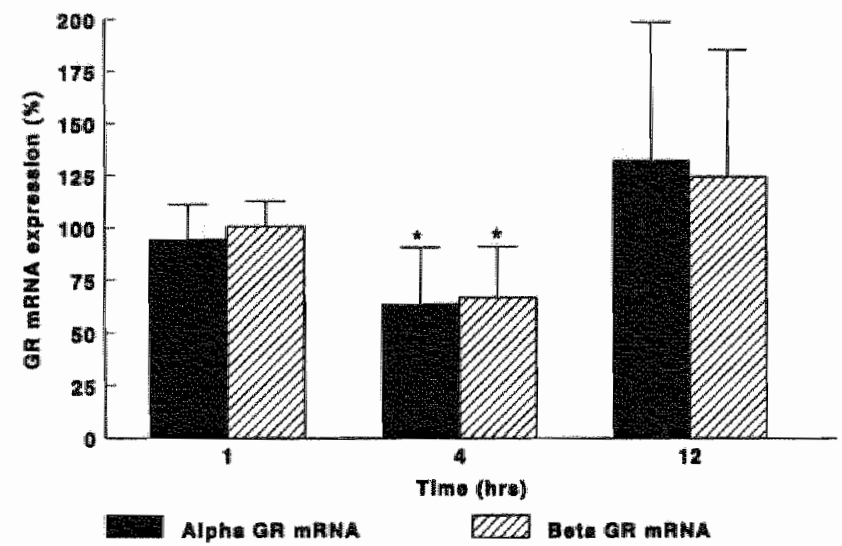

Fig. 1. GR mRNA expression in rat gastrocnemius after intratracheal instillation of budesonida. After four hours a downregulation was obsenved for both $\alpha$ and $\beta$ GR MRNAs. The IRNA levels ano oxprossad relatively to GAPDH whin the same sample and subsequently calculated to the mean of the control values within one gel, set at 100\%. significandy different from control vahues. 


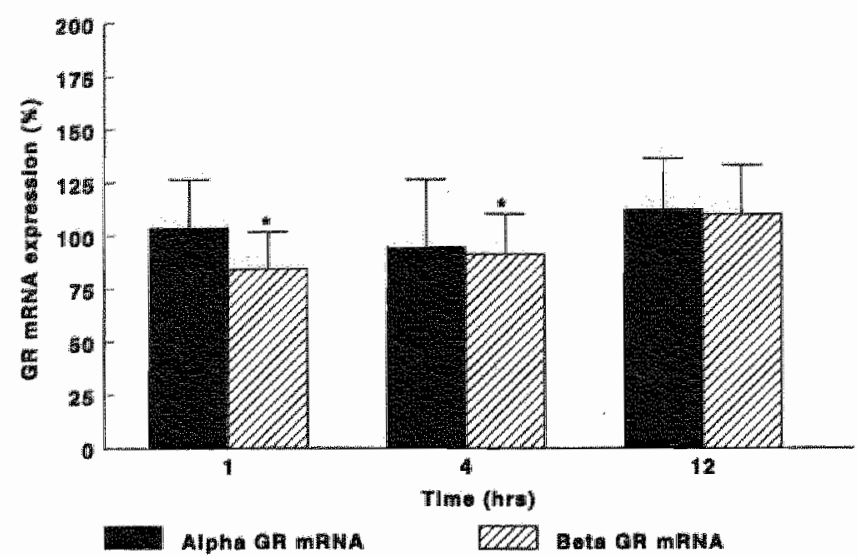

Fig. 2. GR mRNA expression in rat lung after intra-tracheal instillation of budesonide. Rats were sacrificed after 1,4 , and 12 hours. Quantification of a and $\beta$ GR MRNAs is described in Fig. 1. "Significantly different from control values.

The GR mRNA expression in the gastrocnemils showed a clear downregulation $(p<0.05)$ of both $\alpha 1$ and $\beta$ GR types 4 hours after the addition of budesonide, to $64 \%$ and $67 \%$, respectively (figure 1). Within the first hour no change in $\alpha 1$ and $\beta$ GR mRNA expression took place (95\% and $101 \%$, respectively). After $12 \mathrm{~h}$ the gene expression no longer differed from the control animals. The mRNA expression for the $\alpha .1$ GR was $133 \pm 66 \%(p=0.9)$ and for the $\beta$ GR $125 \pm 61 \%(p=0.9)$. In the lungs no difference in $\alpha 1$ GR gene expression was observed after 1,4 or 12 hours (figure 2). The average $\alpha 1$ GR mRNA levels at 1, 4, and 12 hours were $104 \%, 95 \%$ and $113 \%$, respectively. For the $\beta$ GR mRNA a slight downregulation was observed at 1 and $4 \mathrm{~h}$ to $84 \%$ and $91 \%$, respectively. At $12 \mathrm{~h}$ no change was seen compared to the control $(110 \%)$.

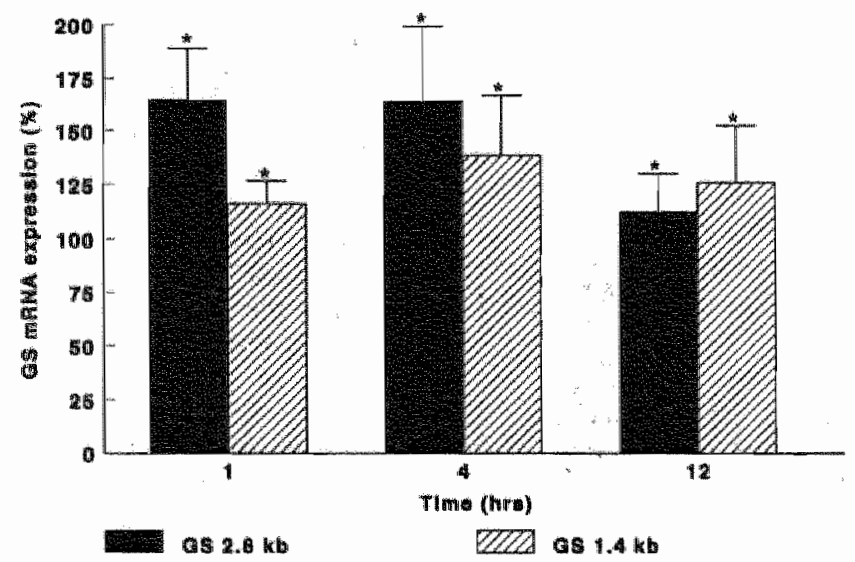

Fig. 3. Glutamine synthetase (GS) mRNA expression in the rat lung. Both glutamine synthetase forms are displayed relatively to the GAPDH-value. At all times an upregulated expression is observed. Calculation of the MRNA expression in percentages is performed as described in Fig. 1. "Significantly different from control values. 


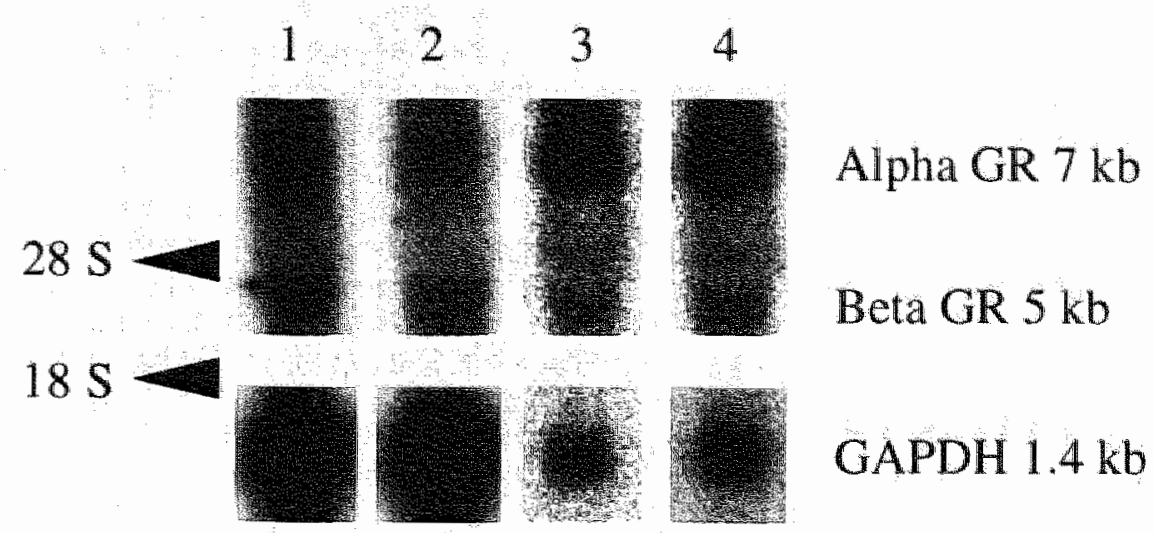

Fig. 4. Northern blot analysis of the GR mRNA from rat lung and gastrocnemius. Both $\alpha$ and $\beta G R$ are shown. The positions of the $\alpha$ and $\beta$ GR mRNA bands are determined by the 285 and $18 S$ ribosomal bands. Lanes 1 and 2 represent RNA from the gastrocnemius, while lanes 3 and 4 represent RNA from the lungs. In lanes $y$ and 3 a control animal is shown, four hours after instillation. Lanes 2 and 4 represent an exposed animal after four hours. Note the GR MRNA downregulation in lane 2 compared with lane 1 , and the cleer difference in $\alpha / \beta$ GR mRNA ratio between the lung and gastrocnemius.

To demonstrate the pharmacological activity of budesonide in the lung. glutamine synthetase mRNA expression was studied as a control gene. The effect of budesonide on the glutamine synthetase gene expression in the lungs is shown in figure 3. Both glutamine synthetase mRNA forms were at all time points upregulated by budesonide. The $2.8 \mathrm{~kb} \mathrm{mRNA}$ expression was upregulated to $165 \%, 164 \%$, and $112 \%$ at 1,4 , and $12 \mathrm{~h}$, respectively $(p<0.05)$. The $1.4 \mathrm{~kb}$ form was also significantly $(p<0.05)$ upregulated at $1(116 \%), 4(138 \%)$, and $12(126 \%) h$, but to a lesser degree.

A difference in $\alpha 1 / \beta$ GR ratio was observed between the gastrocnemius and llungs, resulting in a lower ratio in the muscle $(1.1 \pm 0.2)$, compared to a ratio of $2.6 \pm 0.6$ in the lungs $(\rho<0.05)$. In figure 4 an example is shown of a northern blot hybridization with the GR probe. In addition, lower $\alpha 1$ and $\beta$ GR mRNA levels are detected in the gastrocnemius muscle compared to the lungs. For the $\alpha$ GR ImRNA, the amount in the gastrocnemius muscle is $12 \%$ of that in the lungs. For the $\beta$ GR mRNA the expression is slightly higher, namely $20 \%$ of that in the lungs.

\subsection{Discussion}

The purpose of this study was to investigate the occurrence and regulation of the $\alpha$ and $\beta$ GR mRNA levels in gastrocnemius muscle in comparison with lung tissue of rats. In both tissues the $\alpha 1$ and $\beta$ GR mRNAs were present. Concerning the $\alpha 1 / \beta$ GR mRNA ratio, a lower ratio was observed in the gastrocnemius muscle compared with the llung. The gastrocnemius showed a reversible downregulation of both $\alpha 1$ and $\beta$ GR mRNAs four hours after instillation of budesonide. No downregulation of either receptor form was observed in the lung after exposure to budesonide, except for the $\beta$ GR mRNA after 1 and 4 hours. As demonstrated by the upregulation of the control gene glutamine symthetase in lung tissue. the steroild was adequately delivered and pharmacologically active. 
It has long been known that the response of cells to glucocorticoids is positively correlated with the avallability of the ligand and the amount of receptor present in cells, and that both vary strongly between different tissues (Pui et al., 1984; lida et al., 1985; Vanderbilt et al. 1887). Because of the known inhibitory function of the $\beta$ on the $\alpha$ GR form (Bamberger et al., 1995; Oakley et al., 1996), it is also important to take $\alpha / \beta$ GR ratios into consideration in studying these responses. In the present study, 5 to 8 times lower $\alpha$ and $\beta$ GR mRNA levels were demonstrated in the gastracnemius compared with the lung. Also, a tissue dependent variation in $\alpha / \beta$ GR ratio was observed, resulting in a ratio of 2.6 in the lungs compared with a ratio of 1.1 in the gastrocnemius. The $\alpha / \beta$ GR mRNA ratio in the lungs of rats is similar to that observed in human bronchial epithelial cells and alveolar macrophages (Korn et al., 1997). In theory " because of the lower GR mRNA levels and $\alpha / \beta$ ratio in the gastrocnemius, a smaller effect of glucoconticoids on gene transcription might be expected in the gastrocnemius compared with the lungs. Nevertheless, we observed a smaller change in gene transcription of the GR. This is similar to the results obtained previously in bronchial epithelial cells and alveolar macrophages (Korn et al., 1997) and in agreement with the in vitro model system where $\alpha / \beta$ ratios equivalent to or lower than 0.5 were clearly inhibiting.

The systemic side-effects that occur after oral glucocorticoid use are well documented. Controversy surrounds the possible systemic side-effects that may take place after a long period inhalation of glucocorticoids (Hanania et al., 1995). A clear relationship, though, is observed with the size of the administered dose, the pharmacokinetics of the steroid, and the method for inhaled drug delivery (Kamada et al., 1996). Among the many side-effects are myopathy and atrophy of fast-twitch skeletal muscles. Type $2 \mathrm{~b}$ fibres are considered particularly susceptible to the catabolic action of glucocorticoids (Kelly et al., 1986; Almon \& Dubois, 1990; Dubois \& Almon, 1984). By demonstrating a downregulation of both $G R$ mRNA levels in the gastrocnemius muscle four hours after instillation of $100 \mu \mathrm{g}$ budesonide, it can be supposed that the amount of budesonide entering the systemic circulation was high enough ( ${ }^{3} 10^{-6} \mathrm{M}$, see (Korn et al., 1997)) to create a similar change in both $\alpha$ and $\beta \mathrm{GR}$ mRNA paiterns to those seen before in bronchial epithelial cells and alveolar macrophages (Korn et al., 1997). No change in gastrocnemius muscle GR mRNA was demonstrated 1 or 12 hours after instillation.

Surprisingly, despite the higher GR amounts and $\alpha 1 / \beta$ GR ratios, and the broader availability of glucocorticoids in the lungs, no change in GR gene expression was observed in this tissue. In a previous study (Korn et al., 1997) a clear downregulation of the $\alpha$ and $\beta$ GR mRNA was observed in human bronchial epithelial cells. Since it is not possible to obtain enough bronchial epithelial cells of such high purity from rats, whole lung tissue was investigated in this study. This tissue therefore contained a mixture of different cells such as epithelial cells, alveolar macrophages, mast cells, enciothelial cells, smooth muscle cells, fibroblasts, and lymphocytes. A clear downregulation of the $\alpha \mathrm{GR}$ by glucocorticoids has been demonstrated before in rat liver, rat lung epithelial cells, cervix carcinoma cells, human lymphocytes, human bronchial epithelial cells, and human alveolar macrophages (Dong et al., 1988; Silva et al., 1994; Sweezey et al., 1995; Knutsson et all., 1995; Schlecte et al., 1982; Korn et al., 1997). However, in other reports studying human peripheral blood mononuclear cells, Kaposi's sarcoma cells, rat pulmonary fibroblasts, and human leukaemic T-cells, an upregulation of the GR mRNA expression was found (Adcock et al., 1995; Cole et al., 1996; Sweezey et al. 1995; Eisen et al. 1988). Other investigations observe a biphasic expression pattern of the GR mRNA after exposure of rat hepatoma tumour cells and human lung parenchyma cells to glucocorticoids, resulting at first in an upregulation followed by a downregulation of the GR ImRNA expression (Okret et al., 1991, 1986; Adcock et al., 1996). This diversity of transcriptional responses to glucocorticoids in different cells is probably caused by the concentrations of various transcription factors and their interactions in the cell, clearly varying from one cell type to another. Opposite responses in GR mRNA expression to glucocorticoids between different cell types can result in absence of an overall 
measurable effect, as seen in this study. One of the options to study the GR MRNA expression solely in bronchial cells would be the use of mRNA in situ hybridization. However; to be able to determine reliably the differences in $\alpha$ and $\beta$ GR mRNA expression between control and exposed animals with in situ hybridization, these differences must exceed a factor of 2. Since in our studies the changes in $\alpha$ and $\beta$ GR mRNA levels are less than $50 \%$ after exposure to budesonide, it is probably not possible to detect these differences using mRNA in situ hybridization. An imperfect distribution of budesonide through the lungs coull be another explanation for the unchanged GR mRNA expression found in this study. From the histological examination in the pilot study, however, it can be concluded that the distribution of the glucocorticoid in the lungs was good. Also, the observed upregulated glutamine synthetase mRNA expression indicates proper steroid function in the lungs (Feng et al., 1990; Abcouwer et al., 1995).

Recently, a downregulation of the GR mRNA after topical glucocorticoid application has been shown in vivo in peripheral lymphocytes (Knutsson et al., 1995), bronchial epithelial cells and alveolar macrophages (Korn et al., 1997) of humans. In the publication by Knutsson and coworkers (1995), a downregulated a GR mRNA expression was observed after intranasal inhalation of budesonide and fluticasone propionate. In the present study the amount of steroid per $\mathrm{kg}$ of body weight instilled in the rats was approximately 40 times more than the amount inhaled by the human volunteers in the study by Kom ef al. (Kom et al., 1997). The size of the administered dose could be an explanation for the observed downregulation of both $\alpha$ and $\beta$ GR mRNA expression at four hours.

In a recent study of Oakley and coworkers (Oakley et al. 1996), the $\beta$ GR was investigated. As described before in a study by Bamberger and colleagues (1995), the $\beta$ GR had a dominant negative inhibitory effect on the activity of the $\alpha$ form. Oakley and coworkers made the striking observation that, using Northern blot analysis, three GR mRNA forms were present. Instead of the routinely demonstrated $\alpha(7 \mathrm{~kb})$ and $\beta(5 \mathrm{~kb})$ GR mRNA (Hollenberg et al., 1985; Rosewicz et al., 1988; Bronnegard et al., 1991; Zeiner \& Gehring, 1993), an $\alpha 1$ band of $7 \mathrm{~kb}$, an $\alpha 2$ band of $5.5 \mathrm{~kb}$ and a $\beta$ band of $4.3 \mathrm{~kb}$ were demonstrated (Oakley et al., 1996). Similar results can be observed in the study of Brönnegård and Okret (1991). Also, in a previous study by Korn and colleagues (1997), the third isoform was occasionally seen in patients expressing high levels of GR mRNA and in a bronchial epithelial cell line. In the present study we investigated both $\alpha 1$ and $\beta$ GR mRNA forms, and the identity of these isoforms was determined by the location of the 28 and $18 \mathrm{~S}$ ribosomall bands. However, in rats, no sign of the third $\alpha 2$ band was observed.

In conclusion, in rats both $\alpha$ and $\beta$ GR mRNA forms are present and modulated by budesonide in the gastrocnemius muscle. Systemic effects of intra-tracheally instilled budesonide on the GR mRNA levels in the gastrocnemus muscle were observed. However, no GR mRNA downregulation of intra-tracheally instilled budesonide in rat lung was observed, probably owing to the diversity of the cell population. The $\alpha 1 / \beta$ GR mRNA ratios and concentrations were lower in the gastrocnemius muscle compared with the lungs, which suggests a possible difference in gene regulation by glucocorticoids between these tissues.

\section{Acknowledgments}

The assistance of Peter Kelderman with the animal study is greatly appreciated.

\section{References}

Abcouweri. S.F., Bode, B.P. \& Souba, W.W. (1995) Gucoconticoids regulate rat glutamine synthetase expression in a tissue-specific manner. J. Surg. Res. 59, 59-65.

Adicock, I.M., Brown, C.R. Gelder, C.M. Shirasaki, H., Peters, M.J. \& Barnes, P.a. (1995) Effects of gliucocorticoids on transcription factor activation in human peripheral blood mononuclear cells. Am. J. Physiol. 268, C331-C.338. 


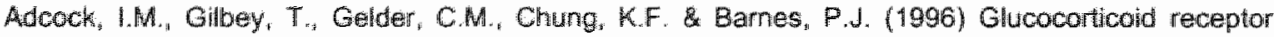
lotalization in normal and asthrratic lung. Am. J. Respir. Crit. Care. Med. 154, 771-782.

Aimon, R.R. Dubois, O.C. (1990) Fiber-type discrimination in disuse and gucocorticoid-induced atrophy. Med. Sci. Sports. Exerc. 22, 304-311.

Bamberger, C.M., Bamberger, A.M. de Castro, M. Chrousos, G.P. (1995) Gucocorticold receptor betw, poteritial endogenous inhibitor of glucocorticoid action in humans. J. Chin. Inwest. 95, 243524.41.

Earnes, P.J. (1995) Inhaled glucocorticoids for astima. N. Engl. J. Med. 332, 868-875.

Bronnegard, M. \& Okret, S. (1991) Regulation of the glucocorticoid receptor in felal rat lung during development. J. Steroid. Biochem. Mot. Biol. 39, 13-17.

Bronneglard, M. Wemer, S. \& Gustafsson, J.A. (1991) Regulation of gucocorticoid receptor expression in culured fibroblasts from a patient with familial glucocorticoid resistance. J. Steroid. Biocherin. Mol. Biol. 39,693-701.

Brostian, C., Anrather J. Csizmadia, V. Stroka, D., Soares, M., Bach, F.H. \& Whkler, H. (1996) Gucocorticoid-mediated repression of $\mathbb{N F B}$ activily in endothelial cells does not involve induction of IkBalpha synthesis. J. Bioll. Chem. 271, 19612-19616.

Buntea, C. Lefter, C., Butnaru, F. David, A. (1992) Steroid homones control on nucleic acid biosynthesis in skeletal muscle. Rom. J. Endocinol. 30, 109-114.

Chomczynski. P. \& Sacchi, N. (1987) Single-step method of RNA isolation by acid guanidinium thocyanate-phenol-chloroform extraction. Anal. Biochem. 162, 156-159.

Cole, N.B., Smith, C.L., Sciaky, N., Terasaki, M. Edidin, M. \& Lippincott-Schwartz, J. (1996) Diffusional mobility of golgi proteins in membranes of living cells. Science. $273,797.801$.

Dong, $Y$. Poellinger "L., Gustafsson, IA. \& Okret, S. (1988) Regulation of glucocorticoid receptor expresision: evidence for transcriptional and posttranslational mechanisms. Mol. Endocrinol. 2 , $1256-1264$.

Dubols, D.C. \& Amon, R.R. (1984) Glucocorticoid siltes in skeletal muscle: adrenalectomy, maturation, fiber type, and sex. Am. J. Physiol. 247, E118-E125.

Elsen, L.P., Elsasser, M.S. \& Harmoni. J.M. (1988) Positive regulation of the glucocorlicoid receptor im humen T-cells sensitive to the cytolytic effects of glucocorticoids. J. Biol. Chem. 263, 12044-12048.

Feng, B., Hilt, D.C. \& Max, S.R. (1990) Transcriptional regulation of glutamine synthetase gene expression by dexamethasone in L6 muscle cells. J. Biol. Chem. 265, 18702-18706.

Hanania, N.A. Chapman, K.R. \& Kesten, S. (1995) Adverse effects of inhaled corticosteroids. Am. J. Med. 98, 196-208.

Hollenberg. S.M., Wenberger, C., Ong, E.S., Cerelli, G., Oro, A., Lebo, R., Thompson, E.B., Rosenfield. M.G. \& Evans, R.M. (1985) Primary structure and expression of a functional human glucocorticolid receptor cDNA. Nature. 318,635-641.

lida, S., Gorni, M. Morlwaki, K., Itoh, Y., Hirobe. K., Malsuzawa, Y., Katagiri, S., Yonezawa. T. \& Tarui., S. (1985) Primary contisol resistance accompanied by a reduction in glucocorticoid receptors in two members of the same family. J. Chin. Endocrinol. Matab. . 60, 967-971.

Kalinyak, U. E., Grifin, C.A., Hamilton, R.W., Bradshaw, J.G., Periman, A.J. \& Hoffman, A.R. (1989) Dewelopmental and thormonal regulation of glucocorticoid receptor messenger RNA in the rat. J. Clla. Invest. $84,1843-1848$.

Kamada, A.K., Szefler, S.,., Martin, R.J.,Boushey, H.A., Chinchilli, V.M., Drazen, JM.,Fish. J.E., Israel E. Lazarus, S.C. Lemanske, R.F. (1996) Issues in the use of inhaled glucocorticoids. Am. J. Respir. Crit. Care. Med. 153, $1739-1748$

Kely, F.J., McGrath, U.A., Goldspink, D.F. \& Cullen, M.d. (1986) A morphological biochemical study or the actions of corticosteroids on rat sketetal muscle. Muscle and Nene. $9,1-10$

Khaleeli, A.A., Edwards, R.H.T., Gohil, K. McPhall, O., Rennie, M.J., Round, \&. Ross, E.J. (1983) Conticosteroid myopathy: A clinical and pathological study. Clin. Endocrinol. 18, 155-166.

Knutsson, U., Stierne, P. Mancus, C., Carlstedt-Duke, d., Carlstrom, K. \& Bronnegard, M. (1995) Effects of intranasal glucocorticoids on endogenous glucocorticoid peripheral and central function: J. Endocinol. 144, 301-310.

Ko, MS. \& Takano, T. (1989) A highty inducible system of gene expression by positive feedback production of glucocorticoid receptors. DNA. $8,127-133$.

Korm, S.HI., Wouters, E.F.M. Wesseling, G.J., Arends, d.-W. \& Thumnissen, F.B.J.M. (1997) in vitro and in vivo modulation of alpha and beta glucocorticoid receptor MIRNA in human bronchial epithelium. Am. J. Respir. Crit. Care. Mled. 155, 1117-1122.

Lee, TH. Brattsand, R. Leung, D. (1996) Corticosteroid action and resistance in asthma. Am. J. 
Respir. Crit. Care Med. 154, S1-S79.

Meyer, A.S. \& Schmidt, T.J. (1994) In contrast to glucaconticoid receptors, mineralocorticoid receptors are not autoregulated in rat distal colon epitheita. Endocrinology. 134, 1163-1172.

Oakley, R.H., Sar, M. \& Cidlowski, J.A. (1996) The human glucocorticoid receptor beta isoform: Expression, biochemical properties, and putative function. J. Biol. Chem. 271,9550-9559.

Okret, S. Poellinger. L., Dong, Y. \& Gustafisson, J.A. (1986) Down-regulation of glucocorticoid receptor MRNA by glucocorticoid hormones and recognition by the receptor of a specific binding sequence within a receptor cDNA clone. Proc. Natl. Acad. Sci. U. S. A. 83, 5899-5903

Okret. S., Dong, Y.. Bronnegard, M. \& Gustafsson, J.A. (1991) Regulation of gilucocorticoid receptor expression. Blochimie. 73, 51-59.

Peters, M.J. Adcock, I.M., Brown, C.R. \& Barnes, P.J. (1995) Beta-Adrenoceptar agonists interfere with glucocorticoid receptor DNA binding in rall hung. Eur. J. Pharmacol. 289, $275-281$.

Picado, C., Fiz, J.A., Montserrat, J.M., Grau, J.M., Fernandez-Sola, J., Luengo, M.T., Casademont, J. \& Agusti-Vidal, A. (1990) Respiratory and skeletal muscle function in steroid-dependent bronchial asthina. Am. Rev. Respir. Dis. 141, 14-20.

Pratt, W.B., Scherrer, L.C., Hutchisom, K.A. \& Dalman, F.C. (1992) A model of glucocorticoid receptor unfiolding and stabilization by a heat shock protein complex. J. Steroid. Biochem. Mol. Biol. 41, 223 229.

Pui, C.H., Dahl, G.V. Rivera, G., Murphy, S.B. \& Costlow, M.E. (1984) The relationship of blast cell glucocorticoid receptor levels to response to single-agent steroid trial and remission response in children with acute lymphoblastic leukemia. Leuk. Res. 8, 579-585.

Rosewicz, S., McDonald, A.R., Maddux, B.A., Goldfine, I.D., Miesfeld, R.L. \& Logsdon, C.D. (1988) Mechanism of glucocorticoid receptor down-regulation by glucocorticoids. J. Biol. Chem. 263, 2581. 2584 .

Saartok, T. (1984) Steroid receptors in two types of rabbit skeletal muscle. Int. J. Sports Med. 5 "130136.

Sauerwein, H. Dursch, I. \& Meyer, H.H.D. (1991) Quantitation of glucocorticoid receptors in bovine skeletal muscle: topographical distribution, sex effect and breed comparisons. J. Steroid. Biochem. Mol. Biol. 39, 941-945.

Schlecte, J.A., Ginsberg, B.H. \& Sherman; B.M. (1982) Regulation of the glucocorticoild receptor in human lymphocytes. J. Steroid. Biochem. 16, 69-74.

Seene, T. (1994) Turnover of skeletal muscle contractile proteins in glucocorticoid myopathy. I. Steroid. Biochem. Mol. Biol. 50,1-4.

Silva, C.M." Powell-Oliwer, F.E., Jewell, C.M., Sar, M., Allgood, V.E. \& Cidiowski, J.A. (1994) Regulation of the human glucocorticoid receptor by long-term and chronic treatment with glucocorticoid. Steroids. $59,436-442$.

Stockin, E., Missler, M., Goulleux, F. \& Groner, B. (1996) Functional interactions between Stat5 and the glucocorticoid receptor. Nature. 383, 726-728.

Sweezey, N., Mawdsley, C., Ghibu, F., Song, L., Buch, S., Moore, A., Antakly, T. \& Post, M. (1995) Differential regulation of glucocorticoid receptor expression by ligand in fetal rat lung cells. Pediatr. Res. $38,506-512$.

Vanderbilt, J.N., Miesfeld, R., Maler, B.A. Yamamoto, K.R. (1987) Intracellular receptor concentration limits glucocorticoid-dependent enhancer activity. Mol. Endocrinol. 1, 68-74.

Yang-Yen, H.F., Chambard, J.C., Sun, Y.L., Smaal, T., Schmidt, T.d., Drouin, J. \& Karin, M. (1990) Transcriptional interference between $c-$ Jun and the glucocorticoid receptor: mutual inhibition of DNA binding due to direct protein-protein interaction. Cell. 62, $1205-1215$.

Zeiner, M. \& Gehring, U. (1993) Glucocorticoid receptor expression during differentiation of human promyeloic leukemia cells. Cancer. Res. 53, 3543-3547. 



\section{Summary and general discussion}




\subsection{Introduction}

The studies described in this thesis were designed to discriminate between the effects of corticosteroids and undernutrition on muscle functioning, as determined by muscle mass, morphology and muscle metabolism. Our aim was to investigate whether the metabolic pathways and the functional and struclural consequences of muscle wasting are comparable between these two situations. The current literature on this particular subject reveals many unclarities and omissions. Firstly the results of our studies will be framed in perspective of the literature; thereafter the results regarding the differentiation between corticosteroids and undernutrition will be discussed.

\subsection{Effects of undernutrition on muscle mass, morphology, contractility and metabolism}

In all the studies reported in the present thesis, it was shown that undernutrition resulted in muscle mass reduction of both peripherall skeletal and respiratory muscles. However in contrast to diaphragm muscle wasting, wasting of peripheral skeletal muscles was less pronounced than body wasting. As mentioned in chapter 1, muscle wasting of the diaphragm was accompanied by an overall fibre type atrophy pattern (1-5), which was confirmed by our results in chapter 2 . However in chapter 3 , atrophy was limited to type $\| x / b$ fibres under conditions of less severe and shorter undernutrition.

As earlier observed in in vitro diaphragm bundles after nutritional deprivation, existence of a decreased fatigability (1-4), an increased half-relaxation time (1) and a leftward shift of the force-frequency curve was confirmed in chapter $2(1,2)$. In addition, an increased time to peak tension was observed, which was not reported earlier. Considering the fact that the cross-sectional area of type I fibres is relatively increased in the diaphragm (chapter 2$)(1$ ), it is not surprising that in vitro diaphragm fatigability was decreased and that half-relaxation time and time to peak tension were increased. However, in situ muscle contractility of dorsiflexor muscles showed only a reduced external work as a consequence of the diminished muscle mass, while normalised for muscle mass, no changes were observed (chapter 4). This could imply different muscle atrophy patterns between the diaphragm muscle and the studied peripheral skeletal muscle. This is however not likely, since other studies have found similar effects of undernutrition on the diaphragm and peripheral skeletal muscles, like a generalised muscle fibre atrophy $(1,3)$. Therefore, other alterations have to be considered, as muscle metabolism and also motor unit characteristics.

In our studies muscle metabolism of both the diaphragm and peripheral skeletal muscies after chronic undernutrition was investigated. In chapter 4 , it was confirmed that glycogen levels in the peripheral skeletal muscle after undernutrition are decreased (6). However, other studies also showed alterations in muscle enzyme activities involved in carbohydrate and $B$-oxidation $(7,8)$. In chapter 5 unchanged PFK, LDH, CS and HAD activities were found in the peripheral skeletal muscle. No muscle enzyme activities were measured in the diaphragm. Lactate concentrations were found to be unchanged in the diaphragm after undernutrition, while in the peripheral skeletal muscle an increased lactate level was observed (data not published), which was also reported by others $(8,9)$.

In addition, muscle energy status was studied. Earlier studies observed decreased $\mathrm{PCr}$ lewels associated with maintained ATP levels in the peripheral skeletal muscle after undernutrition (8-10). In chapter 3 as well, a decreased energy metabolism in the diaphragm was found as shown by decreased $\mathrm{PCr}$ levels and total adenine nucleotides. However, a decreased diaphragmatic ATP concentration could also be demonstrated. This has not been reported before in the diaphragm. In addition, total creatine pool was maintained, suggesting the establishment of a new metabolic equilibrium, with lower ATP and PCr levels. This was accompanied by an increased creatine concentration. A similar tendency was also observed earlier in the gastrocnemius muscle (10). This increase could be caused by an increased $\mathrm{Cr}$ 
and ATP production from PCr in order to satisfy the need for ATP. In future research it would be interesting to compare muscle energy metabolism after undernumition between the peripheral skeletal muscle and the diaphragm, since in contrast to the findings in the diaphragm muscle in chapter 2, ATP levels were never found to be decreased (8-10) and lactate levels were increased in peripheral skeletal muscles $(8,9)$.

In order to obtain more insight in muscle amino acid metabolism, muscle glutamine metabolism was studied in the peripheral skeletal muscle. This conditionally essentiall amino acid is an important nitrogen and ammonia carrier in interorgan metabolism (11). Littie information is available on muscle glutamine metabolism after chronic undernutrition. However, an increased glutamine concentration in the gastrocnemius muscle was demonstrated after 2 days of undernutrition (12), and confirmed in chapter 6 of this thesis. Additionally, glutamine efflux from the hindquarter was studied in chapter 6 and found to be increased, as well as glutamine de novo production and membrane transport rates. However in the diaphragm, unchanged intramuscular glutamine levels were found after undernutrition and basal intramuscular glutamine levels were twice as high as in the gastrocnemius (data not published). This suggests different muscle glutamine metabolism between the diaphragm and the peripheral skeletal muscle. Further research on this phenomenon is needed.

It can be concluded from these studies that muscle wasting induced by undernutrition differs between the peripheral skeletal muscle and the diaphragm. More information could be obtained in future research, studying simultaneously diaphragm and peripheral skeletal muscle energy metabolism. However, it should be realised that amino acid and substrate fluxes cannot (yet) be studied across the diaphragm muscle.

\subsection{Effects of corticosteroids on muscle mass, morphology, contractility and metabolism}

Intramuscular prednisolone treatment in the studies of the present thesis did not resull in a decrease in body and muscle mass (chapter 4). After intramuscular or intraperitoneal prednisolone administration no body or muscle mass reduction was reported earlier $(13,14)$. Reductions in body and muscle mass were however observed after subcutaneous prednisolone administration (15-17). The observed absence of muscle wasting after i.m. prednisolone treatment was accompanied by minor alterations in in situ peripheral skeletal muscle contractility, as an increased recovery during a rest period. This implies that muscle wasting is not related to muscle recovery.

More striking effects were found after triamcinolone treatment. It was clearly demonstrated that triamcinolone treatment resulted in loss of body and muscle mass. Strikingly. wasting of the tibialis anterior and the gastrocnemius muscle was more pronounced than body wasting. This was also found earlier after triamcinolone treatment in the gastrocnemius $(13,18)$. Diaphragm muscle mass was however decreased to a comparable extent than body mass (chapter $2+3)$ as observed earlier $(1,13,19)$. In chapter 2 , the effects of muscle mass reduction on muscle fibre atrophy was described. Atrophy of type lla and $11 \mathrm{l} / \mathrm{b}$ fibres in the diaphragm was found after $0.5 \mathrm{mg}$ triamcinolone per $\mathrm{kg}$ body weight during 4 weeks. Other studies have reported only type $\| \mathrm{l} / \mathrm{b}$ atrophy of the diaphragm after a similar treatment of triamcinolone of 6 weeks (1). Even after a shorter triamcinolone treatment with a higher dose, both type I and $1 \mathrm{Ix} / \mathrm{b}$ fibre atrophy was observed (20). This variation in atrophy pattern may be partly caused by the complications of corticosteroid treatment. During our study and that of Dekhuijzen and colleagues (1), many triamcinolone-treated rats died, while Petrof and coworkers (20) prevented corticosteroid-related pneumonia and reported no deaths. It is likely that high dose triamcinolone treatment induced also infections (like pneumonia), which may also affect the muscle atrophy pattern. Anyway, it is clear that at least fibre llx/b atrophy occurred after triamcinolone treatment. In chapter 3 , we have found only type $\| x / b$ atrophy in the diaphragm after triamcinolone treatment with a lower dose and of shorter duration than in chapter 2 . This was also supported by earlier studies $(1,13,21)$. 
The observed triamcinolone-induced atrophy of both type lla and lix/b fibres resulted in a decreased in witro diaphragm fatigability, an increased half-relaxation time as well as a leftward shift of the force-frequency relationship (chapter2), in accordance with earlier studies $(1,13,21)$. This could be the consequence of a relative increase in cross-sectional area of type Ifibres. In addition, in situ muscle function of peripheral skeletal muscles was studied. The absolute external work was reduced, caused by muscle mass loss. However, normalised for muscle mass, an increased external work was found. Furthermore, muscle faltigue was diminished, in line with diaphragm in vitro contractility and in contrast to hindlimb muscle fatigue after prednisolone treatment (17). As discussed earlier, this decreased faltigue could be caused by a relative increase of type I fibre cross-sectional area since type I fibres are more fatigue resistant. Furthermore, during a 5 minute rest period in between the stimulation sessions, triamcinolone rats fully recovered. This phenomenon was also found for the prednisolone rats.

Ferguson and coworkers (22) observed only in the diaphragm increased glycogen levels after cortisone treatment. However in this thesis, we found increased glycogen stores in the peripheral skeletal muscle both after triamcinolone and prednisolone treatment. This increased muscle glycogen concentration did not seem to be related to alterations in muscle function, except for the abovementioned increased muscle recovery. An increased glucose influx was abserved in the hindquarter muscles after triamcinolone treatment in chapter 6 , but data on glucose muscle influx after prednisolone treatment are not yet available. This increased glucose muscle influx is very surprisingly, since other studies have demonstrated a decreased glucose uptake by the muscle after dexamethasone treatment (23). However, the increased glucose muscle influx after triamcinolone administration could very well contribute to the increased muscle performance of the peripheral skeletal muscle. In addition, Lieu and colleagues (16) observed after prednisolone treatment, in the peripheral skeletal muscle a decreased PFK activity. However, we could not confirm changes in PFK activity after prednisolone treatment in the peripheral skeletal muscle. After triamcinolone treatment however, PFK activity was increased, in line with an increased glycolysis. In addition, oxidative capacity was also found to be increased after triamcinolone in contrast to prednisolone. We furthermore confirmed for the diaphragm after triamcinolone treatment, the earlier observed increased intramuscular pyruvate and lactate levels after corticosteroid treatment $(22,24)$, suggesting also in the diaphragm an increased glycolysis. The increased glycolysis could be related to the increased glucose influx.

To the best of our knowledge, no data are available in literature on diaphragm muscle energy metabolism after triamcinolone treatment. We found decreased levels of ATP, PCr and total adenine nucleotides and creatine pools (chapter 3), suggesting a metabolic impairment. This could be related to the observed increased glycolysis, but further research is needed.

As mentioned earlier, a disproportionall loss of peripheral skeletal muscie mass to body mass was observed after triamcinolone treatment. Therefore muscle amino acid metabolism was studied in the peripheral skeletal muscle after triamcinolone treatment. We demonstrated an increased intramuscular glutamine concentration only after acute triamcinolone treatment (chapter 6), in contrast to earlier studies. A decreased intramuscular glutamine concentration was found after corticosteroid treatment in the peripheral skeletal muscle (24-27), except for the soleus (25). Intramuscular amino acid concentrations by themselves however, do not give any information about muscle uptake or release. Therefore, it is necessary to study amino acid fluxes. Increased glutamine and phenylalanine efflux from the hindquarter was observed in this thesis after chronic triamcinolone treatment. This observation is in line with previously reported datta $(24,27)$. This indicates net muscle degradation and metabolic stress. These effluxes were accompanied by an increased glutamate influx, as well as a decreased BCAA influx. Glutamate is probably a precursor for glutamine production, since glutamine de novo production was found to be increased. The decreased BCAA influx implies no precursor activity of the BCAAs for glutamine production. In addition we 
demonstrated increased glutamine membrane transport rates in the muscle after triamcinolone treatment. The latter finding as well as the decreased BCAA influx were not reported previously.

The action of corticosteroids is mediated by glucocorticoid receptors. Two functionally distinct receptor forms $\alpha$ and $\beta$ have been demonstrated in human tissues (28). The $\beta$ GR form is considered as a dominant negative inihibitor of the $\alpha$ form $(28,29)$. Several studies have shown that the $\alpha$ GR is downregulated in lung cells and peripheral lymphocytes after exposure to corticosteroids (30-32). However, little is known about the autoregulation of the $\beta$ form. In rats, no information is available about the existence of the $\beta$ GR in skeletal muscles. In chapter 7 , the presence of both the $\alpha$ and $\beta$ glucocorticoid receptor WRNA forms in the rat gastrocnemius muscle was described. These two GR forms were found to be downregulated in the muscle even after corticosteroid inhalation, suggesting a systemic effect in the peripheral skeletal muscle after this local corticosteroid administration. it is to be expected that similar effects could be found after systemic administration, but further research is needed to study GR mRNA expression under these conditions.

In conclusion. we observed different effects of prednisolone and triamcinolone in an equipotent dose and similar treatment, on muscle wasting, function and metabolism. Both corticosteroids were found to be associated with increased muscle glycogen concentrations and an increased recovery of the peripheral skeletal muscle in between two stimulation sessions. In addition, we observed no muscle wasting and alterations in peripheral skeletal muscle performance and metabolism after prednisolone treatment. Triamcinolone treatment however, was accompanied by muscle wasting of both the diaphragm and peripheral skeletal muscles, associated with type $/ 1 x / \mathrm{b}$ atrophy of the diaphragm and a decreased fatigability of the diaphragm and peripheral skeletal muscles. In addition an increased glycolytic and oxidative capacity was found. Furthermore, decreased ATP. PCr and total adenine nucleotides and creatine pools were observed, suggesting melabolic impairment. Muscle protein metabolism was also disturbed, as indicated by an increased glutamine efflux from the muscie and an increased glutamine de novo production and membrane transport rates.

\subsection{Differentiation between corticosteroids and undernutrition}

During our first experiment it was shown that muscle wasting induced by triamcinolone treatment, was a consequence of an increased energy expenditure not adequately restored by dietary intake, which takes us to the basic difference between triamcinolone treatment and nutritional deprivation. Triamcinolone treatment showed acutely a temporarily anorexia accompanied by hypermetabolism, which was also found chronically. Therefore, one control group was matched for the temporanily diminished food intake and one for the diminished body mass. Unfortunately, peripheral skeletal muscle mass reduction was not proportional to body mass reduction and could not be controlled for.

After both triamcinolone treatment and undernutrition, diaphragm muscle mass was reduced proportional to body mass reduction. On the other hand, peripheral skeletal muscle wasting after triamcinolone treatment, was more pronounced than body wasting, indicating a pronounced catabolic response. During nutritional deprivation, relative sparing of the peripheral skeletal muscle was observed. This discrepancy in muscle wasting between these two treatments, is also reflected by different atrophy patterns of the diaphragm. Triamcinolone treatment caused type II fibre atrophy, while undernutrition caused a generalised atrophy of all fibre types. Both treatments resulted in a relative increasie of type I fibre cross-sectional area of the diaphragm, which could be responsible for the decreased fatigability of the diaphragm bundle in vitro. Other diaphragm contractility characteristics were also comparable between triamcinolone treatment and nutritional deprivation, like an increased half-relaxation time and a leftward shift of the force-frequency relationship. 
Contractility of dorsiflexor hindlimib musicles however, was not comparable between these two treatments as studied in chapter 4 . Undernutrition showed a decreased fatigability and external work was actually not altered when normalised for muscle mass, while triamcinolone treatment showed an increased fatigue resistance and extemal work. Probably muscle structure alterations cannot explain the discrepancy in in situ muscie performance between these wo treatments.

Metabolic differences after triamcinolone treatment and undernutrition have to be considered as well. As above mentioned, triamcinolone rats were hyperglycaemic and an increased glucose influx in the hindquarter muscles was abserved. Undernutrition however, showed no alterations in glucose metabolism. It was even demonstrated that triamcinolone treatment was associated with increased intramuscular glycogen levels, while undernutrition was accompanied by decreased intramuscular glycogen concentrations. In chapter 5 it was shown that muscle enzyme activities of both glycolytic and oxidative pathways were increased after triamcinolone treatment in contrast to undernutrition. These alterations in muscle metabolism could very well explain the increased muscle performance per gram muscle after triamcinolone treatment.

The alterations in muscle energy metabolism seem comparable between triamcinolone treatment and undernutrition, as reflected by decreased ATP and $\mathrm{PCr}$ levels and total adenine nucleotides. However, the additionally reduced creatine pool and the increased pyruvate and lactate levels in the muscle after triamcinolone treatment in contrast to undernutrition, suggest other mechanisms for the decreased muscle energy status. The alterations in muscle metabolism after triamcinolone treatment could iimply metabolic impairment, while those after undernutrition imply a new metabolic equilibrium with lower ATP and PCr levels.

Surprisingly, muscle glutamine metabolism was almost comparable after triamcinolone treatment and undernutrition. Muscle wasting was accompanied by an increased glutamine de novo synthesis, membrane transport rates and glutamine efflux. These alterations were however, more pronounced for the triamcinolone-treated rats.

In summary, despite several similarities in muscle structure, function and metabolism after triamcinolone treatment and undernutrition, some alterations in muscle metabolism were triamcinolone specific. The most important differences were the increased glucose influx, increased glycogen levels and increased glycolytic and oxidative capacities after triamcinolone treatment. These observed differences are important to consider in the choice of adequate interventions to prevent muscle wasting induced by triamcinolone or undernutrition.

\section{References}

1. Dekhuilizen PNR, Gayan Ramirez $G$, Bisschop $A$, Bock de $V$, Dom $R$, Decramer $M$. Corticosteroid treatment and nutritional deprivation cause a different pattern of atrophy in rat diaphragm. Appl Physial 1995:78:629-637.

2. Lewis MI. Sieck GC, Foumier M. Belman MJ. Effect of nutritional deprivation on diaphragm contractlity and muscle fiber size. J Appl Physiol 1986;60:596-603.

3. Sieck GC. Lewis MII, Blanco CE. Effects of undernutrition on diaphragm fiber size, SDH activity and fatigue rosistance. J Appl Pthysiol 1989;66(5):2196-2205.

4. Prezant DJ. Richner B, Aldrich TK, Valentine DE, Gentry EI, Cahill J. Effect of long-term undernutrition on male and female rat diaphragm contractility, fatigue, and fiber types. J Appl Physiol 1994;76:1540-1547.

5. Prezant $D_{*}$ Karwa $M_{*}$ Richner $B_{*}$ et all. Short term vs long term dexamethasone treatment: Effects on rat diaphragm structure and function. Lung 1998:176:267-280.

6. Bissonnette D., Madlapallimatam $\mathbb{A}$, Jeejeebhoy KN. Effect of hypoenergetic feeding and highcarbohydrate refeeding on muscle tetanic tension, relaxation rate, and fatigue in slow ${ }^{-}$and fasttwitch muscles in rats. Alm J Clin Nutr 1997;66:293-303.

7. Layman D, Merdian-Bender $M$. Hegarty $P$, Swan $P$. Changes in aerobic and anaerobic metabolism in rat cardiac and skeletal muscles after total or partial dietary restrictions. J Nutr 1981;111:994-1000. 
8. Russall DW, Atwood HL, Whittaker JS, et al. The effect of fasting and hypotelorit diets on the functional and metabolic characteristics of rat gastrocnemius muscle. Chin Sci $4984,67: 185$-194.

9. Mijan dTA, Madapallimatiam A Cross A. Armstrong RL, Jeejeebhoy KN. Effect of fasting. hypocaloric fieding, and refeeding on the energetics of stimulated rat imusche as assessed by nuclear magnetic resonance spectroscopy. J Cllin inves $1993.92: 114-121$.

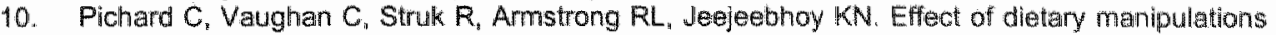
(fasting, hypocaloric feeding, and subsequent refeeding) on rat muscie energetics as assessed by nuciear magnetic resonance spectrosicopy. J Clin Invest 1988;82:895-904.

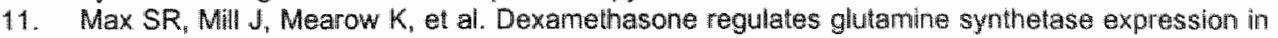
rat skeletal muscles. Am J Physiol 1988:255:E397-E403.

12. Khan $K$, Wusteman $M$, Wood $S$, Elia $M$. The effect of severe dietary restriction on intramuscutar gutamine concentrations and protein synthetic rate. Cin Nutr 1991;10:120-124.

13. Dekhuijzen PNR, Gayan Ramirez $G_{1}$ Bock de V, Dom $R_{*}$. Decramer M. Triamcinolone and prednisolone affect contractile properties and histopathology of rat diaphragm differently. $U$ Clin Invest 1993,92:1534-1542.

1.4. Faludi $G$, Gotlieb J, Meyers J. Experimentally induced primary myopathies Factors infuencing the dewelopment of steroid-induced myopathies. Ann NY Acad Scil 1966;138:61-72.

15. Kelly FJ. McGratth JA, Goldspink DF, Cullen MJ. A moiphological / biochemical study on the actions of corticosteroids on rat skeletal muscle. Muscle \& Nerve 1986;9:4-10.

16. Lieu FK, Powers SK, Herb RA, et all. Exercise and glucocorticoid-induced diaphragmatic myopathy. J Appl Physiol 1993;75:763-771.

17. Dodd SL, Powers SK, Vrabas 1S, Eason JM. Interaction of glucocorticoids and activity patterns affect muscle function. Muscle Nerve 1995;18:190-195.

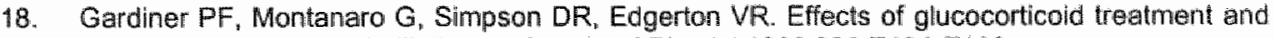
food restriction on rat hindlimb muscles. Am I Physiol 1980,238:E124-E130.

19. Moore BJ, Miller MJ, Feldman HA, Reld MB. Diaphragm atrophy and wealwess in cortisone. treated rats. J Appl Physiol 1989;67:2420-2426.

20. Petrof BJ. Gottitied SB, Eby $J_{1}$ Lamanca $J$. Levine S. Growth hormone does not prevent corticosteroid-induced changes in rat diaphragm structure and function. $J$ Appl Physiol $1995 ; 79: 1571-1577$.

21. Wilcox PG, Hards JM, Bockhold K, Bressler B, Pardy RL. Pathologic changes and contractille properties of the diaphragm in corticosteroid myopathy in hamsters: Comparison to peripheral muscle. Am J Resplr Cell Mol Biol 1989:1:191-199.

22. Ferguson GT. Effects of cortisone and testosterone on diaphragmatic function and biochemistry in the rabbit. $\mathrm{J}$ Appl Physiol 1995;78:1459-1468.

23. Weinstein SP, Wilson CM. Pritsker A, Cushman SW. Dexamethasone inhibits insulin-stimulated recruitment of GLUT4 to the cell surface in rat skeletal muscle. Metabolism 1998;47:3-6.

24. Ardawi MSM, Jamal YS. Glutamine metabolism in skeletal muscle of gllucocorticoid-treated rats. Cilin Scll 1990;79:139-147.

25. Parry Billings $M$, Leighton $B$, Dimitridis $G D$, Bond $J$. Newsholme EA. Effects of physiological and pathological levels of glucocorticoids on skeletal muscle glutamine metabolism in the rat. Blochem Phamacol 1990;40:1145-1148.

26. Hicksion RC, Czerwinski SiW, Wegryn LE. Gutamine prevents downegulatlon of myogin heawy chain synthesis and muscle atrophy from glucocorticolds. Am J Physiol 1995:268:E730-734.

27. Hundal HS, Babij P. Taylor PM, Watt PW, Rennie MU. Effects of corticosteroid on the transport and metabolism of glutamine in rat skeletal muscle. Biochim Biophys Acta 1994:1092:376-383.

28. Bamberger CM, Bamberger AM, de Castro M. Chrousos GP. Glucocortlicoid receptor beta, a potential endogenous inhibitor of glucocorticoid action in humans. J Clin Invest 1995:95:2435 41.

29. Oakiey RH, Sar M, Cidlowsiki JA. The human glucocorticoid receptor beta isolorm. Expressilon. biochemical properties, and putative function. I Biol Chem 1996:271:9550-9.

30. Knutsson $U$, Stiema $P_{t}$ Marcus $C$, Carlstedt Duke $J$. Carlstrom $K$, Bronnegard $M$. Effects ơl intranasal giucocorticoids on endogenous glucocorticoid peripheral and central function. J Endocrinol $1995 ; 144: 301-10$.

31. Silva CM, Powell Oliver FE, Jewell CM, Sar M, Allgood VE, Cidlowsk WA. Regulation off the human glucocorticoid receptor by long-term and chronic treatment with glucocorticoid. Steroids $1994,59: 436-42$

32. Sweezey N. Mawdstey C. Ghibu $F_{4}$ et al. Differenhal regulation of glucocorticoid receptor expression by lgand in fetal lung cells. Pediatr Res 1995,38:506-512. 



\section{Samenvatting}

Veel chronisch zieke patiënten zoals die met chronisch harttaien (CHF), nierfalen of obstructieve longziekten (COPD) zijn erg beperkt in hun dagelijks lunctioneren. Dit is niet alleen het gevolg van het slecht functioneren van het aangetaste orgaan maar spierzwakte speelt hierbij ook een belangrijke rot. Bovendien krijgen veel van deze patienten chronisch corticosteroilden toegediend, een medicijn wat ontstekingsremmend werkt. Een van de bijeffecten van corticosteroïden is het optreden van spierzwakte. Verder vertonen veel van deze patiënten gewichtsverlies, wat ook kan bijdragen aan de spierzwakte. Aangezien chronisch corticosteroildgebruik zelf kan leiden tot ondervoeding, is het relevant on deze twee factoren te bestuderen in relatie tot spierfunctie.

Spierfunctie wordt bepaald door de massa van de spier, de opbouw (morfologie) en door de biochemische processen die zich hierin afspelen (metabolisme). Al deze componenten zijn lastig in patiënten te bestuderen en daarom is gebruik gemaakt van een rattenmodel. Hierbij kunnen ook gemakkelijk interventies worden uitgevoerd en het verstorende effect van de ziekte kan worden uitgeschakeld. We hebben gekozen voor het gefiuorideerde corticosteroild triamcinolon. In dit corticosteroïd is een fluoridegroep ingebouwd, waardoor het een ontsteking beter kan remmen, maar bovendien ook meerdere bij-effecten veroorzaakt zoals spiermassaverlies. De ratten die met triamcinolon behandeld werden, werden vergeleken met een paarsgewijs-gevoede groep, ter correctie van de verminderde voedselinname. Vervolgens werd een paarsgewijze-gewichtsgroep geîntroduceerd, omdat hel lichaamsgewicht van de met triamcinolon behandelde ratten sterker daalt dan alleen door de verminderde voedselinname verklaard kan worden. Tenslotte werd een controlegroep gebruilkt met een normale voedselinname, die diende als referentie voor nomale onbehandelde ratten. Het diafragma (de middenrifspier) is de belangrijkste ademhalingsspier. De functie van deze spier werd bestudeerd in vitro (buiten de rat) zoals beschreven in hoofdstuk 2 . Een bundel van het diafragma werd opgehangen in een weefselbadje en gestimuleerd. Hierbij werd de spierfunctie van de verschillende groepen vergeleken. Het viel op dat de paarsgewijze-gewichtsgroep en de met triamcinolon behandelde groep tot dezelfde veranderingen in contractiliteit van het diafragma leidden, zoals een verminderde vermoeibaarheid van de spier en een verlenging van de halfrelaxatietijd na stimulatie.

Een spierbundel is opgebouwd uit verschillende spiervezels die verschillende eigenschappen bezitten. Type I vezels kunnen bijwoorbeeld maar een kleine kracht opbouwen, maar zijn pas na lange tijd vermoeid. Type llx/b vezels kunnen veel kracht opbouwen en zijn snel vermoeid, terwijl de eigenschappen van type lla vezels ertussenin liggen. Wanneer de spiervezels gekleurd en dwars doorgesneden worden, kunnen de verschillende vezeltypes en hun oppervlakten worden bepaald. Dit werd gedaan in het diafragma van de verschillende groepen (hoofdstuk 2) en we wonden dat het oppervlakte van type lla en llx/b splervezels afgenomen was (atrofie) in de met triamcinolon behandelde groep vergeleken met de controlegroep. De paarsgewijze-gewichtsgroep vertoonde een vergelijkbaar beeld maar vertoonde ook type ( vezel atrofie. Na een behandeling met een lagere dosis triancinolon vertoonde het diafragma alleen type lix/b atrofie (hoofdstuk 3). Dit werd ook gevonden, hoewel in mindere mate, na ondervoeding in de paarsgewijze-gewichtsgroep. In geen enkele groep waren de spiervezels op een andere manier aangetast (myopathie) in het diafragma.

Zoals eerder gezegd wordt de spierfunctie ook bepaald door de biachemische kenmerken in de spier. Energierijke fosfaten, zoals adenosine tri- en difosfaat (ATP en ADP) en creatine fosfaat (CrP), leveren energie voor spiercontractie. Na triamcinolonbehandeling en na ondervoeding vinden we een daling van ATP. ATPIADP ratio, totale adenine nucleotiden. 
$\mathrm{CrP}$ en $\mathrm{CrP} / \mathrm{Cr}$ ratio in het diafragma (hoofdstuk 3). De met triamcinolon behandelde ratten hadden daarnaast ook nog een verlaagde totale creatinepool en een werhoogde concentratie wan eindsubstraten van de glycolyse (pyruvaal en lactaat). Dit werd niet gevonden in de paarsgewijze-gewichtsgroep, maar deze had een verlaagde creatineconcentratie in het diafragma. Hierult werd geconcludeerd dat deze twee groepen met behulp van verschillende metabole routes leiden tot vergelijkbare veranderingen op thet niveau van energierijke fosfaten. De ondervoede groep leidi tot een verlaagde energiestatus in de spier maar herwint hierbij een nieuw metabool evenwicht, terwijl de met triamcinolon behandelde groep dit ewenwicht niet kan vinden als gevolg van een verstoring tussen de glycolytische afbraakroute en het oxidatief metabolisme (de afbraakroute waar zuurstof voor nodig is).

Zoals gezegd is in hoofdstuk 2 de functie van het diafragma beschreven in vitro. In dit model is de spierfunctie voornamelijk afhankelijk van de substraten die in de spier (en het weefselbadje) aanwezig zijn. Hierbij speell de spiervezelsamenstelling een belangrijke rol evenals de diffusie van substraten. In situ spierfunctie (in de levende rat) echter is ook nog afhankelijk van de bloedtoevoer en afvoer, die belangrijk is bij de aan- en afvoer van substraten en afvalprodukten. Daarom werd de spierfunctie in een rattendynamometer bestudeerd (hoofdstuk 4), wat fysiologisch meer overeenkomt met een normale spierfunctie. Hierin werden de achterpootspieren bestudeerd van ratten behandeld met triamcinolion en met prednisolon in een vergelijkbare ontstekingsremmende dosis. De met triamcinolon behandelde ratten werden daarnaast ook weer met een ondervoede groep vergeleken. Tijdens dit experiment werd een zenuw van de achterpootspieren gestimuleerd tijdens twee sessies van 60 contracties. Tijdens de eerste sessie daalde de externe arbeid van de met triamcinolon behandelde en de ondervoede ratten als gevolg van de daling in spiermassa. Wanneer de externe arbeid uitgedrukt werd per gram gestimuleerde spier, dan was de externe arbeid aan het begin van de sessie hoger voor de met triamcinolon behandelde ratten dan voor de met prednisolon behandelde ratten. Verder daalde de externe arbeid thet minst (dus minder vermoeibaarheid werd geconstateerd) in de met triamcinolon behandelde ratten vergeleken met alle ander groepen. Prednisolombehandeling en ondervoeding hadden geen effect op de externe arbeid (per gram gestimuleerde spier) tijdens de sessies. Het herstel in externe arbeid, tijdens de 5 minuten rust tussen de sessies in, was voor de met triamcinolon en prednisolon behandelde ratten nagenoeg volledig, in tegenstelling tot de ondervoede en controlegroep. Dit zou kunnen samenhangen met het verhoogde spierglycogeengehalte na triamcinolon of prednisolonbehandeling. Vervolgens werden de activiteiten van enkele splerenzymen bestudeerd (hoofdlstuk 5). De fosfofructokinaseactiviteit (PFK: een glycolytisch enzym) en de glycogeen synthetase (GS) activiteit waren werhoogd in de met triamcinolon behandelde groep, terwijl er geen veranderingen waren in spierenzymactiviteiten in de met prednisolon behandelde en de ondervoede groep. Vergeleken met prednisolonbehandeling en ondervoeding was ook de citraat-synthaseactiviteit (CS: enzym ulit de citroenzuurcyclus) in de met triamcinalon behandelde groep toegenomen. In geen enkele groep was de activiteit van glycogeen fosforylase (GP), 3hydroxyacyl COA dehydrogenase (HAD: enzym uit de vetzuur $\beta$-oxidatie) en lactaat dehydrogenase (LDH: voming van melkzuur) veranderd. Hieruit werd geconcludeerd dat de veranderingen in spierenzymactiviteiten corticosteroï-type specifiek zijn en onafhankelijk van de samenhangende ondervoedingstoestand.

Tot nu toe hebben we alleen het koolhydratenmetabolisme en de energierijke fosfaten bestudeerd. Een spier bestaat grotendeels uit eilwit, en we verwachten ook veranderingen op eiwitniveau na triamcinolonloediening. Het metabolisme van glutamine, een belangrijk aminozuur tijdens stresssituaties, werd bestudeerd in de achterpootspier (hoofdstuk 6). Hierbij werd kortdurende ( 3 dagen) triamcinolonbehandeling, waarbij ook een verminderde voedselinname meespeelt, vergeleken met langdurige behandeling ( 14 dagen). Drie dagen 
triamcinolontoediening leidde tot verhoogde glutamineconcentraties in de achterpootspler van de rat, en een veminderde in- en uitbouw van glutamine in spiereilwit. Chronische triamcinolontoediening leidde tot een verhoogde afgifte van glutamine uit de achterpootspier; een verhoogde glutamineproductie en verhoogde snelheden van transport van glutamine in en uil de spier. Chronische ondervoeding resulteerde in dezelfde veranderingen, maer in een mindere mate.

In de voorafgaande studies zijn de corticosteroilden telkens toegediend in de spier. Dit betekent dat ze in de bloedbaan terechtkomen en systemisch effecten kunnen veroorzaken in het hele lichaam. Bij patiënten worden corticosteroïden vaak locaal toegediend, bijvoorbeeld in de vorm van inhalatiesteroiden bij patiënten met ademhalingsstoornissen.

De glucocorticoild receptor (GR) speelt een centrale rol tijdens de werking van corticosteroïden. In verschillende humane weefsels is messenger RNA van twee functioneel verschillende glucocorticoild receptors, $\alpha$ en $\beta$ gevonden. In de rat is de aanwezigheid van de $\beta$ GR vorm in skeletspieren nog niet beschreven. Daarom hebben wij in de rat de expiessie van de $\alpha$ en de $\beta$ GR vorm in een perifere skeletspier bestudeerd, ook om na te gaan of er systemische effecten na corticosteroild inhalatie optraden (hoofdstuk 7). Zowel het mRNA van de $\alpha$ als de $\beta$ GR vorm werd gevonden in deze spier. Tenslotte worden de belangrijkste resultaten van de studies samengevat en bediscussieerd in hoofdstuk 8 .

In het algemeen zijn er redelijk wat overeenkomstige effecten op de spier gevonden na triamcinolonbehandeling en na ondervoeding. waaruit geconcludeerd zou kunnen worden dat ondervoeding deels verantwoordelijk is voor de veranderingen na triamcinolonbehandeling. Er zijn echter aanwijzingen gevonden dat deze effecten door verschillende mechanismen veroorzaakt worden. Na triamcinolonbehandeling is er sprake van een verhoogde glucoseopname door de spier en verhoogde glycogeenconcentraties in de spier. Zowel de glycolytische als de oxidatieve capaciteit van de spier is verhoogd, maar de verhoogde lactaat- en pyruvaatconcentraties duiden op een verstoring tussen deze twee afbraakroutes. Prednisolonbehandeling leidt in tegenstelling tot triamcinolonbehandeling niet tot spiermassaverlies en metabole veranderingen. Om spierzwakte te voorkomen bij patienten die chronisch behandeld worden met corticosteroïden, is het van belang om de oorzaak van deze spierzwakte te achterhalen en eventueel rekening te houden met het type corticosteroïd. 


\section{Nawoord}

Diegene die nu even snel dit nawoord leest in de hoop er een smeuig verhaal te vinden moet ik helaas teleurstellen. Momenteel ben ik gewoon blj dat dit boekje er eindelijk ligt en wil ik hier alle mensen bedanken die mij in deze tijd hebben geholpen en gesteund.

Allereerst mijn promotor professor Wouters, die mij in de gelegenheid heeft gesteld om mij dit onderzoek te laten doen bij de vakgroep Longziekten. Professor Wouters, hoewel ons contact weinig frequent was, was uw rol in het behouden van de lijn van het onderzoek duidelijk merkbaar. Bedankt voor uw inzicht en wetenschappelijke bijdrage!

Vervolgens milin co-promotor Annemie Schols, zonder wiens wetenschappelijke en inhoudelijke bijdrage dit onderzoek niet tot z'n recht zou zijn gekomen. Beste Annemie, het was vast een moeilike aanpassing om dierexperimenteel onderzoek te begeleiden terwijl die ratjes je weinig zeggen. Gelukkig kon jij mij helpen om uit de brij van resultaten juist de interessante bevindingen te benadrukken. $\mathrm{k}$ heb veel van je geleerd, waarvoor mijn dank.

Verder wil ik alle leden van de beoordelingscommissie, Prof $\mathrm{Dr}$ ir WHM Saris, Dr R Dekhuijzen, Prof Dr JP van Hooff, Prof Dr H Kuipers en Prof Dr C Pison bedanken voor de bereidheid dit proefischrift te lezen en te beoordelen, merci beaucoup!

De eerste twee experimenten heb ik in Leuven uitgevoerd, waar ik erg goede herinneringen: aan overgehouden heb. Beste professor Decramer, hartelijk dank voor de mogelijkheid die u mij geboden heeft om deze experimenten bij u uit te woeren. Het was een leerzame en rijke ervaring. Ghislaine, hartelijk dank voor alles wat ik van jou (en van Nancy en Anja) heb geleerd! De kelder waar jullie labo in onder was gebracht was erg somber maar met jullie aanwezigheid was het er erg gezellig! Ook erg bedankt voor je wetenschappelijke bijdrage aan de twee artikels, je bent erg kritisch op een motiverende wijze. Nancy "Anja en Heleen, bedankt voor alle praktische hulp tijdens de experimenten, zonder jullie was het nooit gelukt! Verder heb ik nog een aantal experimenten in samenwerking met Algemene Heelkunde uitgevoerd. Mick, van jou heb ik alles geleerd wat betreft operatietechnieken. Dat ik het in m'n vingers kreeg om efficiënt en nauwkeurig de operaties uit te voeren heb ik aan jou te danken. Het is jammer dat ik niet alsnog chirurg kan worden... Ook de verwerking van de eindeloze spreadsheets had ik niet zonder je hulp gekund. Wetenschappelijk heb ik veel van je geleerd. Je enthousiasme en doelgerichtheid waren erg motiverend. Gabrie, jii ook bedankt voor je hulp bij de ratten en op het lab. Het was ook erg gezellig met je te werken. Ivo, jij ook bedankt voor je rattenhulp en de hulp bij het artikel. Hans, Gabrie en Dennis bedankt voor de aminozuurbepalingen.

De bepalingen voor de energierijke fosfaten zijn uitgevoerd bil Humane Biologie. Ton Wagemakers wil ik bedanken voor deze mogelijkheid. Olav heeft mij erg geholpen met de Cobas waarop de bepalingen gedaan werden. Helaas voor hem sloeg dit apparaat altijd op tilt zodra ik in de buurt kwam (of was thet andersom) en heb ik talloze keren een beroep op hem moeten doen. Heel erg bedankt, ook voor al je hulp met het artikell

Verder wil ik Maarten en Matthijs van Bewegingswetenschappen hartelijk bedanken voor het experiment met de mooie rattendynamometer. Ook veel dank voor jullie wetenschappelijke en praktische bijdragen! Zonder alle praktische hulp van Matthijs en Jolanda had ik niet veel gekund:

Prof van der Vusse wil ik ook hartelijk bedanken voor zijn wetenschappelijke bijdrage aan een deel van het onderzoelk en artikels. Uw uitleg was altijd erg duidelijk (met tekening en al) en uw enthousiasme werkte erg motiverend. Jadil bedankt voor de nucleotiden en enzymbepalingen.

Natuurlijk wil ik ook alle andere (oud) AlO's en Francine bedanken voor alle gezelligheid, etentjes en miet te vergeten ook hun praktische hulp bij de ratten experimenten! Erica "Tim, Eva, Marielle, Solange, Mieke, Veerle en Jeske. Later ook André, Ramon, Harry "Juanita " Diederick, Mehmed, Karin, Marja en Lotte, en natuurlijk Esther, m'n kamergenoot tijdens de laatste twee jaar. Doordat ik niet-klinisch onderzoek deed had ik ook weinig contact met de 
longartsen op de afdeling, wat op zich wel jammer was. Misschien dat een gemeenschappelijke koffiekamer het contact tussen de staf en de AlO's zou bevordelijken... Met Erica heb ik veell lief en leed gedeeld omdat wij als eerste twee de AlO-kamer hebben bewoond. Hier kwam Tim op een gegeven moment bij om aan zijn boekje te werken (arme hij, maar het was wel gezellig) voordat Eva en Mariëlle AlO werden.

lik will Solange ook nog bedanken voor hoofdstuk 7 van dit boekje. Het was erg leuk om samen met jou een experiment te doen en dan 's avonds laat nog even een Macshake halen...

Mieke en Erica, ik ben jullie ook erg dankbaar voor het feit dat we samen met Annemie over de inleiding konden discussiëren. Bedankt voor al jullie moeite en tijd. Sorry dat er uiteindelijk een heel ander stuk gekomen is, jullie hebben wel erg geholpen in de hele situatie.

Daarnaast ben ik ook nog een aantal mensen van Pathologie mijn dank verschulldigd, waaronder Erik Thunnissen, Cor Beek en John Paulissen en andere mensen van het lab op wie ik een beroep heb moeten doen.

Op het CPV heb ik ook hulp gekregen van een aantal mensen, Frans Weekers, Harry, Peter Kelderman, Brigit en alle anderen, heel erg bedankt!

Alle mensen van het secretariaat Longziekten will ik ook nog bedanken voor hun secretarielle hulp, Manon, France, Resi, Gonda, Anouk, Nicole en eerder ook Marie-José.

Het feit dat ik niet in de buurt van de universiteit woonde deed mij besluiten om te gaan carpoolen. Jeske, Marianne, Annelie bedankt voor al die uren in de auto. Lily, met jou carpoolen was altijd erg gezellig en ik dank je voor al je steun. Francine, al jouw verhalen over het lief en leed van je kroost was altijd erg ontspannend en gezellig. Karla, leuk dat jij ook in Maastricht terechtgekomen bent. Je meelevendheid en heldere blik en je mondigheid uit Amsterdam heb ik erg gewaardeerd.

Vooral de laatste twee jaren heb ik naast de twee dagen kinderdagverbilif Casper vaak weg moeten brengen naar de oppas. Lieve Saskia, hartstikke bedankt voor je flexibiliteit en al je zorgen en liefde voor Casper.

Wanneer ik het even niet zag zitten hielpen de mailtjes wan Karen, Solange en Inge me weer om alles in perspectief te zien, heel erg bedankt!

Ook alle verdere vrienden en zussen heel erg bedankt voor alle morele steun.

Mam, bedankt voor de mogelijkheid die jullie mij hebben gegeven om te gaan studeren en voor je hulp in moeilijke tijden.

Tenslotte dan de twee mannen in m'n leven. Bert, ik ben blij dat we zo'n sterk team zijn. Met jouw vermogen tot relativeren en jouw goede analyses heb je me enorm geholpen in deze tijd. En Casper, je bent eem heerlijk vrolijk onderzoekertje. Door jou leer ik wat belangrilk is in het leven. 


\section{Curriculum Vitae}

Esther de Lang was bom on 8 June 1966 in Eindhowen. She went in 1978 to the Eindhovens Protestants Lyceum and got her Athenaeum in 1985. She studied medical biology at the Free University in Amsterdam. She studied as a student the antigen-presentation of macrophages from the peritoneal fluid from continuous ambulatory peritoneal dialysis patients (vakgroep histologie en electronenmicroscopie), the chromosomal in situ hybridisation techniques to locate the $11 \mathrm{p} 13$ band for the Wims' tumour gen (vakgroep antropogenetica at the Academisch Medisch Cenirum in Amsterdam) and the copulation behaviour of male monkeys (vakgroep vergelijkende fysiologie at the Rijksuniversiteit Utrecht). She married Bert Koents in 1988 and finished her study in 1991. In 1992 she began as an AlO at the department of Pulmonology at the Maastricht University, which led to this thesis. Her son was born in 1997 and in that year she became a co-ordinator of the animal studies at the department of Pulmonology for two years. 


\section{Full papers}

Koerts-de Lang E, Schols AMWd, Gayan-Ramirez G, Wouters EFM, Decramer M. Contractile properties and histochemical characteristics of the rat diaphragm after prolonged tritamcinolone treatment and nutritional deprivation. J Muscle Res Cell Mollity 1998; 19:5449-555.

Koerts-de Lang $E$, Hesselink MKC, Drost MR, Van der Vusse GJ, Wouters EFM, Sohols AMWJ. Enzyme activity of rat tibialis anterior muscle differs between treatment with triamcinolone and prednisolone and nutritional deprivation. Eur $₫$ Appl Physiol 1999;79:274-279.

Koerts-de Lang E, Schols AMWJ. Rooyackers OE, Gayan-Ramirez G, Decramer M. Wouters EFM. Differen effects of corticosteroid-Induced muscle wasting compered with undernutrition on rat diaphragm energy metabolism. Submitted.

Koerts-de Lang E, Hesselink MKC, Drost MR, Van der Vusse GJ, Wouters EFM, Schols AMWJ. The effects of corticosteroids and undernutrition on work capacity of skeletal muscle in an in situ rat model. Submitted.

Koents de Lang E, de Blaauw I, Deutz NEP, Mouters EFM, Schols AMWJ. Erfects of corticosteroids and undernutrition on glutamine metabolism in rat skeletal muscie. Submifted.

Korn SH, Koerts-de Lang E, Engel GEJ, Arends JW, Wouters EFM, Thunnissen FBiM. Alpha and beta glucocorticoid receptor mRNA expression in skeletal muscle. J Muscle Res Cell Motil $1998 \cdot 19: 757 \div 765$

Pouw EM, Koerts-de Lang E, Gosker HR. Freling G, Van der Vusse GJ, Wouters EFM, Schois AMWJ. Muiscle metabolic status in patients with severe COPD with and without logterm prednisolone. Eur Respir J in press.

\section{Abstracts}

Koerts-de Lang E, Schols AMWJ, Wouters EFM, Gayan-Ramirez G, Decramer M. Does prolonged corticosteroid treatment affect the diaphragm differently from chronic underimutrition in rats? Am J Resp Crit Care Med 1994;149: A273.

Koents-de Lang E, Schols AMWJ, Deutz NEP, Decramer M, Gayan-Ramirez G, Rooyackersi OE, Wouters EFM. Metabolic statts of gastrocnemius and diaphragm differs after prolonged corticostteroid treatment in rats. Am I Resp Crit Care Med 1995; 151:A812.

Koerts-de Lang E, Schols AMWJ, Deutz NEP, de Blaauw I, Wouters EFlM. Effacls of combinud prolonged conticosteroid treatment and underritutition on muscle glutamine matabolism hrits. Arn $\mathrm{d}$ Resp Crit Care Med 1995; $151: A B 12$.

Koerts-de Lang E, Hesselink MKC. Drost MR, Wouters EFM, Schols AMWJ. Different effects of triamcinolone, prednisolone and muscle wasting on muscle function of rat tibialis anterior. Am J Resp Crit Care Med 1997:155:A921.

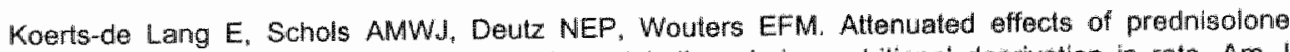
treatment on muscle glutamine and protein metabolism during inutritional deprivation in rats. Am $J$ Resp Crit Care Med 1997:155:A921.

Koerts-de Lang E Van der Vusse G., Hesselink MKC, Wouters EFM, Schols AMWa. Effects of prednisolone, triamcinolone and nutritional deprivatlon on enzyme capacity of rat libialis anterior muscle. Am J Resp Crit Care Med 1997:155:A922. 